Gilberto Pereira Dias

\title{
Avaliação das condições redox das águas intermediárias do Oceano Atlântico Sudoeste nos últimos 40 mil anos
}

Dissertação apresentada ao Instituto Oceanográfico da Universidade de São Paulo, como parte dos requisitos para obtenção do título de Mestre em Ciências, área de Oceanografia Química.

Orientador:

Prof. Dr. Rubens Cesar Lopes Figueira

Coorientadora:

Profa. Dra. Renata Hanae Nagai

São Paulo 


\author{
Universidade de São Paulo \\ Instituto Oceanográfico
}

Avaliação das condições redox das águas intermediárias do Oceano Atlântico Sudoeste nos últimos $\mathbf{4 0} \mathrm{mil}$ anos

Dissertação apresentada ao Instituto Oceanográfico da Universidade de São Paulo, como parte dos requisitos para obtenção do título de Mestre em Ciências, área de Oceanografia Química.

Mestrando: Gilberto Pereira Dias

Orientador:

Prof. Dr. Rubens Cesar Lopes Figueira

Coorientadora:

Profa. Dra. Renata Hanae Nagai

São Paulo 


\title{
Universidade de São Paulo \\ Instituto Oceanográfico
}

Avaliação das condições redox das águas intermediárias do Oceano Atlântico Sudoeste nos últimos 40 mil anos

\author{
Gilberto Pereira Dias \\ VERSÃO CORRIGIDA
}

Dissertação apresentada ao Instituto Oceanográfico da Universidade de São Paulo, como parte dos requisitos para obtenção do título de Mestre em Ciências, área de Oceanografia Química.

Julgada em

Prof(a). Dr(a).

Conceito

Prof(a). Dr(a).

Conceito

$\operatorname{Prof}(\mathrm{a}) . \operatorname{Dr}(\mathrm{a})$.

Conceito 


\section{Agradecimentos}

Obrigado, meu Deus! Muito obrigado!

Obrigado, Mama! Peço desculpas pela ausência, prometo ser mais presente.

Obrigado, Helbert e Lilian, meus irmãos, pelo apoio e pelas palavras de incentivo.

Obrigado, Prof. Rubens Figueira, pela oportunidade de trabalhar com o senhor, uma pessoa que admiro. Aprendi muito com o senhor.

Obrigado, Prof. a Renata Nagai, pelos ensinamentos. Você foi uma pessoa muito importante para realização deste trabalho.

Agradeço também aos professores Silvia Helena, Eduardo, Márcia, Michel e Luigi pelo apoio. Em especial à Prof. ${ }^{a}$ Bete pelo apoio e incentivo.

Obrigado, Aninha, Lê, Dani, Silvana, Eder, Nilson, André, Luizito, Vitor, meus amigos, pelo apoio e incentivo! Vocês me ajudaram muito nesta fase da minha vida.

Obrigado, Samara e Edilson, o apoio de vocês foi muito, muito importante. Contem comigo.

Agradeço ao pessoal da biblioteca em especial ao Wagner por me ensinar a usar o Mendeley e outras plataformas de pesquisa.

Agradeço ao pessoal do laboratório de química inorgânica marinha (LAQIMAR): Bianca, Nancy, Juliê, Paulo, Marcela, Lourenço, Alexandre, Tailisi pelos cafés e pelas conversas.

Agradeço aos meus amigos Farley, Marcos, Elvis, Lívia, Patrícia, Jasão, Hélio, Barba, Armando, Pedrão, Pedro Serrao pelo apoio e incentivo.

Agradeço também ao IOUSP por me permitir continuar estudando.

Gilberto Pereira Dias 
"Eu vejo o futuro repetir o passado Eu vejo um museu de grandes novidades O tempo não para

Não para não, não, não para."

(Cazuza) 


\section{Lista de Figuras}

Figura 1 - Mapa da área de estudo com a localização do ponto de coleta do registro sedimentar NAP63-1 (estrela vermelha), Alto de Cabo Frio (ACF) e Cabo de Santa Marta (CSM), pontos em amarelo, ao largo da margem continental sudeste brasileira (adaptado de Google Earth, 2018). 18

Figura 2 - Representação esquemática das massas d'água e das correntes de contorno oeste ao largo da margem continental brasileira (adaptado de Soutelino et al., 2013).

Figura 3 - Representação esquemática da ventilação e submersão de massas d'águas no Oceano Austral (Adaptado de Anderson et al., 2009), sendo ACP (Água Circumpolar Profunda), AMSA (Água Modal Subantártica), AIA (Água Intermediária Antártica), FPA (Frente Polar Antártica), ZFP (Zona da Frente Polar), FSA (Frente Subantártica), ZSA (Zona Subantártica), FST (Frente Subtropical) e HN (Hemisfério Norte). .22

Figura 4 - (a) Perfil vertical da distribuição do oxigênio dissolvido ( $\mu \mathrm{mol} \mathrm{kg}-1$ ) ao longo da borda oeste do Oceano Atlântico; (b) Perfil vertical da distribuição da salinidade ao longo da borda oeste do Oceano Atlântico e (c) Diagrama temperatura/salinidade (T-S) ao longo da borda oeste do Oceano Atlântico. A estrela vermelha representa a região de coleta do registro sedimentar NAP63 (a e b); no diagrama T-S, a estrela vermelha representa a posição da AIA referente às suas propriedades hidrográficas (Adaptado de EGEOTRACES, 2017). .23

Figura 5 - Esquema climático de verão austral com os principais componentes atmosféricos (adaptado de Wang et al., 2006), sendo: ZCIT (Zona de Convergência Intertropical), ZCAS (Zona de Convergência do Atlântico Sul) e JBN (Jatos de Baixos Níveis). A estrela vermelha indica a área de estudo do presente trabalho. 25

Figura 6 - Fluxograma do procedimento EPA 3052 (segundo USEPA, 1996). 30

Figura 7 - Modelo de idade cal. (anos AP) em função da profundidade (cm) no testemunho NAP63-1 (Figura cedida pela Profa. Dra. Renata Hanae Nagai)...........34

Figura 8 - Distribuição das razões elementares (a) V/Sc, (b) V/Cr, (c) V/Al x10 ${ }^{-4}$, (d) $\mathrm{Mn} / \mathrm{Al} \times 10^{-4}$ e (e) Ni/Co ao longo do testemunho NAP63 em função da Idade cal. (anos AP).

Figura 9 - Distribuição das razões (a) $\ln (\mathrm{Fe} / \mathrm{Ca})$ e (b) $\ln (\mathrm{Ti} / \mathrm{Ca})$ ao longo do testemunho NAP63-1 em função da ldade cal. (anos AP).

Figura 10 - Distribuição das variáveis (a) COT (\%), (b) $\mathrm{CaCO}_{3}(\%)$, (c) $\delta^{13} \mathrm{C}(\%)$ e (d) $\mathrm{C} / \mathrm{N}$ ao longo do testemunho NAP63-1 em função da ldade cal. (anos AP).

Figura 11 - Distribuição das razões elementares (a) V/Sc, (b) V/Cr, (c) V/Al x10 ${ }^{-4}$, (d) $\mathrm{Mn} / \mathrm{Al} \times 10^{-4}$ e (e) Ni/Co ao longo do testemunho NAP63 em função da Idade cal. (anos AP). Em destaque, os limites dos estágios isotópicos marinhos (MIS 1, 2 e 3) (Lisiecki e Raymo, 2005). Os eixos das coordenadas (Y) dos gráficos a, b, c e d estão invertidos para facilitar a interpretação. 
Figura 12 - Distribuição de (a) COT (\%); (b) $\ln \left(\mathrm{Ti} / \mathrm{Ca}\right.$ ); (c) razão $\mathrm{V} / \mathrm{Al} \times 10^{-4}$ (eixo Y invertido); (d) nível médio do mar (m) (Spratt e Lisiecki, 2016) e (e) insolação de verão a $30^{\circ} \mathrm{S}\left(\mathrm{W} / \mathrm{m}^{2}\right)$ (Berger e Loutre, 1991) ao longo dos últimos $40 \mathrm{ka}$. Em destaque, os limites dos estágios isotópicos marinhos (MIS 1, 2 e 3) (Lisiecki e Raymo, 2005). 44

Figura 13 - Distribuição das variáveis (a) COT (\%), (b) $\mathrm{CaCO}_{3}(\%)$, (c) $\delta^{13} \mathrm{C}(\%)$ e (d) $\mathrm{C} / \mathrm{N}$ ao longo do testemunho NAP63 em função da Idade cal. (anos AP). Em destaque, os limites dos estágios isotópicos marinhos (MIS 1, 2 e 3) (Lisiecki e Raymo, 2005).... 46

Figura 14 - Distribuição das razões elementares (a) V/Sc, (b) V/Cr, (c) V/Al x10 ${ }^{-4}$, (d) $\mathrm{Mn} / \mathrm{Al} \times 10^{-4}$ e (e) Ni/Co ao longo do testemunho NAP63 em função da Idade cal. (anos AP) com os respectivos eventos climáticos abruptos (H4, H3, H2, LGM, H1, YD e 8.2) dos últimos $40 \mathrm{ka}$ e os limites dos estágios isotópicos marinhos (MIS 1, 2 e 3) (Lisiecki e Raymo, 2005). Os eixos das coordenadas (Y) dos gráficos a, b, c e e estão invertidos para facilitar a interpretação.

Figura 15 - Representação esquemática dos três modelos propostos da circulação do Atlântico (AMOC). (a) O estado de circulação quente com a AMOC forte e profunda; (b) $O$ estado de circulação fria típico do Último Máximo Glacial, com a AMOC fraca e rasa; (c) E um estado sem circulação (Desligado) típica dos eventos Heinrich. ACN - águas da componente norte e ACS - águas da componente sul (Lynch-Stieglitz, 2017) .53

Figura 16 - Distribuição das razões (a) $\ln (\mathrm{Fe} / \mathrm{Ca})$ e (b) $\ln (\mathrm{Ti} / \mathrm{Ca})$ ao longo do testemunho NAP63 em função da Idade cal. (anos AP) com os respectivos eventos climáticos abruptos dos últimos $40 \mathrm{ka}$ e os limites dos estágios isotópicos marinhos (MIS 1, 2 e 3) (Lisiecki e Raymo, 2005). 55

Figura 17 - Distribuição das variáveis (a) COT (\%), (b) $\mathrm{CaCO}_{3}(\%)$, (c) $\delta^{13} \mathrm{C}(\%)$ e (d) $\mathrm{C} / \mathrm{N}$ ao longo do testemunho NAP63 em função da Idade cal. (anos AP) com os respectivos eventos climáticos abruptos dos últimos 40 ka e os limites dos estágios isotópicos marinhos (MIS 1, 2 e 3) (Lisiecki e Raymo, 2005). .56 


\section{Lista de Tabelas}

Tabela 1 - Associação entre os valores das razões elementares e a classe redox do ambiente deposicional.

Tabela 2 - Eventos de mudanças climáticas de escala orbital e milenar ocorridos nos últimos $40 \mathrm{ka}$.

Tabela 3 - Exemplos de trabalhos realizados desde a última década com foco de interesse na paleocenografia e paleoprodutividade da região do Atlântico Sudoeste.

Tabela 4 - Concentração dos elementos com as respectivas taxas de recuperação dos materiais de referência certificados SS-2 e MESS-3. .29

Tabela 5 - Resultados das idades médias obtidas por AMS ${ }^{14} \mathrm{C}$ e calibradas pelo programa Calib 7.10. Utilizou-se $2 \sigma$ (sigma) por apresentar $95,4 \%$ do intervalo dos resultados das idades calibradas. 


\section{Lista de Abreviações}

AC

Água Costeira

ACAS Água Central do Atlântico Sul

ACF

Alto de Cabo Frio

ACN

Água da Componente Norte

ACP

Água Circumpolar Profunda

ACS

Água da Componente Sul

AFA

Água de Fundo Antártica

AIA

Água Intermediária Antártica

AIGAN

Água Intermediária Glacial do Atlântico Norte

AMOC

Circulação Meridional do Atlântico

(Atlantic Meridional Overturning Circulation)

AMS

Accelerator Mass Spectrometry

AMSA Água Modal Subantártica

AP

Antes do Presente

APAN Água Profunda do Atlântico Norte

B-A Bølling-Allerød

CB Corrente do Brasil

CCA Corrente Circumpolar Antártica

$\mathrm{CCl} \quad$ Corrente de Contorno Oeste Intermediária

CCP Corrente de Contorno Oeste Profuna

$\mathrm{CM}$

Corrente das Malvinas

$\mathrm{C} / \mathrm{N}$

Razão Carbono/Nitrogênio

CNB

Corrente Norte do Brasil

COT

Carbono Orgânico Total

CSM

Cabo de Santa Marta 


\begin{tabular}{|c|c|}
\hline D-O & Dansgaard-Oeschger \\
\hline EA-IRMS & $\begin{array}{l}\text { Analisador Elementar de Espectrometria de Massa com Razão } \\
\text { Isotópica (Elemental Analysis - Isotope Ratio Mass } \\
\text { Spectrometry) }\end{array}$ \\
\hline FPA & Frente Polar Antártica \\
\hline $\mathrm{H}$ & Evento Heinrich \\
\hline ICP-OES & $\begin{array}{l}\text { Espectrometria de Emissão Óptica com Plasma Indutivamente } \\
\text { Acoplado (Inductively Coupled Plasma Optical Emission } \\
\text { Spectrometry) }\end{array}$ \\
\hline IRD & Ice-Rafted Detritus \\
\hline JBN & Jatos de Baixos Níveis \\
\hline LGM & Último Máximo Glacial (Last Glacial Maximum) \\
\hline MIS & Estágios Isotópicos Marinhos (Marine Isotope Stages) \\
\hline MO & Matéria Orgânica \\
\hline MRC & Material de Referência Certificado \\
\hline N/Oc. & Navio Oceanográfico \\
\hline NSW & Northern Source Water \\
\hline $\mathrm{N}_{\text {tot }}$ & Nitrogênio total \\
\hline SE & Sudeste \\
\hline SEAS & Sudeste da América do Sul \\
\hline SMAS & Sistema de Monção da América do Sul \\
\hline SNB & Subcorrente Norte do Brasil \\
\hline SSW & Southern Source Water \\
\hline SW & South Western \\
\hline TSM & Temperatura da Superfície do Mar \\
\hline UMG & Último Máximo Glacial \\
\hline
\end{tabular}




$\begin{array}{ll}\text { USEPA } & \text { United } \\ & \text { Agency } \\ \text { YD } & \text { Younger Dryas } \\ \text { ZCAS } & \text { Zona de Convergência do Atlântico Sul } \\ \text { ZCIT } & \text { Zona de Convergência Intertropical } \\ \text { ZFP } & \text { Zona da Frente Polar }\end{array}$




\section{Sumário}

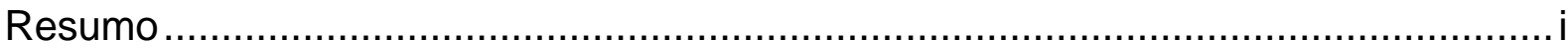

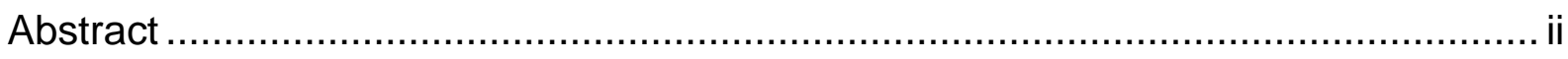

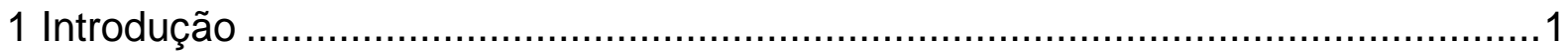

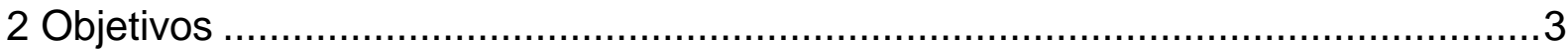

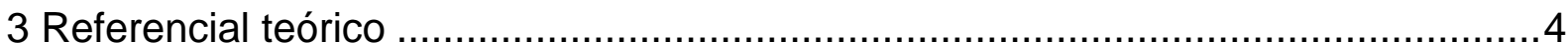

3.1 Proxies geoquímicos em estudos paleoceanográficos e paleoclimáticos .............4

3.1.1 Proxies de condições redox ........................................................... 4

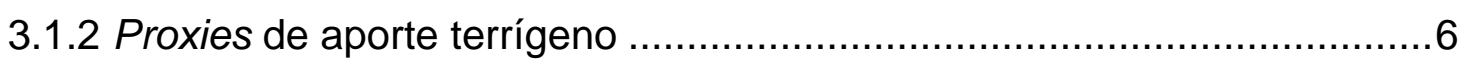

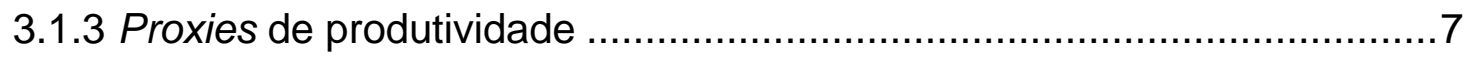

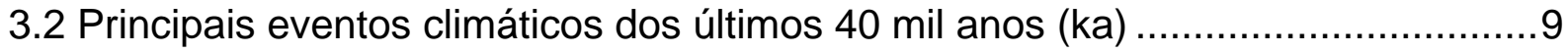

3.3 Paleoceanografia do Atlântico Sudoeste..........................................................15

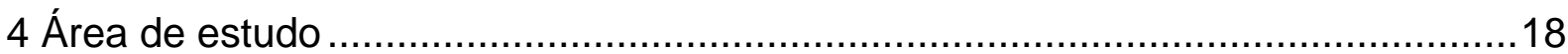

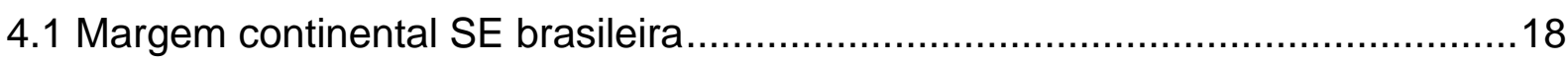

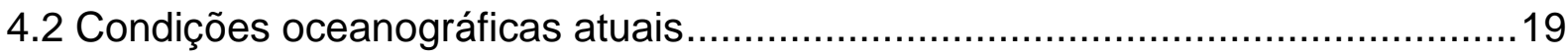

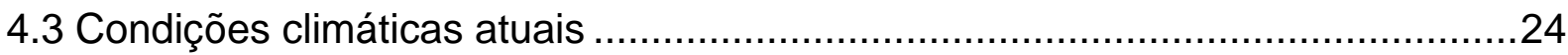

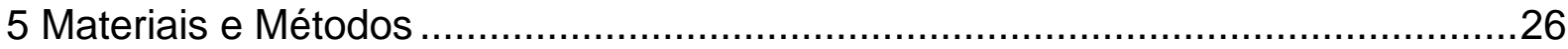

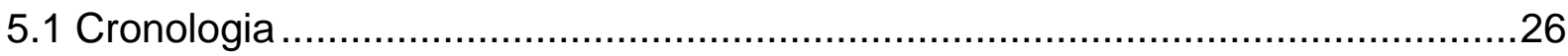

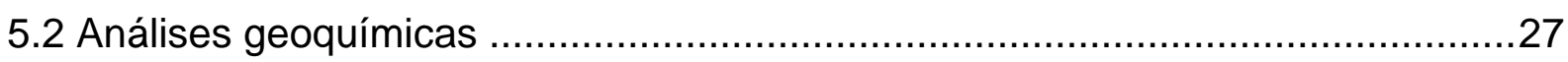

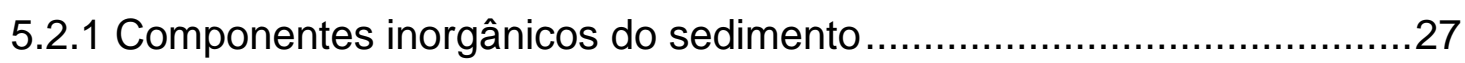

5.2.2 Carbono orgânico total, nitrogênio total, conteúdo de carbonato de cálcio e isótopo estável de carbono em sedimento.... 31

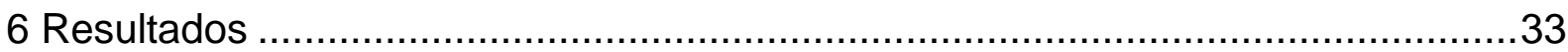

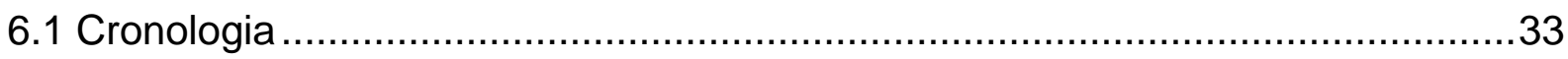

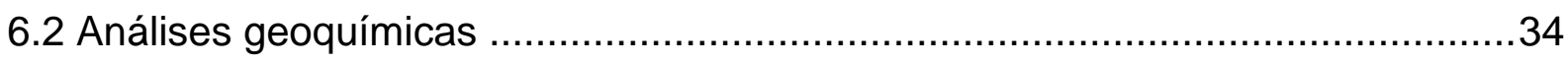

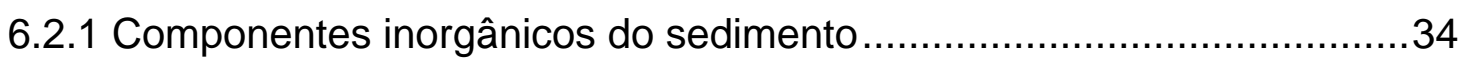

6.2.2 Carbono orgânico total, conteúdo de carbonato de cálcio, isótopo estável de carbono e a razão $\mathrm{C} / \mathrm{N}$ em sedimento....................................................38

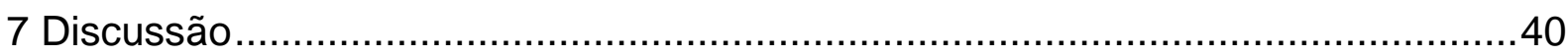

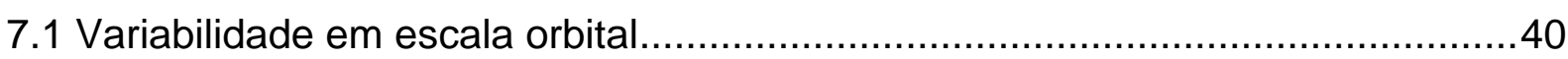

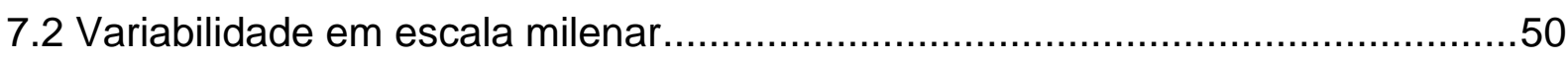

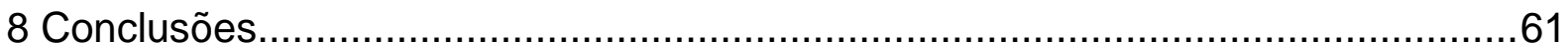

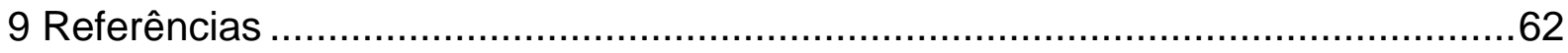

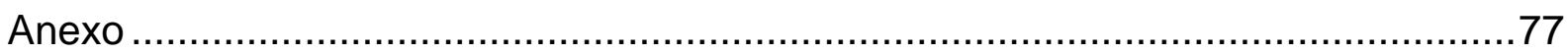


Tabela 1 - Resultados 


\section{Resumo}

O conhecimento da paleoceanografia do Oceano Atlântico Sul tem aumentado nas últimas décadas, porém ainda são raros os trabalhos sobre o Atlântico Sudoeste que utilizam dados de proxies de condições redox de massas d'água, relacionados às mudanças climáticas entre os períodos Pleistoceno superior e Holoceno. Diante disso, esta Dissertação de Mestrado avaliou as condições redox das águas intermediárias do Atlântico Sudoeste nos últimos 40 mil anos. Este trabalho fez estudos de proxies geoquímicos - de condições redox ( $\mathrm{V} / \mathrm{Sc}, \mathrm{V} / \mathrm{Cr}, \mathrm{V} / \mathrm{Al}, \mathrm{Mn} / \mathrm{Al}$ e $\mathrm{Ni} / \mathrm{Co}$ ), de aporte de sedimentos ter ${ }^{\mathrm{TM}} \mathrm{TM}^{\mathrm{r}}$ ígenos (Fe/Ca e $\mathrm{Ti} / \mathrm{Ca}$ ), de produtividade $\left(\mathrm{COT}, \mathrm{CaCO}_{3}\right)$ e origem da matéria orgânica $\left(\delta^{13} \mathrm{C}\right.$ e $\left.\mathrm{C} / \mathrm{N}\right)$ - em um registro sedimentar marinho coletado na região do talude continental da margem sudeste brasileira, e os relacionou com as mudanças da Célula de Revolvimento Meridional do Atlântico (sigla em inglês AMOC - Atlantic Medirional Overturning Circulation) e com os principais eventos climáticos em escala orbital, como o Último Máximo Glacial, e de escala milenar, como os eventos tipo Heinrich Stadials, Younger Dryas e 8.2. Os resultados demonstram que, nos últimos $40 \mathrm{mil}$ anos, as águas intermediárias que banham a costa sudeste brasileira apresentam níveis óxicos, 0 que classifica o ambiente como oxidante, porém foi possível observar variações na quantidade de oxigênio dissolvido nessas águas durante determinados eventos climáticos, bem como variações no aporte de sedimentos terrígenos e na produtividade. Em escala orbital a insolação de verão do Hemisfério Sul e a variação do nível do mar, governadas pelo ciclo de precessão, apresentam-se como os principais mecanismos que influenciam essas variações. Em escala milenar a variabilidade da AMOC apresenta-se como o principal mecanismo responsável por essas variações. Dentre os eventos climáticos de escala milenar, o evento 8.2 demonstrou complexa variabilidade nas condições redox das águas intermediárias do Atlântico Sudoeste, uma vez que, durante sua ocorrência, observamos aumento das concentrações de oxigênio dessas águas e baixos valores de produtividade.

\section{Palavras-chave: Pleistoceno superior; Atlântico Sudoeste; proxies geoquímicos; condições redox.}




\section{Abstract}

The interest in the paleoceanographic history of the South Atlantic Ocean has increased in the last decades, however there are still few studies regarding the redox conditions of the intermediate water masses of the Southwest Atlantic and their relationship to the climatic changes during the upper Pleistocene and Holocene. Within this context, this work aims to evaluate the redox conditions of the intermediate waters of the Southwest Atlantic in the last $40 \mathrm{ka}$. For this, geochemical proxies - of redox conditions ( $\mathrm{V} / \mathrm{Sc}, \mathrm{V} / \mathrm{Cr}, \mathrm{V} / \mathrm{Al}, \mathrm{Mn} / \mathrm{Al}$ and $\mathrm{Ni} / \mathrm{Co}$ ), of terrigenous sediments supply ( $\mathrm{Fe} / \mathrm{Ca}$ and $\mathrm{Ti} / \mathrm{Ca}$ ), of productive (COT, $\mathrm{CaCO}$ ), and organic matter source $(\delta 13 \mathrm{C}$ and $\mathrm{C} / \mathrm{N})$ - were applied to marine sediments from a core collected on the continental slope of the Brazilian Southeastern margin and then related it to changes in the Atlantic Meridional Overturning Circulation (AMOC) and with the main cold climatic events of North Atlantic, such as the Last Glacial Maximum and millennial scale, such as events type the Heinrich Stadials, Younger Dryas and 8.2. Our results show that, over the last 40,000 years, the redox conditions of the intermediate waters of the Brazilian Southeast margin present oxic levels, which classifies the environment as oxidant, however, variations was noticed in the amount of oxygen dissolved in these waters influenced by certain climatic events, as well as changes in the input of terrigenous sediments and in the productivity. In orbital scale, the summer insolation of the Southern Hemisphere and the variation of sea level, leaded by the cycle of precession, are presented as the main mechanisms that influence these variations. On the other hand, at millennia scale, the AMOC variability is the main mechanism responsible of these variations. Among the climate events at millennia scale, the event 8.2 demonstrated a complex variability of the redox conditions of the intermediate waters of the Southwest Atlantic, once during its occurrence we observed increase concentrations of oxygen in these waters and a decrease of productivity.

Key words: upper Pleistocene; Southwest Atlantic; geochemical proxies; redox conditions. 


\section{Introdução}

Estudos paleoceanográficos e paleoclimáticos buscam reconstituir ambientes pretéritos a fim de compreender e distinguir forçantes naturais e antrópicas (Doug et al., 2007; Garzoli e Matano, 2011; Villalba et al., 2009). A compreensão dessas forçantes pretéritas auxiliam no entendimento dos processos associados às mudanças climáticas futuras, por meio, por exemplo, de modelos numéricos de projeções climáticas. Além disso, melhoram nosso entendimento sobre as possíveis respostas ambientais frente a modificações climáticas como 0 aumento da concentração de gases de efeito estufa na atmosfera terrestre (Perretti et al., 2015).

Estudos baseiam-se em proxies $^{1}$ geoquímicos provenientes de registros sedimentares marinhos para reconstituir parâmetros oceanográficos, como paleocirculação, paleoprodutividade, paleotemperaturas e condições paleoredox. Uma esses parâmetros ficam registrados nesses proxies durante o processo de sedimentação (Martinez-Ruiz et al. 2015; Tribovillard et al. 2006). A composição geoquímica dos sedimentos, por exemplo, pode ser influenciada pela concentração de oxigênio dissolvido no ambiente marinho durante o processo de deposição e diagênese no passado (Tribovillard et al., 2006). O estudo de condições redox em ambientes marinhos evidencia a distribuição relativa de agentes oxidantes ou redutores em gradientes deposicionais e diagenéticos, dado que os processos biogeoquímicos são os principais responsáveis por controlar essa distribuição (Tribovillard et al., 2006). Assim, por meio de proxies geoquímicos (e. g., metais traços) podemos estimar as condições redox $^{2}$ do meio ou da massa d'água predominante em tempos pretéritos (Powell et al. 2003), ainda que o principal mecanismo de entrada de oxigênio em massas d’água ocorra em sua área de formação, quando há interação com os gases atmosféricos e a superfície do mar,

\footnotetext{
${ }^{1}$ proxies, segundo Fischer e Wefer (1999) são: “descritores mensuráveis para as variáveis desejadas (mas não observáveis)" como, por exemplo, temperatura, salinidade e condições redox de ambientes oceânicos no passado.

2 condições redox: o estado de redução-oxidação (redox) está em função da abundância de elétrons livres no sistema (Essington, 2015). Em geral, quando o sistema é rico em elétrons denomina-se reduzido e quando pobre em elétrons denomina-se oxidado.
} 
como pode ser visto, na região de formação da Água Intermediária Antártica (AIA) (Anderson et al., 2009; Wainer et al., 2012).

A AIA é uma massa d'água caracterizada pela baixa temperatura, baixa salinidade (Anderson et al., 2009; Wainer et al. 2012) e por ser rica em oxigênio (Silveira et al., 2015). Ela se forma na região Antártica, a partir da ressurgência da Água Circumpolar Profunda (ACP), que posteriormente sofre submersão, sendo introduzida no sistema de circulação do Oceano Atlântico pela Corrente de Contorno Oeste Intermediária ( $\mathrm{CCl})$. A CCl é o principal componente do membro superior da Célula de Revolvimento Meridional do Atlântico (em inglês Atlantic Meridional Overturning Circulation - AMOC) e está associada ao transporte de calor e sal para o Atlântico Norte (Huang et al., 2014; Silveira et al., 2004; Wainer et al., 2012). Essa transferência de energia inter-hemisférica é foco de muitos estudos paleoceanográficos e paleoclimáticos por representar um dos principais componentes reguladores do clima terrestre (Chiessi et al., 2015; Huang et al., 2014; Makou et al., 2010; Wainer et al., 2012; Lund et al., 2015, Lynch-Stieglitz, 2017). Esses estudos sugerem que eventos climáticos frios (e. g., eventos Heinrich) do Atlântico Norte estão associados ao enfraquecimento da AMOC, o qual pode alterar tanto o padrão de circulação oceânico quanto atmosférico do Atlântico Sul, desequilibrando, assim, a transferência de calor inter-hemisférico.

No âmbito das condições de redox das massas d'água do Oceano Atlântico Austral, observa-se que são escassos os estudos voltados para esse parâmetro oceanográfico tão importante, principalmente por caracterizar a distribuição da concentração de oxigênio dissolvido no ambiente marinho devido a mudanças climáticas associadas a alterações da AMOC entre os períodos do Pleistoceno superior e do Holoceno. Dessa forma, esta Dissertação de Mestrado visa qualificar as condições paleoredox da região do talude Sudeste brasileiro por meio de proxies geoquímicos de um registro sedimentar coletado sob o domínio da Água Intermediária Antártica (AIA), além de correlaciona-las a eventos climáticos tanto de escala orbital quanto em escala milenar. 


\section{Objetivos}

Avaliar as condições redox das águas intermediárias do Oceano Atlântico Sudoeste nos últimos 40 mil anos, a partir das análises da composição química e da razão elementar de sedimentos marinhos, provenientes de um testemunho coletado no talude da margem Sudeste brasileira.

Para este trabalho, foram definidos os seguintes objetivos específicos:

(i) Verificar mudanças na concentração de elementos traço, teor de carbonato de cálcio, carbono orgânico total, nitrogênio total e a razão dos isótopos estáveis de carbono ao longo do registro sedimentar;

(ii) Avaliar possíveis variações nas condições redox das águas intermediárias do Atlântico Sudoeste, nos últimos 40 mil anos, a partir de razões elementares (V/Al, $\mathrm{V} / \mathrm{Cr}, \mathrm{V} / \mathrm{Sc}, \mathrm{Ni} / \mathrm{Co}$ e $\mathrm{Mn} / \mathrm{Al}$ );

(iii) Interpretar e discutir as condições pretéritas das águas intermediárias do Atlântico Sudoeste sob perspectiva de mudanças oceanográficas e climáticas regionais e globais. 


\section{Referencial teórico}

\subsection{Proxies geoquímicos em estudos paleoceanográficos e paleoclimáticos}

\subsubsection{Proxies de condições redox}

Praticamente todos os metais são encontrados no oceano, na forma dissolvida ou particulada, e são introduzidos por rios, ventos, fontes hidrotermais, difusão a partir dos sedimentos e atividade antrópica (Valdés, 2004). Os metais, geralmente traços ou elementos traços, que reagem às condições de oxigenação do meio são denominados redox-sensíveis (Martinez-Ruiz et al. 2015; Tribovillard et al. 2006). Em registros sedimentares esses metais redox-sensíveis fornecem informações importantes sobre o estado de oxigenação predominante no ambiente deposicional no passado (Algeo e Rowe, 2012; Calvert e Pedersen, 2007; MartinezRuiz et al., 2015).

Os elementos traços são caracterizados como elementos químicos encontrados no ambiente marinho em baixas concentrações $\left(<0,1 \mu \mathrm{g} \mathrm{g}^{-1}\right.$ ou 0,1 ppm) e são essenciais para o metabolismo de alguns seres vivos, na forma de micronutrientes (Essington, 2015; Pierzynski et al., 2005; Sparks, 2003). Segundo Calvert e Pedersen (2007) os elementos traços são agrupados em duas categorias, a saber:

(i) Aqueles cujo estado de oxidação pode variar em função do potencial redox como, por exemplo, o Mn (possui uma forma insolúvel em oxi-hidróxidos em condições óxicas); $\mathrm{Cr}$, Mo, Re, U e V (os quais ocorrem como espécies aniônicas altamente solúveis em águas óxicas, mas são reduzidas a espécies reativas ou insolúveis em condições anóxicas).

(ii) Aqueles em que o estado de oxidação não muda: por exemplo $\mathrm{Ag}, \mathrm{Cd}, \mathrm{Cu}, \mathrm{Ni}$ e $\mathrm{Zn}$, os quais formam sulfetos altamente insolúveis e são usualmente removidos da solução na presença de $\mathrm{H}_{2} \mathrm{~S}$.

O Ni em ambiente com alto teor de Carbono Orgânico Total (COT) sofre remobilização diagenética, reduzindo seu potencial como proxy redox, porém em ambiente com baixo teor de COT este elemento torna-se um bom proxy redox. 
Alguns elementos traços são mais solúveis em condições de oxidação e menos solúveis em condições de redução, resultando em enriquecimentos autigênicos em fácies sedimentares pobres em oxigênio (Calvert e Pedersen, 2007; Tribovillard et al., 2006). Dessa maneira, Tribovillard et al. (2006) propuseram uma classificação redox do ambiente deposicional para os oceanos atuais, referente à concentração de oxigênio $\left[\mathrm{O}_{2}\right]$ em $\mathrm{mL} \mathrm{L}^{-1}$, a saber: (i) Óxica $\left[\mathrm{O}_{2}\right]>2$; (ii) Subóxica $2>\left[\mathrm{O}_{2}\right]>0,2$; (iii) Anóxica $\left[\mathrm{O}_{2}\right]<0,2$ (com presença de $\mathrm{H}_{2} \mathrm{~S}$ na coluna d'água; (iv) Euxínico $\left[\mathrm{O}_{2}\right]=0$ (sem presença de $\mathrm{H}_{2} \mathrm{~S}$ na coluna d'água).

As inferências relativas às condições paleoredox baseadas em dados de elemento traço são geralmente pouco confiáveis se for utilizada a distribuição de um único elemento, pois a concentração desse metal pode ser influenciada por muitos fatores (Tribovillard et al., 2006), tais como: aumento no fluxo siliciclástico detrital, taxa de produtividade primária, degradação da matéria orgânica (MO) e processos de bioturbação (Martinez-Ruiz et al. 2015; Tribovillard et al. 2006). Além disso, esses elementos traços podem ser utilizados desde que suas concentrações resultem de fontes hidrogenadas e não de fontes detritais ou hidrotermais (Tribovillard et al., 2006). Outro fator importante são os procedimentos analíticos, como no caso das amostras sedimentares que são digeridas ${ }^{3}$ (Martinez-Ruiz et al., 2015). Segundo os autores mencionados, procedimentos adequados são essenciais para garantir a dissolução dos minerais e trazer maior confiabilidade para interpretações relacionadas às condições paleoredox. Entretanto, avanços técnicos contribuíram muito para o desenvolvimento de novos proxies geoquímicos, melhorando os limites de detecção, precisão e calibração (Martinez-Ruiz et al., 2015).

A fim de aumentar a confiabilidade das inferências relativas às condições redox no ambiente marinho, alguns autores (Jones e Manning, 1994; Martinez-Ruiz et al., 2015; Moreno et al,. 2004; Pattan e Pearce, 2009; Powell et al., 2003) utilizam razões elementares como: V/Al, V/Cr, V/Sc, Ni/Co e Mn/Al. Segundo Powell et al. (2003), o comportamento do metal, representado pelo numerador da razão elementar, depende das condições redox do meio, ao passo que o outro elemento (denominador) geralmente independe das variações redox do meio. Portanto, o valor da razão deve aumentar quando o metal dependente das condições redox precipita

\footnotetext{
${ }^{3}$ Amostras digeridas: amostras que passam por procedimento analítico o qual dissolve todos os minerais.
} 
e é adicionado ao sedimento. Um exemplo de como são utilizadas as razões elementares para classificar um ambiente deposicional em níveis de condições redox está representado na Tabela 1.

Tabela 1 - Associação entre os valores das razões elementares e a classe redox do ambiente deposicional.

\begin{tabular}{lcll}
\hline Razões & Óxica & Subóxica & Anóxica \\
\hline $\mathrm{V} / \mathrm{Cr}^{\mathrm{a}}$ & $<2,00$ & $2,00-4,25$ & $>4,25$ \\
$\mathrm{Ni} / \mathrm{Co}^{\mathrm{a}}$ & $<5,00$ & $5,00-7,00$ & $>7,00$ \\
$\mathrm{~V} / \mathrm{Sc}^{\mathrm{b}}$ & $<9,1$ & - & - \\
\hline${ }^{\mathrm{a}}$ Jones e Manning, 1994. & & \\
& &
\end{tabular}

\subsubsection{Proxies de aporte terrígeno}

Metais como $\mathrm{Ca}$, Fe e Ti podem indicar a origem do sedimento, uma vez que, Ca componente da calcita e aragonita, reflete principalmente o conteúdo de carbonato marinho no sedimento, ou seja, representando os componentes biogênicos. Enquanto que o Ti e Fe estão associados a componentes siliciclásticos e especialmente minerais argilosos (Arz et al., 1998; Govin et al., 2012). Logo esses metais variam diretamente com a fração terrígena dos sedimentos. Dessa forma, as razões $\mathrm{Fe} / \mathrm{Ca}$ e Ti/Ca são amplamente utilizadas como indicadores de aporte de material terrígenos para oceano (Arz et al., 1998; Govin et al., 2012).

Em estudos paleoclimáticos a variação de aporte de terrígenos ao longo do tempo pode inferir condições climáticas continentais mais ou menos úmidas, uma vez que em condições mais úmidas estes elementos alcançariam o ambiente marinho principalmente por processos de drenagens das bacias hidrográficas e variações das vazões de rios costeiros, respondendo ao regime pluviométrico do passado (Burckel et al., 2015; Burone et al., 2013; Govin et al., 2012; Jaeschke et al., 2007). 


\subsubsection{Proxies de produtividade}

As características da matéria orgânica (MO) depositada nos sedimentos marinhos têm sido amplamente utilizadas no entendimento de diversos processos oceanográficos, tais como: produtividade de águas superficiais, aporte de materiais continentais, dinâmica das massas d'água, potencial de oxirredução e taxas de sedimentação (Mahiques et al., 1999).

O carbonato de cálcio $\left(\mathrm{CaCO}_{3}\right)$ nos sedimentos marinhos é composto predominantemente pelos esqueletos dos organismos que vivem no mar e representa $95 \%$ do carbono transferido dos oceanos para o sedimento (Brummer e Van Eijden, 1992). Dessa forma, $0 \mathrm{CaCO}_{3}$ tem sido amplamente utilizado como proxy em estudos de paleoprodutividade (Costa et al., 2016; Mahiques et al., 2004, 2007, 2017; Moreno et al., 2004; Nagai et al., 2009; Pattan e Pearce, 2009).

A produção de carbonato no talude e no ambiente pelágico é feita quase que exclusivamente por organismos planctônicos, principalmente cocolitoforídeos, foraminíferos e, em menor dimensão, por pterópodes e dinoflagelados calcários (Rühlemann et al., 1999). Segundo Volat et al. (1980), três fatores controlam o conteúdo de $\mathrm{CaCO}_{3}$ nos sedimentos, a saber: (i) variações na produtividade planctônica; (ii) dissolução das testas calcárias durante e após a deposição; (iii) diluição por material não-carbonático por meio do aumento no aporte de material terrígeno.

Além do teor de carbonato, a MO sedimentar também pode ser estudada em nível elementar e isotópico. O carbono orgânico total (COT), o nitrogênio total (Ntot) e a razão $\mathrm{C} / \mathrm{N}$, além do isótopo estável de carbono $\left(\delta^{13} \mathrm{C}\right)$, podem ser aplicados para inferir a fonte da $\mathrm{MO}$. O carbono orgânico é o principal constituinte dos compostos biológicos e, assim, a avaliação do seu teor no sedimento pode ser aplicada na reconstituição da produtividade oceânica exportada da superfície. Porém, devido aos processos de degradação da $\mathrm{MO}$ ao longo da coluna d'água, apenas uma pequena fração chega ao sedimento e encontra-se preservada (Paytan, 2006).

A razão $\mathrm{C} / \mathrm{N}$ tem sido utilizada para distinguir entre $\mathrm{MO}$ sedimentar, cuja origem está associada a algas marinhas e plantas terrestres (Silliman et al., 1996). Em geral, a MO derivada das algas marinhas (rica em proteínas, ou seja, contendo alta quantidade de nitrogênio) apresenta valores de $\mathrm{C} / \mathrm{N}$ entre 4 a 10 , enquanto as 
plantas vasculares terrestres (ricas em celulose) apresentam valores maiores ou igual a 20 (Meyers, 1997). É importante salientar que a razão $\mathrm{C} / \mathrm{N}$ pode ser influenciada pela granulometria, ou seja, pelo tamanho do sedimento (Meyers, 1997). Desse modo, é conveniente associar outros proxies para inferir a fonte da $\mathrm{MO}$, como a razão isotópica do carbono orgânico $\left(\delta^{13} \mathrm{C}\right)$, que independe das dimensões sedimentares (Meyers, 1997).

A utilização de isótopos estáveis em estudos ambientais é baseada nas variações da abundância relativa do isótopo mais leve a partir de processos bióticos (respiração, fotossíntese, dentre outros) e abióticos (precipitação, evaporação, congelamento etc.) (Bianchi e Canuel, 2011). Esses processos promovem certa discriminação isotópica por geralmente assimilar e/ou selecionar o isótopo mais leve. A isso se denomina fracionamento isotópico, sendo expresso na forma de uma razão (ex.: ${ }^{13} \mathrm{C} /{ }^{12} \mathrm{C}$ ou $\delta^{13} \mathrm{C}$ ) pela terminologia "delta per mil" ( $\delta \%$ ) (Bianchi e Canuel, 2011; Fry, 2006).

A razão isotópica do carbono orgânico $\left(\delta^{13} \mathrm{C}\right)$ é amplamente utilizada para distinguir as fontes da MO sedimentar (marinha e terrestre), além de diferenciar entre os tipos de plantas terrestres $\left(C_{3}\right.$ e $\left.C_{4}\right)$ (Meyers, 1997). A variação da razão isotópica do carbono é controlada pelos processos biológicos, sendo a fotossíntese o processo mais importante (Bianchi e Canuel, 2011). No ambiente marinho, as principais fontes de carbono inorgânico são $0 \mathrm{CO}_{2}$ (gás carbônico) dissolvido e o $\mathrm{HCO}_{3}{ }^{-}$(ânion bicarbonato). $\mathrm{O} \mathrm{CO}$ dissolvido possui valores de $\delta^{13} \mathrm{C}\left(\delta^{13} \mathrm{C}=-7 \%\right.$, quando em equilíbrio com o $\mathrm{CO}_{2}$ atmosférico) menores do que o $\mathrm{HCO}_{3}{ }^{-}\left(\delta^{13} \mathrm{C}=0 \%\right)$, de modo que o fitoplâncton assimilará preferencialmente $\mathrm{O}_{\mathrm{CO}_{2}}$ quando disponível (Meyers, 1997). Segundo esse autor, a proporção entre tais compostos é influenciada pelo $\mathrm{pH}$ do ambiente, o que faz com que $\mathrm{O}_{\mathrm{HCO}_{3}}{ }^{-}$seja a fonte predominante de carbono inorgânico no meio marinho.

Valores de $\delta^{13} \mathrm{C}$ da $\mathrm{MO}$ sedimentar produzida a partir do $\mathrm{CO}_{2}$ atmosférico em plantas $C_{3}$ variam entre $-23 \%$ e $-34 \%$, e, em plantas $C_{4}$, entre $-9 \%$ e $-17 \%$ (Zhou et al., 2006). Entretanto, a $\mathrm{MO}$ marinha possui valores de $\delta^{13} \mathrm{C}$ que variam entre $-20 \%$ e -22\% (Meyers, 1997). 


\subsection{Principais eventos climáticos dos últimos $\mathbf{4 0}$ mil anos (ka)}

Nossa pesquisa se refere ao Período Quaternário (2,5 Ma até o Presente), subdividido nas épocas do Pleistoceno (2,5 Ma até 11,7 ka) e do Holoceno (11,7 ka até o Presente) (ICS, 2017). O Período Quaternário compreende eventos de mudanças climáticas tanto de escala orbital (como, por exemplo, os ciclos de Milankovitch) (Berger, 1992) quanto de escala milenar (tais como os eventos frios Heinrich Stadials e os eventos quentes Dansgaard-Oeschger (D-O) Interstadial) (Lynch-Stieglitz, 2017). Dentro do recorte deste estudo - que abrange o período de 40 ka até 2,5 ka -, estudaremos os três últimos Estágios Isotópicos Marinhos ${ }^{4}$ (Marine Isotope Stages - MIS).

O termo escala orbital é geralmente utilizado em estudos paleoclimáticos a fim de referenciar oscilações climáticas decorrentes das variações nos parâmetros orbitais da Terra, também conhecidos como ciclos de Milankovitch ${ }^{5}$ (Berger, 1992). O evento climático em escala orbital observado no período de interesse foi o Último Máximo Glacial (LGM, do inglês Last Glacial Maximum, entre 23 ka e 18 ka AP) (Lund et al., 2015).

Em termos de escala milenar, os eventos climáticos são caracterizados por mudanças abruptas no clima, apresentando, no último período glacial ( 50 ka a 18 ka), episódios de frio extremo nas altas latitudes do Hemisfério Norte, conhecidos como Heinrich Stadials (HS), seguidos por episódios de elevação brusca de temperatura, conhecidos como Dansgaard-Oeschger (D-O) (Lynch-Stieglitz, 2017). Durante a última deglaciação ( 18 ka a 11,7 ka), os eventos climáticos milenares abruptos que se destacam são: Younger Dryas (YD, evento tipo HS), Bølling-Allerød (B-A, evento tipo D-O) e Heinrich Stadial 1 (H1). Posteriormente, no Holoceno, o

\footnotetext{
${ }^{4}$ Os Estágios Isotópicos Marinhos (MIS) são registros de isótopos de oxigênio derivados, principalmente, de foraminíferos bentônicos preservados em sedimentos marinhos. Através desses isótopos pode-se estimar a temperatura da água no passado, fornecendo assim uma base para os estudos paleoclimáticos sobre a alternância entre períodos quentes e frios em escala global (Wright, 2013).

${ }^{5}$ Esses parâmetros compreendem três ciclos orbitais: (i) precessão - variação da posição dos solstícios e equinócios ao longo da órbita da Terra, com periodicidade de 23 ka e 19 ka; (ii) obliquidade - variação da inclinação do eixo de rotação da Terra, com periodicidade de $\sim 41 \mathrm{ka}$; e (iii) excentricidade - variação do formato da órbita da Terra em torno do Sol, com periodicidade de 400 ka e $120 \mathrm{ka}$. Cada um desses ciclos influencia de maneira diferente a intensidade e a distribuição da insolação sobre a superfície terrestre (Berger, 1992; Zachos et al., 2001).
} 
evento frio conhecido como 8.2 destaca-se por apresentar mudanças abruptas no clima (Ljung et al., 2008).

Os eventos de mudanças climáticas que foram abordados neste trabalho estão representados na tabela 2 com as respectivas idades e referências.

Tabela 2 - Eventos de mudanças climáticas de escala orbital e milenar ocorridos nos últimos 40 ka.

\begin{tabular}{|c|c|c|}
\hline Evento Climático & Idade cal. (anos AP) & Referência \\
\hline Evento 8.2 & $8.275-8.025$ & Ljung et al., 2008 \\
\hline Younger Dryas (YD) & $12.900-11.700$ & $\begin{array}{l}\text { Broecker et al., 2010; } \\
\text { Rasmussen et al., 2006 }\end{array}$ \\
\hline Heinrich $1(\mathrm{H} 1)$ & $16.900-15.400$ & $\begin{array}{l}\text { Hemming, } 2004 ; \\
\text { Weldeab et al., } 2006\end{array}$ \\
\hline $\begin{array}{l}\text { Último Máximo Glacial } \\
\text { (UMG) }\end{array}$ & $23.000-18.000$ & $\begin{array}{l}\text { Martinez-Ruiz et al., } \\
2015\end{array}$ \\
\hline Heinrich 2 (H2) & $26.500-24.000$ & $\begin{array}{l}\text { Harrison e Goñi, 2010; } \\
\text { Hemming, 2004 }\end{array}$ \\
\hline Heinrich $3(\mathrm{H} 3)$ & $32.700-31.000$ & $\begin{array}{l}\text { Harrison e Goñi, 2010; } \\
\text { Hemming, } 2004\end{array}$ \\
\hline Heinrich $4(\mathrm{H} 4)$ & 38.000 & Hemming, 2004 \\
\hline
\end{tabular}

A maior parte dos efeitos climáticos desses eventos apresentaram-se em antifase entre os hemisférios, o que é conhecido como efeito "gangorra" (do inglês, bipolar seesaw). Por exemplo, em períodos de resfriamento no Hemisfério Norte (Hemisfério Sul) observa-se um aquecimento no Hemisfério Sul (Hemisfério Norte) (Barker et al., 2009). Essas oscilações de temperatura apresentaram-se de forma abrupta em registros de gelo na Groenlândia e de forma mais gradual no Hemisfério Sul e na Antártica (Stocker e Johnsen, 2003).

A principal causa desse efeito de antifase entre os hemisférios são as variações na intensidade da $\mathrm{AMOC}$, as quais afetam a distribuição de calor entre os oceanos Atlântico Norte e Atlântico Sul (Böhm et al., 2015; Lynch-Stieglitz, 2017; Schmittner e Lund, 2015).

A seguir serão abordados os principais eventos frios de mudanças climáticas, em ordem cronológica: Eventos Heinrich, Último Máximo Glacial (UMG), Younger Dryas (YD) e Evento 8.2. 


\section{Eventos Heinrich}

Os eventos Heinrich são classificados como eventos frios e curtos que podem ter sinais em todo o globo, uma vez que possuem interação coerente entre a atmosfera, os oceanos e a criosfera em intervalos de tempo milenar (Hemming, 2004). Esses eventos foram estudados pela primeira vez por Hartmut Heinrich, um geólogo marinho, em 1988, e identificados através de testemunhos sedimentares marinhos coletados no Atlântico Norte. Esses testemunhos apresentaram detritos de rochas (IRD - Ice-rafted detritus) que haviam sido erodidos e transportados por icebergs desprendidos principalmente do glacial Laurentidea da América do Norte através do Estreito de Hudson (Hemming, 2004). Tais detritos (IRD) instalaram-se no fundo marinho da região do oceano Atlântico Norte na medida em que os icebergs se desfaziam.

Hemming (2004) identificou em seu trabalho os seis últimos eventos Heinrich $(\mathrm{H})$, tendo o mais antigo deles $(\mathrm{H} 6)$ aproximadamente 60 mil anos AP e o mais novo (H1) aproximadamente 16.900 anos AP (Hemming, 2004; Weldeab et al., 2006).

O derretimento de icebergs durante os eventos Heinrich fez com que grandes quantidades de água doce fossem adicionadas ao Atlântico Norte. Esses insumos de água fria e doce podem ter alterado os padrões de circulação do Atlântico e, muitas vezes, coincidem com indicações de flutuações climáticas globais (Hemming 2004; Lund et al., 2015; Lynch-Stieglitz 2017).

Abaixo são apresentados alguns parâmetros que caracterizam os eventos Heinrich:

- Redução na temperatura e na salinidade no Atlântico Norte (Brummer e Van Eijden, 1992; Maslin et al., 1995);

- Alta concentração de carbonato detrital no Atlântico Norte (Hemming 2004);

- $\quad$ Alta susceptibilidade magnética no Atlântico Norte (Hemming 2004);

- Aumento na intensidade de vento em várias regiões do globo (Hemming 2004);

- $\quad$ Aumento no $\mathrm{CO}_{2}$ atmosférico (Lund et al., 2015); 


\section{Último Máximo Glacial}

Como mencionado anteriormente, o Último Máximo Glacial (UMG) ocorreu entre 23 ka e 18 ka AP e é caracterizado por várias mudanças importantes no estado climático da Terra (Lund et al., 2015). O cenário geral desse período inclui:

- o aumento das extensões de gelo, tanto na América do Norte e Eurásia (Clark et al., 2009) quanto na região da Antártica (Makou et al., 2010; Wainer et al., 2012);

- a variação relativa do nível médio do mar em aproximadamente $130 \mathrm{~m}$ abaixo do atual (Spratt e Lisiecki, 2016);

- a diminuição do $\mathrm{CO}_{2}$ atmosférico (Monnin et al., 2001);

- a diminuição nos teores de $\delta^{13} \mathrm{C}$ no Oceano Austral (Lund et al., 2015);

- a intensificação dos ventos de oeste (Wainer et al., 2012);

- o aumento na produtividade na Margem Continental Brasileira (Nagai et al., 2010; Toledo et al., 2008).

O UMG ocorreu em um período de máxima insolação de verão no Hemisfério Sul e, consequente, mínima insolação de verão no Hemisfério Norte, de acordo com os ciclos de insolação de Milankovitch (Berger e Loutre, 1991). Dessa maneira, a água do Atlântico Norte era mais de $4{ }^{\circ} \mathrm{C}$ mais fria do que hoje e relativamente menos salina em comparação à Água de Fundo Antártica (AFA), formando assim a Água Intermediária Glacial do Atlântico Norte (AIGAN) (Wainer et al., 2012). As principais alterações observadas na formação das massas d'água do Hemisfério Sul consistem no aumento do gelo marinho em torno da Antártica, gerando intensificação da AMOC devido ao aumento da formação da AFA (Wainer et al., 2012). Esses mesmos autores observaram também que houve aumento na formação da Água Intermediária Antártica (AIA) devido à intensificação dos ventos de oeste. 


\section{Evento Younger Dryas}

O evento Younger Dryas (YD) foi um breve período de clima frio e seco no Hemisfério Norte, ocorrido entre 12.900 a 11.700 anos AP (Broecker et al., 2010; Rasmussen et al., 2006). O nome é derivado de registros de pólen que indicaram o retorno da planta Dryas octopetala, tolerante ao frio, após um intervalo quente (Anderson, 1896; Hartz e Milthers, 1901) apud Carlson, 2013).

$O$ evento YD teve registros distintos em diversas partes do mundo. Por exemplo, a leste do Atlântico Norte, os registros mostram queda na temperatura da superfície do mar (TSM) de $1{ }^{\circ} \mathrm{C}$ a $3{ }^{\circ} \mathrm{C}$ (Bard et al., 2000; Cacho et al., 2001), enquanto no Hemisfério Sul, o mesmo fenômeno é caracterizado por um aquecimento (Shakun e Carlson, 2010). Testemunhos de gelo da Antártica registraram aumento no $\delta^{18} \mathrm{O}$ (Jouzel et al., 2007) e registros de espeleotemas e pólens na América do Sul e na Nova Zelândia confirmam essa condição de aquecimento (Moreno et al., 2009).

Globalmente, o evento YD foi caracterizado por anomalias climáticas cujas magnitudes aumentam conforme nos aproximamos dos polos. Essas anomalias apresentam sinais opostos entre os hemisférios norte (frios) e sul (quentes) e resultaram em resfriamento médio global de aproximadamente $0,6{ }^{\circ} \mathrm{C}$ (Shakun e Carlson, 2010).

A principal causa sugerida para a ocorrência do evento YD foi o recuo da camada de gelo da região Laurentidea (próxima dos Grandes Lagos, a oeste do Canadá), o qual aumentou a descarga de água doce para o Atlântico Norte, fazendo com que a AMOC fosse enfraquecida (Carlson 2013).

\section{Evento 8.2}

O evento climático mais proeminente do Holoceno, registrado em proxies de testemunhos de gelo da Groenlândia, ocorreu entre 8.275 e 8.025 anos AP (Ljung et al., 2008), porém suas causas continuam incertas (Alley et al., 1997; Barber et al., 1999). Este evento apresentou período frio, seco, com baixos valores de metano e aumento na intensidade do vento na região do Atlântico Norte, caracterizando condições climáticas semelhantes às de hoje (Alley et al., 1997; Kobashi et al., 2007). Apresentou também alteração na posição latitudinal para o sul da Zona de 
Convergência Intertropical (ZCIT) (Cheng et al., 2009; Ljung et al., 2008; Rohling e Pälike, 2005).

Os registros de temperatura derivados de testemunhos da região central da Groenlândia mostram uma anomalia de temperatura significativa nesse período (Rohling e Pälike 2005), o que frequentemente é atribuído a descarga de água glacial provinda do degelo da região de Laurentidea (Rohling e Pälike 2005; Ljung et al., 2008). A evidência dessa queda de temperatura foi relatada principalmente no Oceano Atlântico Norte, mas um número crescente de observações de anomalias nos registros de proxies climáticos ao redor do globo aponta para uma ocorrência mais generalizada desse evento (Cheng et al., 2009; Ljung et al., 2008; Rohling e Pälike, 2005).

A descarga de água glacial ("doce”) - originada dos lagos glaciários Agassiz e Ojibway (região de Laurentidea) - para o Mar de Labrador (através do Estreito de Hudson) reduz a salinidade da superfície de suas águas, desencadeando o enfraquecimento na AMOC (Barber et al., 1999). Isso causa redução da formação da Água Profunda do Atlântico Norte (APAN) e do transporte de calor inter-hemisférico (Rohling e Pälike 2005; Ljung et al., 2008). Alguns autores (Ljung et al., 2008; Cheng et al., 2009) sugerem relação antifase entre os hemisférios devido a essa redução de transporte de calor, gerando clima frio no Atlântico Norte e clima mais quente no Atlântico Sul (Pivel et al., 2013).

Tal fenômeno pode ser observado em registros sedimentares coletados na região central do Atlântico Sul, os quais mostraram maior precipitação durante o evento 8.2, provavelmente como consequência do aumento da temperatura da superfície do mar (Ljung et al., 2008). Outro exemplo dessa relação de antifase foi observado por Cheng et al. (2009) em registros de isótopos de oxigênio de estalagmites da China, de Omã e do leste do Brasil. Também se observou sistema de monção de verão mais fraco durante o evento 8.2 na região da Ásia - como notam também Rohling e Pälike (2005) -, enquanto na América do Sul pode-se verificar padrão idêntico, mas em antifase, apontando para sistema de monção de verão mais forte nessa região. 


\subsection{Paleoceanografia do Atlântico Sudoeste}

O Oceano Atlântico tem importante papel na transferência de calor interhemisférico através da Célula de Revolvimento Meridional do Atlântico (sigla em inglês $A M O C$ ). De maneira geral, o transporte de calor nos oceanos ocorre dos trópicos em direção aos polos. Entretanto, no Atlântico Sul, esse transporte ocorre do polo em direção ao equador, resultando em exportação de calor e sal para o Atlântico Norte (Silveira et al., 2004; Wainer et al., 2012, Huang et al., 2014).

Estudos revelam que mudanças nesse sistema de transporte de calor interhemisférico e, consequentemente, no sistema climático global estão fortemente correlacionadas às variações na intensidade da $A M O C$ ocorridas no último período glacial e na subsequente deglaciação (Bard et al, 2000). Quando a AMOC está enfraquecida observam-se os seguintes fenômenos:

(i) resfriamento das altas latitudes do Atlântico Norte (Lynch-Stieglitz, 2017);

(ii) aumento na temperatura da superfície do mar (TSM) do Atlântico Sudoeste (Chiessi et al., 2015);

(iii) aumento das concentrações de $\mathrm{CO}_{2}$ atmosférico $\left(\mathrm{CO}_{2} \mathrm{~atm}\right)$ (Lund et al., 2015);

(iv) intensificação dos ventos alísios de nordeste e deslocamento da ZCIT para sul (Zhang et al., 2015);

(v) intensificação dos ventos de oeste na região da Antártica (Anderson et al., 2009).

As mudanças ocasionadas pelo enfraquecimento da $\mathrm{AMOC}$, como o aumento dos ventos de oeste na região da Antártica, intensificam a formação da Água Intermediária Antártica (AIA) (Anderson et al., 2009), a qual é transportada para o Hemisfério Norte pela Corrente de Contorno Oeste Intermediária (CCI) (Silveira et al., 2015). Essa corrente representa a principal componente do membro superior da AMOC, que desempenha um importante papel no balanço energético interhemisférico. Porém, ainda são escassos os estudos que abordam as variações paleoceanográficas das águas intermediárias do Atlântico Sul (Makou et al., 2010; Wainer et al., 2012; Huang et al., 2014; Jonkers et al., 2015). 
Quando comparamos o volume de estudos paleoceanográficos e paleoclimáticos entre os Oceanos Atlântico Sul e Norte, observamos que o setor sul apresenta-se pouco explorado, principalmente na sua porção sudoeste (Villalba et al., 2009; Makou et al., 2010; Nagai et al., 2010); Pivel et al., 2013; Chiessi et al.,2014; Prado et al., 2013).

Desde a última década, alguns autores mostraram interesse em compreender melhor a paleoceanografia do Oceano Atlântico Sudoeste utilizando-se, para esse fim, proxies geoquímicos extraídos da matéria orgânica e de testas de foraminíferos preservados em registros sedimentares marinhos, além de modelagem numérica. $\mathrm{Na}$ página seguinte, listamos alguns estudos com foco na paleoceanografia do Atlântico Sudoeste (Tabela 3). 
Tabela 3 - Exemplos de trabalhos realizados desde a última década com foco de interesse na paleocenografia e paleoprodutividade da região do Atlântico Sudoeste.

\begin{tabular}{|c|c|c|}
\hline Referência & Foco de interesse & Métodos \\
\hline Mahiques et al., 2007 & Paleocenografia do Atlântico SW dos últimos 35 ka & Isótopo de C e geoquímica \\
\hline Toledo et al., 2008 & Paleocenografia do Atlântico SW dos últimos 30 ka & Análise microfaunística \\
\hline Mahiques et al., 2009 & Paleocenografia do Atlântico SW durante Holoceno & Susceptibilidade magnética e geoquímica \\
\hline Nagai et al., 2009 & Paleoprodutividade do Atlântico SW durante Holoceno & Análise microfaunística e geoquímica \\
\hline Nagai et al., 2010 & Paleocenografia do Atlântico SW dos últimos 27 ka & Análise microfaunística e geoquímica \\
\hline Wainer et al., 2012 & Mudanças da AIA desde o UMG & Modelagem numérica \\
\hline Pivel et al., 2013 & Paleoceanografia do Atlântico SW durante Holoceno & Isótopo de O e microfauna \\
\hline Ferreira et al., 2014 & Paleoprodutividade do Atlântico SW dos últimos 570 ka & Isótopos de C, O e microfauna \\
\hline Lund et al., 2015 & Paleocirculação do Atlântico SW durante última deglaciação & Isótopos de C e O \\
\hline Costa et al., 2016 & Variabilidade climática/produtividade durante MIS 5 & Análise microfaunistica e geoquímica \\
\hline Mahiques et al., 2017 & Paleocirculação do Atlântico SW durante Holoceno & Isótopo de $\mathrm{C}$ e geoquímica \\
\hline Campos et al., 2017 & Variabilidade de $\delta^{13} \mathrm{C}$ durante $\mathrm{H} 3$ e $\mathrm{H} 2$ & Isótopo de $\mathrm{C}$ em foraminiferos \\
\hline Salvaterra et al., 2017 & Variação do nível do mar na costa de Santos durante MIS3 & Análise geoquímica \\
\hline
\end{tabular}




\section{4 Área de estudo}

\subsection{Margem continental SE brasileira}

A área de estudo encontra-se na margem continental SE brasileira, na porção em forma de arco conhecida como Embaiamento de São Paulo, compreendida entre o Cabo de Santa Marta - CSM (CSM, $\left.28^{\circ} \mathrm{S}-49^{\circ} \mathrm{W}\right)$ e o Alto de Cabo Frio - ACF $\left(23^{\circ} \mathrm{S}-42^{\circ} \mathrm{W}\right.$ ) (Figura 1). Caracteriza-se por uma área aproximada de $78 \mathrm{mil} \mathrm{km}^{2}$, largura que varia entre $59 \mathrm{~km}$ e $122 \mathrm{~km}$, e declividade entre $1^{\circ}$ e $1^{\circ} 45^{\prime}$ (Zembruscki, 1979). A plataforma continental apresenta aproximadamente $70 \mathrm{~km}$ de extensão ao norte $\left(23^{\circ} \mathrm{S}\right)$ e $230 \mathrm{~km}$ ao sul $\left(25^{\circ} \mathrm{S}\right)$, com declive entre 1:600 e 1:1300 (Zembruscki, 1979). A quebra da plataforma localiza-se, em média, a uma profundidade de aproximadamente $140 \mathrm{~m}$ (Mahiques et al., 2002).

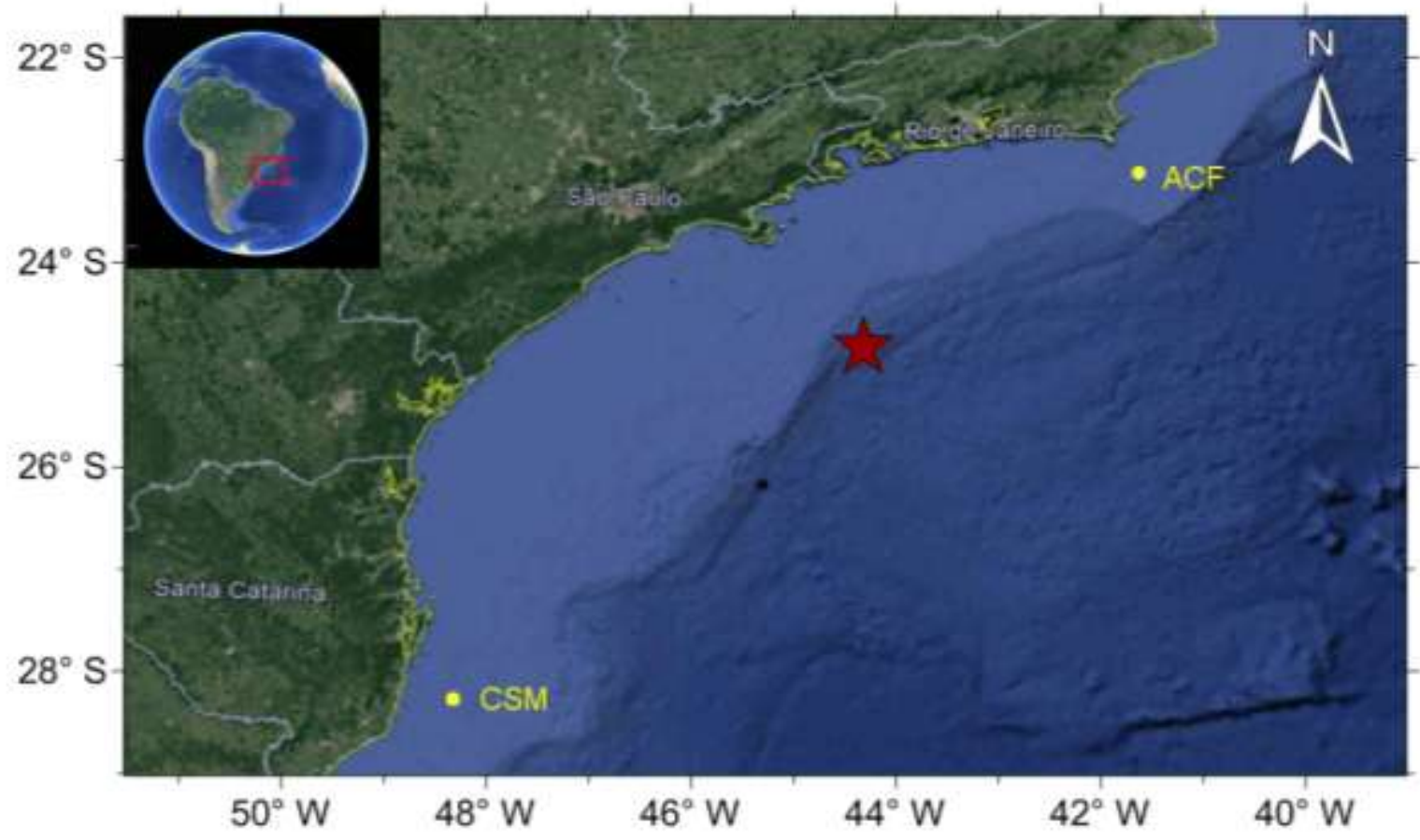

Figura 1 - Mapa da área de estudo com a localização do ponto de coleta do registro sedimentar NAP63-1 (estrela vermelha), Alto de Cabo Frio (ACF) e Cabo de Santa Marta (CSM), pontos em amarelo, ao largo da margem continental sudeste brasileira (adaptado de Google Earth, 2018).

Os processos sedimentares da plataforma SE brasileira são fortemente dominados pela dinâmica oceânica e pela circulação na plataforma, bem como pela 
contribuição de sedimentos fluviais (Mahiques et al., 2004). No geral, a plataforma continental apresenta sedimentos siliclásticos, representados por areia muito fina e silte. Já os sedimentos mais grossos e carbonáticos, que representam menos de $5 \%$ dos sedimentos, estão relacionados a sedimentos relíquias, depositados em condições de nível do mar mais baixo (Mahiques et al., 2004, 2008).

O talude continental é caracterizado por um perfil predominantemente convexo, com extensão de cerca de $2.200 \mathrm{~km}$ e superfície total aproximada de $235.210 \mathrm{~km}^{2}$ (Zembruscki, 1979). Segundo Zembruscki (1979), podemos distinguir duas seções de talude - a superior e a inferior -, tendo a superior um domínio entre $200 \mathrm{~m}$ e $500 \mathrm{~m}$ de profundidade, largura média de $13 \mathrm{~km}$ e declive entre $2^{\circ}$ e $4^{\circ}$, enquanto a inferior apresenta um domínio entre $500 \mathrm{~m}$ e $2.900 \mathrm{~m}$ de profundidade, largura média de $125 \mathrm{~km}$ e declive entre $0^{\circ} 30^{\prime}$ e 150'. A sedimentação que compõe o talude continental desse setor da margem continental brasileira apresenta predomínio de sedimentos lamosos com possibilidade de ocorrência de lamas arenosas em regiões próximas à quebra da plataforma (Figueiredo e Tessler, 1999).

Ao largo da Bacia de Santos, entre o Alto de Cabo Frio $\left(23^{\circ} \mathrm{S}-42^{\circ} \mathrm{W}\right)$ e a Zona de Fratura de Florianópolis $\left(29^{\circ} \mathrm{S}-48^{\circ} \mathrm{W}\right.$ ) (Chang et al., 2008), o talude continental apresenta trechos irregulares (côncavos e convexos), com a presença de sulcos profundos, muitas vezes associados a cânions e vales (Figueiredo e Tessler, 1999). Essas irregularidades resultam ou de possíveis frentes de camadas progradantes modeladas pela abrasão de ondas e correntes (em particular, durante os períodos finais das regressões e os períodos iniciais das transgressões marinhas) ou de escorregamentos provocados por instabilidade do talude (Zembruscki, 1979).

\subsection{Condições oceanográficas atuais}

A circulação de macro escala do Atlântico Sul nos primeiros $200 \mathrm{~m}$ de profundidade pertence a dois sistemas: o Sistema Equatorial do Atlântico e o Giro Anticiclônico Subtropical do Atlântico Sul (Silveira et al., 2000). O Giro Subtropical limita-se pelas seguintes correntes: ao norte, pela Corrente Sul Equatorial (CSE); a oeste, pela Corrente do Brasil (CB); ao sul, pela Corrente do Atlântico Sul; e; a leste; pela Corrente de Benguela (Silveira et al., 2009; Stramma e England, 1999). A CB 
flui para sul-sudoeste, passando de uma extensão vertical de $200 \mathrm{~m}$ na costa baiana a mais de $600 \mathrm{~m}$ ao largo de Santa Catarina (Silveira et al., 2009).

Nos primeiros três quilômetros de coluna d'água da costa brasileira, há o empilhamento das seguintes massas d'água (Figura 2):

- Água Tropical (AT: domínio 0-150 m, temperatura $>20^{\circ} \mathrm{C}$ e salinidade $>36,2)$;

- Água Central do Atlântico Sul (ACAS: domínio 150-500 m, temperatura $<20^{\circ} \mathrm{C}$ e salinidade $<36$ );

- Água Intermediária Antártica (AIA: domínio 500-1200 m, temperatura $<6^{\circ} \mathrm{C}$ e salinidade $\left.<34,6\right)$;

- Água Profunda do Atlântico Norte (APAN: domínio 1200-2500 m, temperatura $<4^{\circ} \mathrm{C}$ e salinidade $<35$ ) (Silveira et al., 2015).

Segundo esses autores, as massas d'água ao longo da costa sudeste brasileira são transportadas pelas seguintes correntes (Figura 2):

- AT - para norte-nordeste pela Corrente Norte do Brasil (CNB) e para sul-sudoeste pela Corrente do Brasil (CB);

- ACAS - para norte-nordeste pela Subcorrente Norte do Brasil (SNB) e para sul-sudoeste pela $\mathrm{CB}$;

- AIA - para norte-nordeste pela Corrente de Contorno Oeste Intermediária $(\mathrm{CCl})$;

- APAN - para sul pela Corrente de Contorno Oeste Profunda (CCP). 


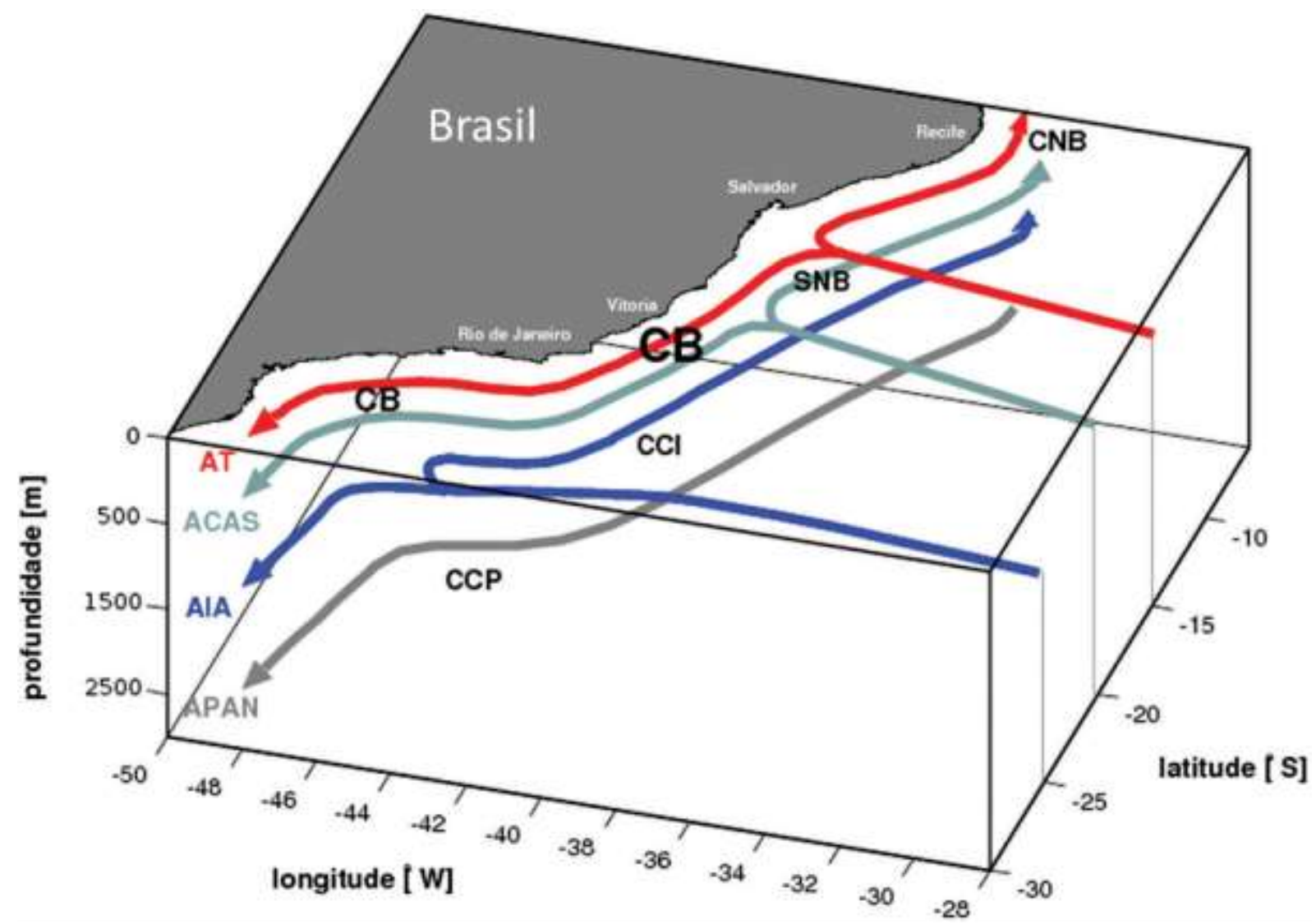

\begin{tabular}{|l|l|}
\hline Massa d'água & Corrente \\
AT & CNB e CB \\
ACAS & SNB \\
AIA & $\mathrm{CCI}$ \\
APAN & $\mathrm{CCP}$ \\
\hline
\end{tabular}

Figura 2 - Representação esquemática das massas d'água e das correntes de contorno oeste ao largo da margem continental brasileira (adaptado de Soutelino et al., 2013).

A AlA é formada a partir da ressurgência da Água Circumpolar Profunda (ACP), trazida para a superfície pelos ventos de oeste, devido ao transporte de Ekman para norte das águas superficiais Antárticas ao sul da Frente Polar Antártica (FPA) (Anderson et al., 2009 - Figura 3). Parte dessas águas superficiais mistura-se com a água superficial subtropical formando a Água Modal Subantártica (AMSA), a qual alimenta a termoclina dos oceanos do Hemisfério Sul, compondo as águas centrais, como a ACAS. A forma mais densa da água superficial sofre submersão ao 
longo da Zona da Frente Polar (ZFP) dando origem à AIA, uma massa d'água fria, de baixa salinidade (Anderson et al., 2009; Wainer et al., 2012) e rica em oxigênio (Silveira et al., 2015).

Após sua formação, a AIA sofre advecção pela Corrente Circumpolar Antártica (CCA) na Passagem de Drake e, então, é direcionada para o giro subtropical do Atlântico Sul pela Corrente das Malvinas (CM) (Tomczak e Godfrey, 2003). O giro subtropical se aproxima da margem continental brasileira em torno de $28^{\circ} \mathrm{S}$ (Schmid et al., 2000). Nessa latitude, as águas no nível intermediário (entre $500 \mathrm{~m}$ e $1200 \mathrm{~m}$ de profundidade - influencia da AIA) bifurcam na região do talude, o que leva a um fenômeno denominado Bifurcação de Santos (Boebel et al., 1999) (Figura 2). Esse fenômeno oceanográfico gera uma corrente de contorno oeste para norte, conhecida como Corrente de Contorno Oeste Intermediário (CCI) (Biló et al., 2014; Boebel et al., 1999; Silveira et al., 2004).

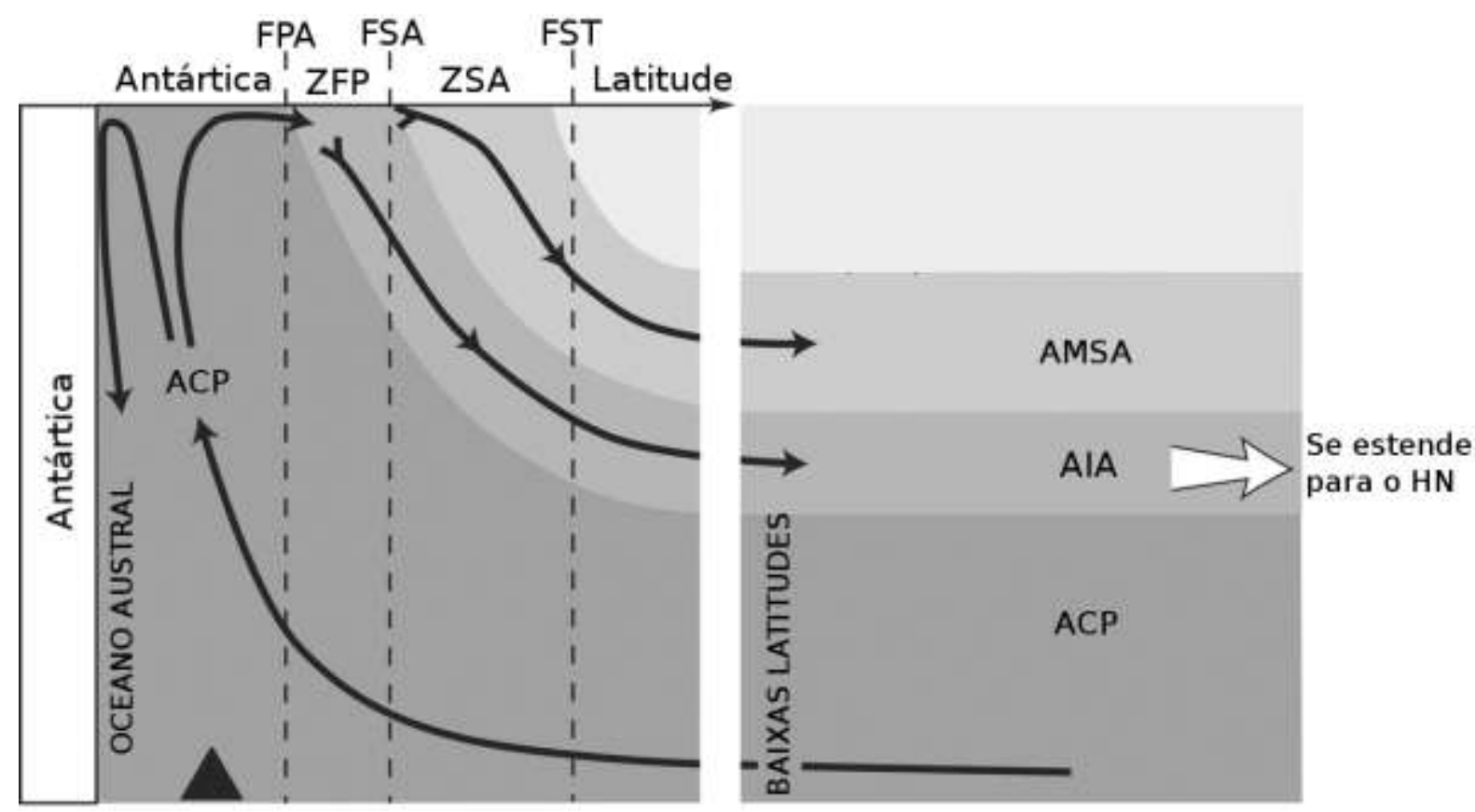

Figura 3 - Representação esquemática da ventilação e submersão de massas d'águas no Oceano Austral (Adaptado de Anderson et al., 2009), sendo ACP (Água Circumpolar Profunda), AMSA (Água Modal Subantártica), AIA (Água Intermediária Antártica), FPA (Frente Polar Antártica), ZFP (Zona da Frente Polar), FSA (Frente Subantártica), ZSA (Zona Subantártica), FST (Frente Subtropical) e HN (Hemisfério Norte). 
Segundo Middag et al. (2015), a AIA apresenta atualmente, na região do talude do SE brasileiro, concentrações de oxigênio dissolvido entre 200 e $220 \mu \mathrm{mol}$ $\mathrm{kg}^{-1}$ (ou seja, entre 4,48 $\mathrm{mL} \mathrm{L}^{-1}$ e 4,92 $\mathrm{mL} \mathrm{L}^{-1}$ ) (Figura 4a). Desse modo, ela se caracteriza como óxica, segundo a definição empregada por Tribovillard et al. (2006), que classifica dessa maneira qualquer ambiente com concentração de oxigênio acima de $2 \mathrm{~mL} \mathrm{~L}^{-1}$.

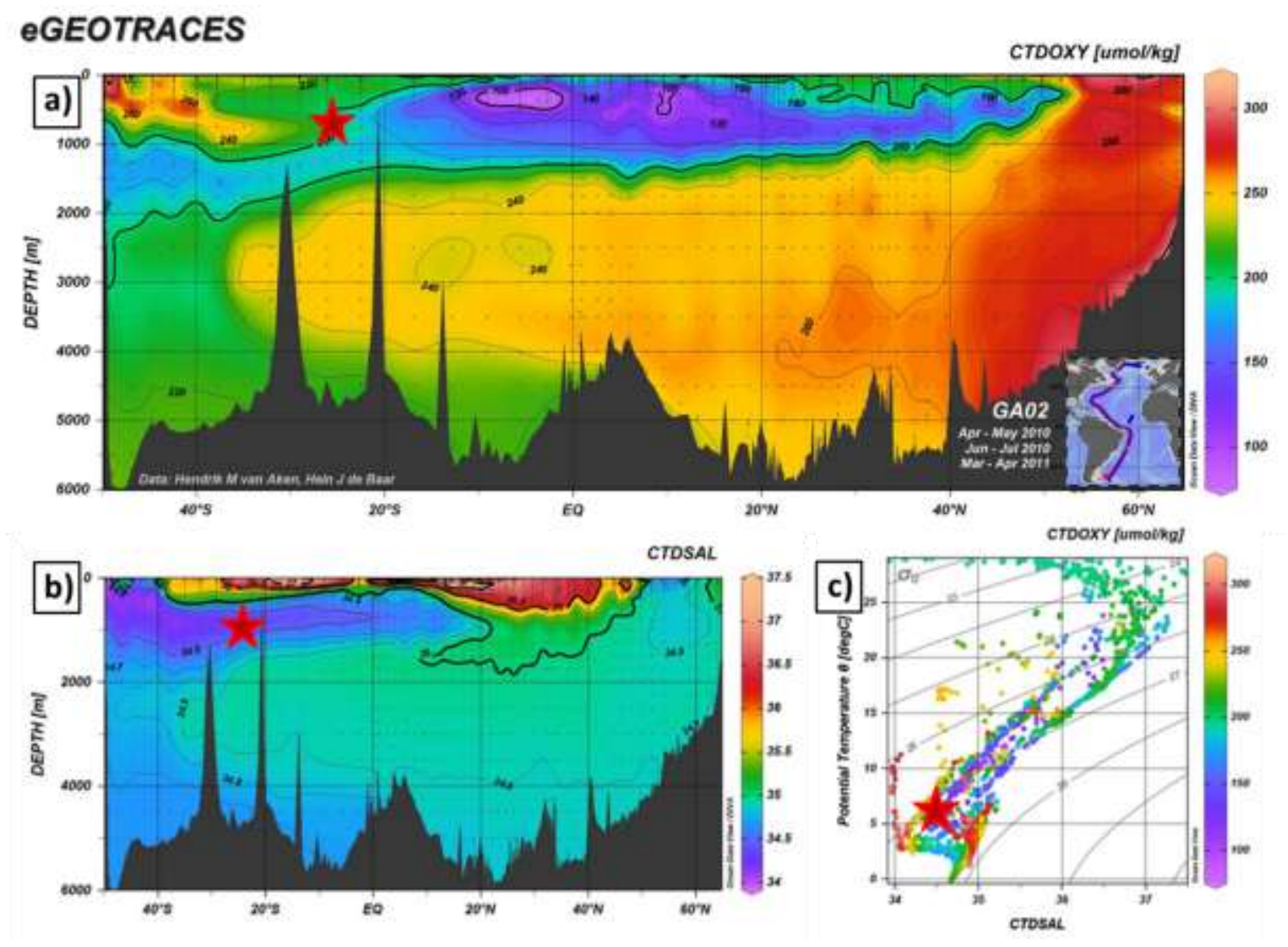

Figura 4 - (a) Perfil vertical da distribuição do oxigênio dissolvido ( $\mu \mathrm{mol} \mathrm{kg}-1)$ ao longo da borda oeste do Oceano Atlântico; (b) Perfil vertical da distribuição da salinidade ao longo da borda oeste do Oceano Atlântico e (c) Diagrama temperatura/salinidade (T-S) ao longo da borda oeste do Oceano Atlântico. A estrela vermelha representa a região de coleta do registro sedimentar NAP63 (a e b); no diagrama T-S, a estrela vermelha representa a posição da AIA referente às suas propriedades hidrográficas (Adaptado de EGEOTRACES, 2017). 


\subsection{Condições climáticas atuais}

O clima é influenciado pela interação entre a circulação oceânica e a atmosférica (Green e Marshall, 2017) em diferentes escalas de tempo (Ruddiman, 2008). Por exemplo, as anomalias positivas na precipitação sobre o sudeste da América do Sul (SEAS), estão, geralmente, relacionadas às anomalias negativas na temperatura da superfície do mar (TSM) das altas latitudes do Atlântico Norte (Garreaud et al., 2009; Vera et al., 2006).

Os principais elementos atmosféricos que atuam no clima da América do Sul são representados pelo Sistema de Monção da América do Sul (SMAS), bem como seus principais componentes - a Zona de Convergência Intertropical (ZCIT), a Zona de Convergência do Atlântico Sul (ZCAS) e o Jato de Baixos Níveis (JBN) sulamericano (Garreaud et al., 2009) (Figura 5). A ZCIT é uma banda de nebulosidade que se desenvolve sobre os oceanos e se localiza próximo à linha do equador, formada pelo desenvolvimento de uma zona de baixa pressão gerada pela ascensão de massas de ar quente e úmido (Garreaud et al., 2009; Green e Marshall, 2017; Vera et al., 2006). No Atlântico Equatorial, a ZCIT migra sazonalmente, influenciando no regime de precipitação no SEAS. Durante o verão austral, o aumento da insolação intensifica o SMAS, fortalecendo os ventos alísios de NE e deslocando a ZCIT para o sul, o que aumenta a nebulosidade sobre a Bacia Amazônica (Garreaud et al., 2009; Green e Marshall, 2017; Vera et al., 2006). Esse aumento de umidade é transportado para a região SEAS pelo Jato de Baixos Níveis, caracterizado por um fluxo noroeste-sudeste (Figura 5) (Garreaud et al., 2009; Vera et al., 2006). Entretanto, no inverno austral, o SMAS encontra-se enfraquecido, deslocando a ZCIT para o norte do equador o que leva à diminuição do regime de chuvas na região SEAS (Garreaud et al., 2009). 


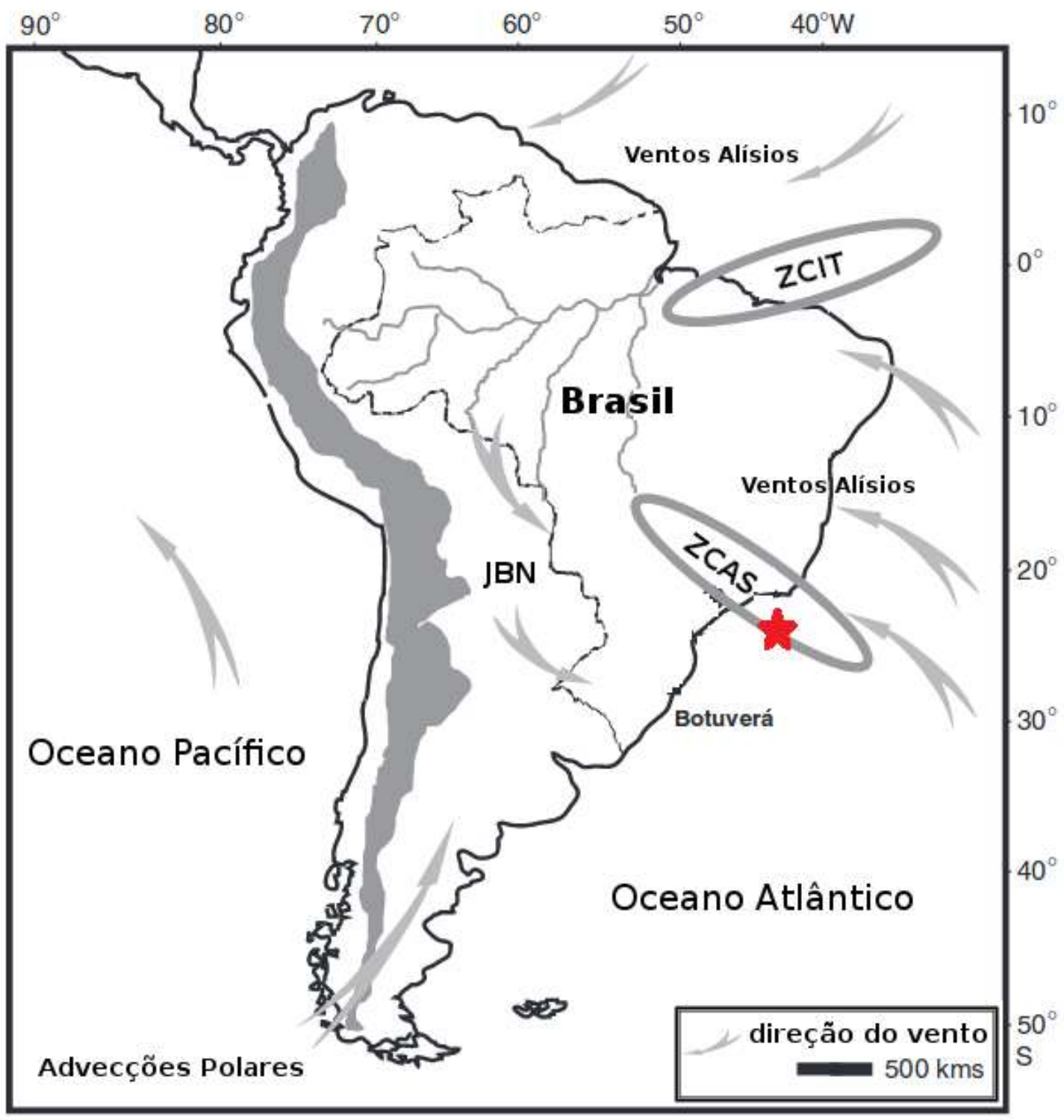

Figura 5 - Esquema climático de verão austral com os principais componentes atmosféricos (adaptado de Wang et al., 2006), sendo: ZCIT (Zona de Convergência Intertropical), ZCAS (Zona de Convergência do Atlântico Sul) e JBN (Jatos de Baixos Níveis). A estrela vermelha indica a área de estudo do presente trabalho. 


\section{Materiais e Métodos}

Foi coletado um registro sedimentar (testemunho NAP63-1) a bordo do N/Oc. Alpha Crucis, em 2013, com auxílio de um piston corer nas seguintes coordenadas: $24,838^{\circ} \mathrm{S}, 044,319^{\circ} \mathrm{W}$; a uma profundidade de $842 \mathrm{~m}$, com recuperação de $224 \mathrm{~cm}$ (Figura 1). O testemunho foi conservado sob refrigeração e, posteriormente, amostrado continuamente a cada dois centímetros, totalizando 112 amostras, que foram congeladas e liofilizadas.

\subsection{Cronologia}

Uma das técnicas mais importantes para a datação em estudos paleontológicos é o método de radiocarbono, ou seja, datação por carbono $14\left({ }^{14} \mathrm{C}\right)$. Essa técnica vem sendo muito utilizada em estudos paleoceanográficos e paleoclimáticos do Quaternário Superior, pois a idade de uma amostra fóssil pode ser determinada pela medição do ${ }^{14} \mathrm{C}$ contido nela após sua morte, dado que, a partir desse momento, inicia-se a desintegração radioativa desse isótopo, resultando em sua redução gradual. Além disso, a taxa de produção de ${ }^{14} \mathrm{C}$ é tida como constante e o estoque desse isótopo na atmosfera é muito próximo àquele encontrado nos organismos vivos (Buso, 2010).

Esse isótopo radioativo $\left({ }^{14} \mathrm{C}\right.$ composto por 8 nêutrons e 6 prótons) forma-se naturalmente em altas camadas da atmosfera terrestre pela colisão de um nêutron, originado pelo bombardeamento de partículas subatômicas (raios cósmicos), com um átomo de ${ }^{14} \mathrm{~N}$ (composto por 7 nêutrons e 7 prótons). Essa colisão faz com que o ${ }^{14} \mathrm{~N}$ perca um próton e ganhe um nêutron, convertendo-se em ${ }^{14} \mathrm{C}$ conforme a equação abaixo (Buso, 2010; Odo, 2000; Scheel-Ybert, 1999).

$$
n+{ }_{7}^{14} N \rightarrow{ }_{6}^{14} \mathrm{C}+p
$$

$\mathrm{O}{ }^{14} \mathrm{C}$, por ser um radionuclídeo instável, sofre decaimento radioativo, com meia-vida aproximada de 5.730 anos, emitindo um elétron (partícula $\beta^{-}$) e originando novamente um átomo de ${ }^{14} \mathrm{~N}$. Como a atividade do ${ }^{14} \mathrm{C}$ é muito fraca, com um tempo de meia-vida longo, estipula-se que o método só é confiável para tempos equivalentes a, no máximo, 10 meias-vidas. Ou seja, aproximadamente 57 mil anos (Buso, 2010). 
Os dados da cronologia do testemunho foram obtidos no âmbito do projeto de pesquisa "Sedimentação da plataforma interna da margem continental sudeste brasileira: base para modelos paleoclimáticos, paleoceanográficos e de geração de gás, Subprojeto 5 do Geodinâmica de Bacias Sedimentares e implicações para o potencial exploratório (petróleo, gás natural e água subterrânea) - GEO-SEDex" sob coordenação da Profa. Dra. Silvia H. de M. e Souza (IOUSP) e subcoordenação do Prof. Dr. Rubens C. L. Figueira (IOUSP).

A cronologia do testemunho NAP63-1 foi obtida por meio da combinação das datações radiométricas por AMS ${ }^{14} \mathrm{C}$ e os resultados de $\delta^{18} \mathrm{O}$ de foraminíferos bentônicos (Uvigerina $s p$. na fração $>125 \mu \mathrm{m}$ ) alinhados à curva de referência para águas Intermediárias do Atlântico Sul (Lisiecki e Stern, 2016). Foram selecionadas 7 amostras dos primeiros $102 \mathrm{~cm}$ do registro para datação por $A M S{ }^{14} \mathrm{C}$ e cada amostra foi composta por cerca de $10 \mathrm{mg}$ de testas de G. ruber (branco) + G. sacculifer, coletados da fração de tamanho $>150 \mu \mathrm{m}$ após peneiramento e secagem em estufa. As idades foram obtidas no laboratório BETA Analytic (Miami, EUA) e calibradas com auxílio da curva Marine13 (Reimer et al., 2013), aplicando um efeito reservatório e erro de $(\Delta R) 7 \pm 200$ anos de acordo com Lund et al. (2015) com auxílio do software Calib 7.10 .

Com os resultados, foi gerado um modelo de idades, um gráfico entre as idades calibradas e a profundidade das amostras, e calculada uma reta de regressão linear, onde o coeficiente de regressão da reta corresponde à taxa de sedimentação.

\subsection{Análises geoquímicas}

\subsubsection{Componentes inorgânicos do sedimento}

Para a determinação dos elementos inorgânicos no sedimento, as amostras foram submetidas ao método de digestão completa, através do procedimento EPA 3052 (USEPA, 1996), ilustrado pelo fluxograma da Figura 6. Após esse procedimento, os elementos $\mathrm{Al}, \mathrm{Ca}, \mathrm{Fe}, \mathrm{Ti}, \mathrm{V}, \mathrm{Ni}, \mathrm{Sc}, \mathrm{Co}, \mathrm{Cr}$ e $\mathrm{Mn}$ foram quantificados por espectrometria de emissão óptica com plasma indutivamente acoplado (ICP-OES) da marca Varian, modelo 710-ES, segundo o método SW-846 USEPA 6010-c (USEPA, 2007). 
O procedimento consiste em pesar aproximadamente $0,1 \mathrm{~g}$ de sedimento seco, condicioná-lo em unidade digestora de teflon com $5 \mathrm{~mL}$ de $\mathrm{HNO}_{3}$ concentrado e introduzido em um sistema de fechado de micro-ondas (procedimento que se repete após o acréscimo de cada reagente). A fim de se eliminarem os silicatos, adiciona-se de 2 a $3 \mathrm{~mL}$ de HF concentrado. Caso não seja digerido todo o silicato, adiciona-se $1 \mathrm{~mL}$ de HF. Para a eliminação de matéria orgânica, adiciona-se 1,5 mL de $\mathrm{H}_{2} \mathrm{O}_{2}$ concentrado. Ao fim dessa etapa, transfere-se a solução para béqueres de teflon a fim de eliminar o $\mathrm{HF}$ por evaporação. Utiliza-se $\mathrm{HNO}_{3} 5 \%$ para lavar as unidades digestoras e para diluir as amostras após o volume ser reduzido a uma gota. Repete-se este procedimento de evaporação duas vezes e avoluma-se a amostra em um tubo Falcon de $15 \mathrm{~mL}$ para posteriormente ser analisada no ICPOES.

Para garantir o controle da qualidade analítica, a cada dez amostras analisadas, um padrão da curva de calibração foi medido novamente para verificar a variação do equipamento. A fim de verificar se houve efeito memória no ICP-OES, um branco de reagentes foi analisado após a leitura das amostras. Dois materiais de referência certificados $(\mathrm{MRC})$ de solos contaminados SS-2 e MESS-3 foram submetidos ao mesmo método de digestão das amostras (EPA 3052) para controle de qualidade analítica, verificando a eficiência de extração. A concentração dos elementos e as porcentagens de recuperação de cada elemento para os MRC SS-2 e MESS-3 estão representados na Tabela 4. Foram realizados brancos de reagentes também sujeitos à mesma digestão, a fim de se eliminarem as possibilidades de contaminações através dos mesmos.

Após a determinação dos elementos inorgânicos relacionamos as razões $\mathrm{V} / \mathrm{Sc}, \mathrm{V} / \mathrm{Cr}, \mathrm{V} / \mathrm{Al}, \mathrm{Mn} / \mathrm{Al}$ e $\mathrm{Ni} / \mathrm{Co}$ aos proxies de condições redox, e as razões $\mathrm{Fe} / \mathrm{Ca}$ e $\mathrm{Ti} / \mathrm{Ca}$ aos proxies de aporte de sedimento terrígenos. Nas razões $\mathrm{V} / \mathrm{Al}$ e $\mathrm{Mn} / \mathrm{Al} \mathrm{o}$ elemento Al foi multiplicado por $10^{-4}$ a fim de simplificar e confrontar os nossos resultados com outros trabalhos que utilizam estes proxies. Além disso as razões $\mathrm{Ti} / \mathrm{Ca}$ e $\mathrm{Fe} / \mathrm{Ca}$ foram expressos em função do logaritmo natural (In) a fim de tirar o efeito de escala entres as razões (Aitchison e Egozcue, 2005) e facilitar as interpretações dos nossos resultados. 
Tabela 4 - Concentração dos elementos com as respectivas taxas de recuperação dos materiais de referência certificados SS-2 e MESS-3.

\begin{tabular}{ccccc}
\hline Elemento & $\begin{array}{c}\text { Concentração } \\
\text { (ppm) SS-2 }\end{array}$ & $\begin{array}{c}\text { Concentração } \\
(\mathbf{p p m}) \text { MSS-3 }\end{array}$ & $\begin{array}{c}\text { Taxa de } \\
\text { Recuperação (\%) } \\
\text { SS-2 }\end{array}$ & $\begin{array}{c}\text { Taxa de } \\
\text { Recuperação (\%) } \\
\text { MESS-3 }\end{array}$ \\
\hline $\mathrm{Ca}$ & 118,73 & $1,47^{*}$ & 81 & - \\
$\mathrm{Ti}$ & 2893 & $0,44^{*}$ & 99 & 98 \\
$\mathrm{~V}$ & 59 & 243 & 94 & 97 \\
$\mathrm{Cr}$ & 58 & 105 & 80 & 86 \\
$\mathrm{Mn}$ & 577 & 324 & 92 & 87 \\
$\mathrm{Fe}$ & 29,07 & $4,34^{*}$ & 81 & - \\
$\mathrm{Co}$ & 14 & 14,4 & 81 & 95 \\
$\mathrm{Ni}$ & 59 & 46,9 & 88 & 87 \\
$\mathrm{Al}$ & 44,85 & $8.59^{*}$ & 97 & 77 \\
\hline
\end{tabular}

* em g/100g 


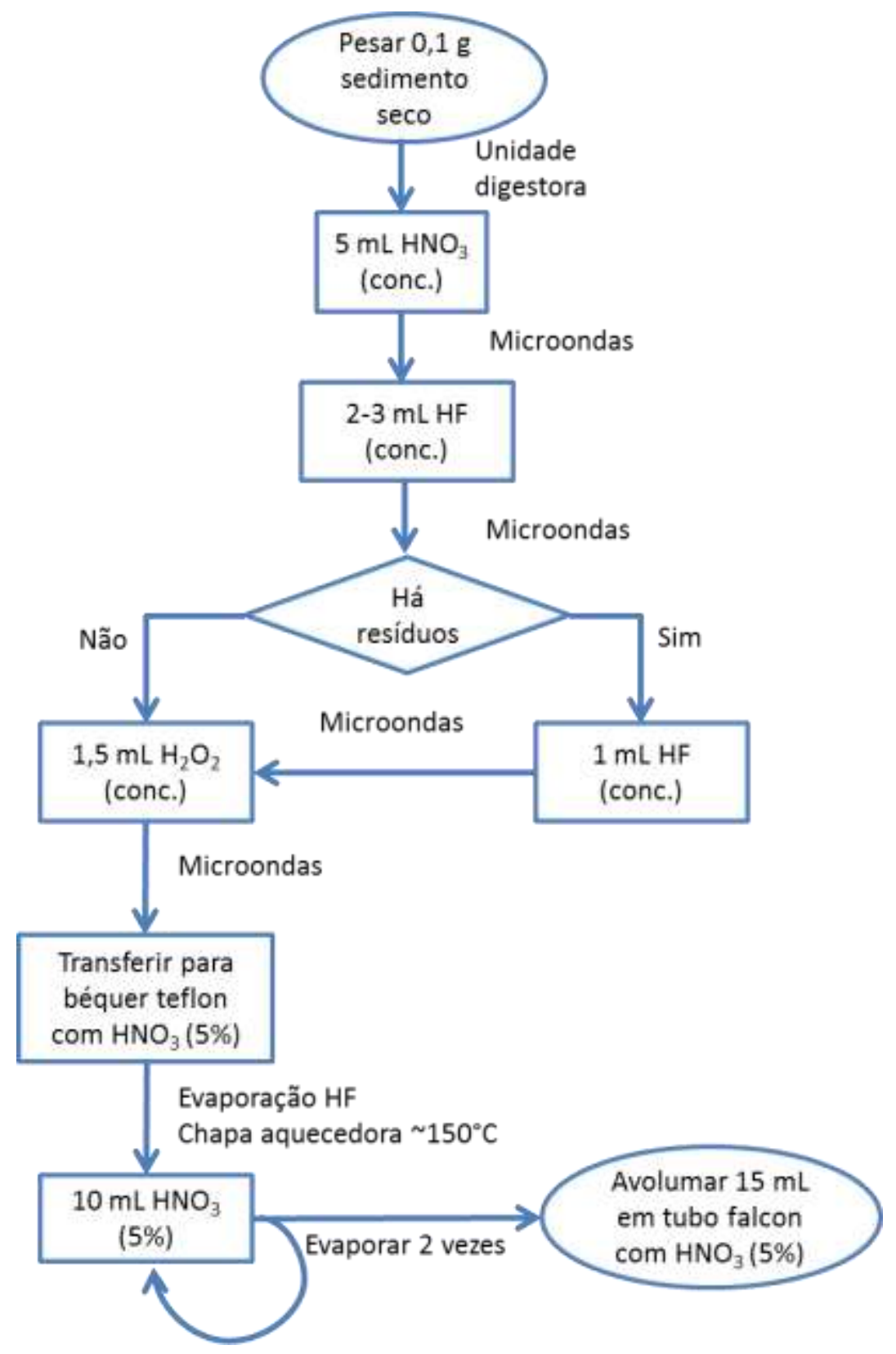

Figura 6 - Fluxograma do procedimento EPA 3052 (segundo USEPA, 1996). 


\subsubsection{Carbono orgânico total, nitrogênio total, conteúdo de carbonato de cálcio e isótopo estável de carbono em sedimento}

A porcentagem de carbono orgânico total (COT) e a razão isotópica $\delta^{13} \mathrm{C}$ foram determinadas em alíquota de sedimento submetido ao ataque de $\mathrm{HCl}$ (eliminação do $\mathrm{CaCO}_{3}$ ). Aproximadamente $10 \mathrm{mg}$ da amostra foram acondicionadas em cápsulas de estanho e submetidas ao analisador elementar Costech Instruments Elemental Combustion System acoplado ao detector de espectrometria de massas com razão isotópica Thermo Scientific Delta V Advantage Isotope Ratio MS (EAIRMS). O teor de nitrogênio total ( $N_{\text {tot }}$ ) foi submetido ao mesmo procedimento, porém sem ataque ácido.

O conteúdo de carbonato de cálcio $\left(\mathrm{CaCO}_{3}\right)$ foi determinado pesando-se aproximadamente $1 \mathrm{~g}$ de sedimento seco, o qual foi digerido com $2 \mathrm{~mL}$ de $\mathrm{HCl} 10 \%$, permanecendo nessa solução por 24 horas. Foram adicionadas algumas gotas de $\mathrm{HCl}$ concentrado a fim de certificar a total eliminação do $\mathrm{CaCO}_{3}$, verificada pela ausência de bolhas. Então, avolumou-se até $9 \mathrm{~mL}$ com água Milli-Q e, em seguida, as amostras foram centrifugadas a $2.100 \mathrm{rpm}$ por 11 minutos. O líquido sobrenadante foi descartado e a lavagem foi repetida por 5 vezes ou mais, até a total eliminação do ácido, com a verificação do sobrenadante com papel indicador de $\mathrm{pH}$. As amostras foram secas em estufa a $60{ }^{\circ} \mathrm{C}$ e o teor de $\mathrm{CaCO}_{3}$ foi determinado pela diferença entre as massas antes e após o ataque com ácido.

Os valores de $\delta^{13} \mathrm{C}$ foram expressos em notação "delta per mil" ( $\left.\delta \%\right)$, na qual a razão isotópica da amostra é comparada com a razão isotópica de um padrão internacional VPDB (Viena Peedee Belemnite), conforme a equação descrita abaixo (Bianchi e Canuel, 2011):

$\delta X \%_{(\text {amostra })}=\left(\frac{R_{\text {amostra }}-R_{\text {padrão }}}{R_{\text {padrão }}}\right) \times 1000$

$\delta X \%$ (amostra) $=$ enriquecimento isotópico da amostra relativo ao padrão;

$\mathrm{R}_{\text {amostra }}=$ razão isotópica da amostra $\left({ }^{13} \mathrm{C} /{ }^{12} \mathrm{C}\right)$;

$\mathrm{R}_{\text {padrão }}=$ razão isotópica do padrão $\left({ }^{13} \mathrm{C} /{ }^{12} \mathrm{C}\right)$.

A definição $\delta$ envolve uma multiplicação final por 1000 que acaba por amplificar diferenças muito pequenas entre os valores de isótopos medidos na amostra e no padrão, facilitando a comparação (Fry, 2006). 
A calibração para a análise isotópica do carbono orgânico foi feita por meio dos padrões certificados USGS-40, IAEA-600 e um padrão secundário de sedimento marinho de Ubatuba (SE Brasil). 


\section{Resultados}

\subsection{Cronologia}

A combinação entre as datações obtidas por $A M S{ }^{14} \mathrm{C}$ e os resultados de $\delta^{18} \mathrm{O}$ de foraminíferos bentônicos alinhados à curva de referência para águas Intermediárias do Atlântico Sul (Lisiecki e Stern, 2016) revelam que o registro sedimentar NAP63-1 cobre o intervalo entre $40 \mathrm{ka}$ cal. AP até aproximadamente 2.5 ka (Tabela 5). A partir da reta de regressão linear obtida pelas idades médias cal. anos AP e as profundidades das amostras foi possível estimar a taxa de sedimentação para o testemunho NAP63-1 ( 3,1 cm ka $\left.{ }^{-1}\right)$ (Figura 7).

Tabela 5 - Resultados das idades médias obtidas por AMS ${ }^{14} \mathrm{C}$ e calibradas pelo programa Calib 7.10. Utilizou-se $2 \sigma$ (sigma) por apresentar $95,4 \%$ do intervalo dos resultados das idades calibradas.

\begin{tabular}{crcc}
\hline Prof. (cm) & Idade ${ }^{14} \mathbf{C}$ (anos AP) & $\begin{array}{c}\text { Variação Idade Calibrada por 2 } \boldsymbol{\sigma} \\
\text { (anos AP) }\end{array}$ & $\begin{array}{c}\text { Idade Média cal. } \\
\text { (anos AP) }\end{array}$ \\
\hline 2 & $2.750+/-30$ & $2.342-2.637$ & 2.489 \\
14 & $7.710+/-40$ & $8.050-8.292$ & 8.171 \\
46 & $19.430+/-110$ & $22.558-23.268$ & 22.913 \\
52 & $24.710+/-100$ & $28.042-28.648$ & 28.345 \\
74 & $33.500+/-400$ & $36.283-38.382$ & 37.332 \\
100 & $40.130+/-440$ & $42.717-44.243$ & 43.480 \\
\hline
\end{tabular}




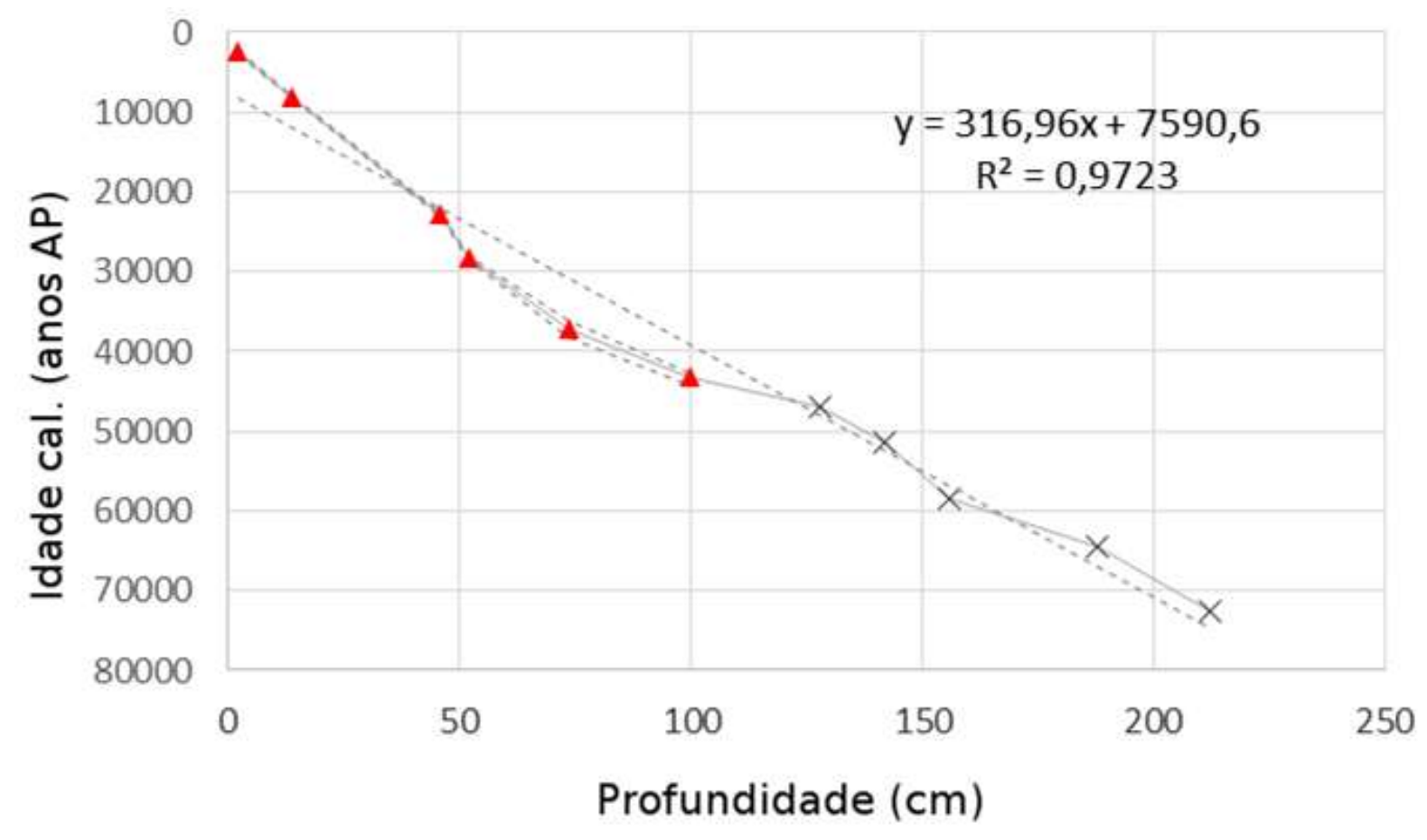

- Amostras datadas por ${ }^{14} \mathrm{C}$

$\times$ Amostras $\delta^{18} \mathrm{O}$ de foraminiferos bentônicos

Figura 7 - Modelo de idade cal. (anos AP) em função da profundidade $(\mathrm{cm})$ no testemunho NAP63-1 (Figura cedida pela Profa. Dra. Renata Hanae Nagai).

\subsection{Análises geoquímicas}

\subsubsection{Componentes inorgânicos do sedimento}

A razão elementar $\mathrm{V} / \mathrm{Sc}$ alcançou desvio padrão de 0,14 , variando entre 4,61 e 5,33. De 40 a $\sim 18 \mathrm{ka}$, os valores de V/Sc variaram em torno da média $(5,02)$. A partir daí, atingiu os maiores valores entre $\sim 11$ a $8 \mathrm{ka}$, o que foi seguido por uma queda até $2,5 \mathrm{ka}$ (Figura 8a).

A razão $\mathrm{V} / \mathrm{Cr}$ exibiu desvio padrão de 0,09 , variando entre 1,00 e 1,49. Os valores de $\mathrm{V} / \mathrm{Cr}$ diminuíram de 40 a $33 \mathrm{ka}$ e variaram em torno da média $(1,32)$ de 33 a 23 ka. Após esse período, a razão apresentou valores mais altos, obtendo, entretanto, o menor resultado em torno de $8 \mathrm{ka}$ (Figura 8b).

A razão elementar $\mathrm{V} / \mathrm{Al} \times 10^{-4}$ apresentou desvio padrão de 0,86 , variando entre 9,68 e 14,79. De 40 a $21 \mathrm{ka}$, os valores de V/Al x10-4 oscilaram em torno da 
média $(11,61)$. Após esse período, os valores tenderam a aumentar até $\sim 12 \mathrm{ka}$, quando se observa o maior resultado. A partir de então, os valores voltaram a diminuir até 5,6 ka, seguindo-se um aumento até 2,5 ka (Figura 8c).

Os valores da razão $\mathrm{Mn} / \mathrm{Al} \times 10^{-4}$ atingiram desvio padrão de 19,47 , variando entre 48,34 e 188,49 . Observamos aumento gradual dos valores de $\mathrm{Mn} / \mathrm{Al} \times 10^{-4}$ de 40 a $2.5 \mathrm{ka}$, os quais, entretanto, apresentaram um pico em $\sim 8 \mathrm{ka} \mathrm{(Figura} \mathrm{8d).}$

A razão Ni/Co obteve desvio padrão de 0,28, variando entre 0,94 e 2,25. Essa variável demonstrou dois períodos com valores mais elevados: primeiro entre $\sim 35 \mathrm{e}$ $29 \mathrm{ka}$, e o segundo entre 7,5 e 2,5 ka. Durante o intervalo entre esses dois momentos, os valores variaram em torno da média 1,57. Observamos também dois períodos em que os menores valores se destacaram $\sim 36$ e $\sim 8$ ka, respectivamente (Figura 8e). 

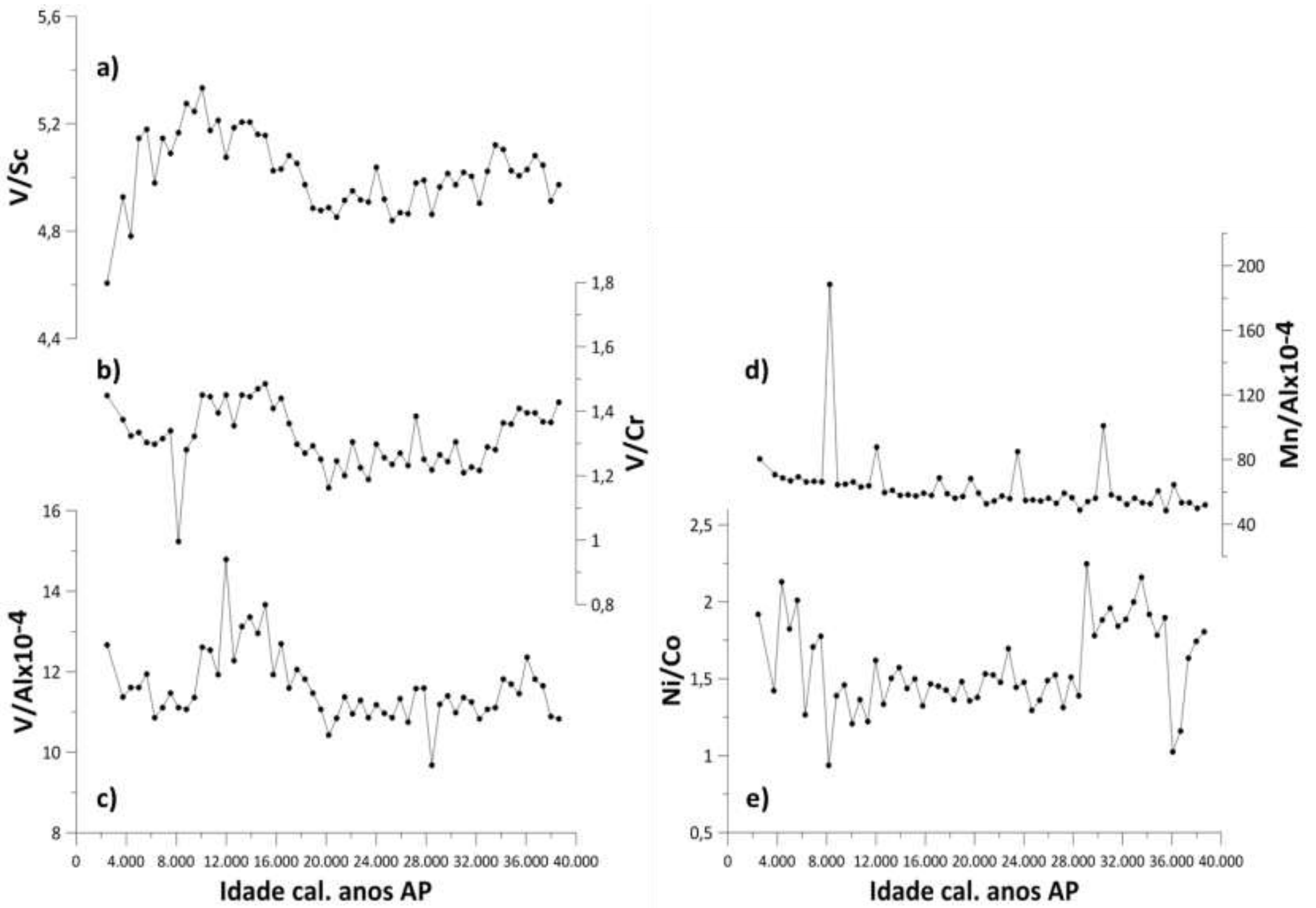

Figura 8 - Distribuição das razões elementares (a) V/Sc, (b) V/Cr, (c) V/Al $\times 10^{-4}$, (d) $\mathrm{Mn} / \mathrm{Al} \times 10^{-4}$ e (e) Ni/Co ao longo do testemunho NAP63 em função da Idade cal. (anos AP). 
A razão $\ln (\mathrm{Fe} / \mathrm{Ca})$ variou entre $-1,40$ e -0,45. Seus valores diminuíram de 40 a 23 ka e aumentaram de 23 a 16 ka. Na sequência, ocorreu uma diminuição de $\sim 16$ a 8 ka. De 8 ka a 2,5 ka, os valores da razão $\ln (\mathrm{Fe} / \mathrm{Ca})$ aumentaram mais uma vez. (Figura 9a).

A razão $\ln (\mathrm{Ti} / \mathrm{Ca})$ variou entre $-2,81$ e $-1,87$. Os valores dessa razão diminuíram de $40 \mathrm{ka}$ (quando se observa o maior valor) até 24 ka e aumentaram de 24 a 13 ka. Seguiu-se, então, uma diminuição de 13 a 2,5 ka (quando se observa o menor valor) (Figura 9b).

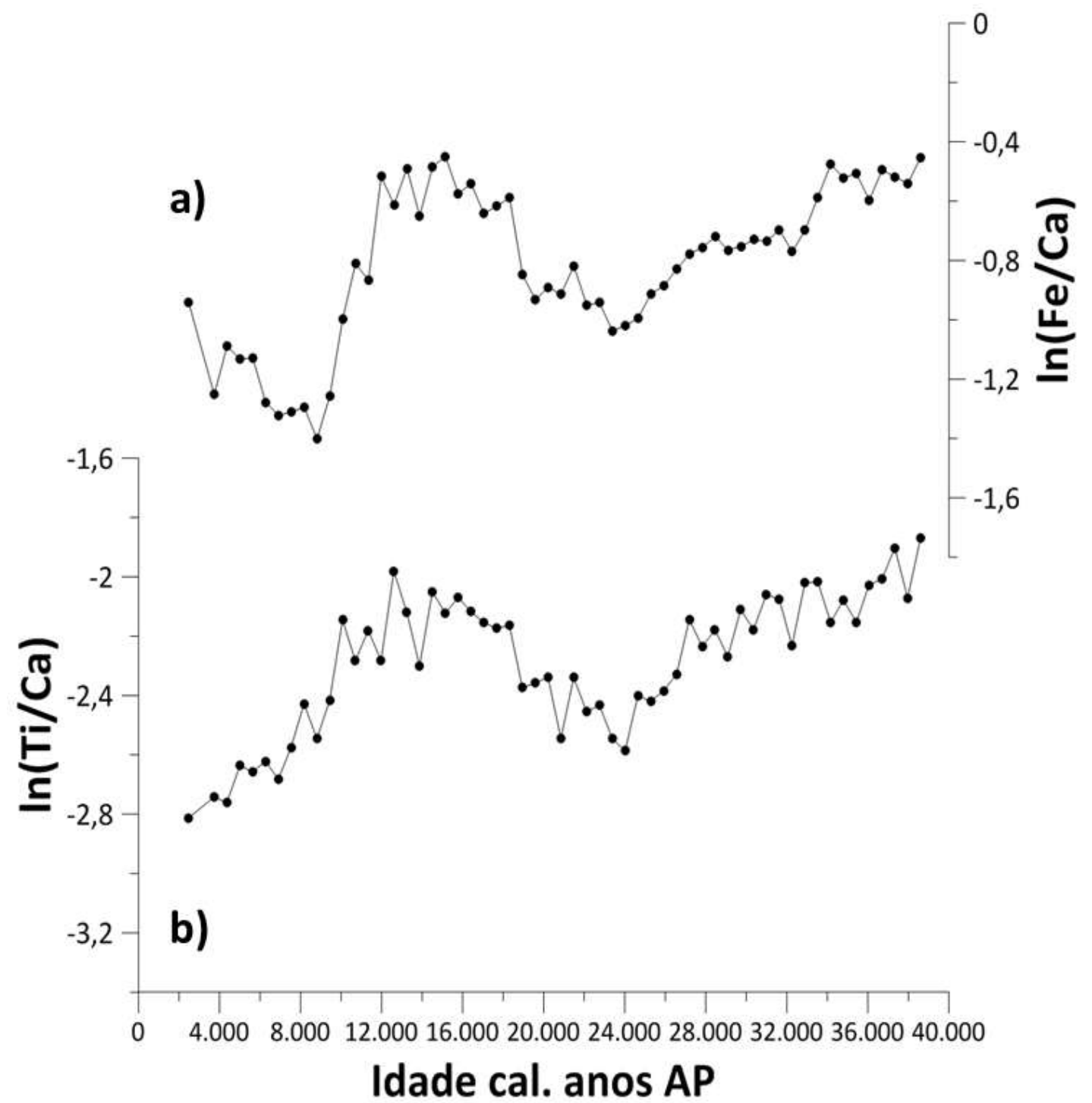

Figura 9 - Distribuição das razões (a) $\ln (\mathrm{Fe} / \mathrm{Ca})$ e (b) $\ln (\mathrm{Ti} / \mathrm{Ca})$ ao longo do testemunho NAP63-1 em função da ldade cal. (anos AP). 


\subsubsection{Carbono orgânico total, conteúdo de carbonato de cálcio, isótopo estável de carbono e a razão $\mathrm{C} / \mathrm{N}$ em sedimento}

A porcentagem do COT em sedimento alcançou desvio padrão de $0,11 \%$, variando entre $0,17 \%$ e $0,69 \%$. Os valores do COT oscilaram em torno da média $(0,48)$ de 40 a $\sim 11 \mathrm{ka}$, seguindo-se uma diminuição de 11 a $\sim 8$ ka (quando se observa o menor valor). Em seguida, o COT passou a aumentar até 2,5 ka (Figura 10a).

O teor de $\mathrm{CaCO}_{3}$ ao longo do testemunho NAP63-1 atingiu desvio padrão de $5,52 \%$, variando entre 18,10 e $37,85 \%$. Essa variável apresentou um aumento gradual de 40 ka até $\sim 23 \mathrm{ka}$, momento a partir do qual observamos uma diminuição até 14 ka. A partir de então, identifica-se aumento até $~ 8$ ka (quando se observa o maior valor) tendo os valores permanecidos altos daí em diante (Figura 10b).

A $\delta^{13} \mathrm{C}$ exibiu desvio padrão de $0,41 \%$, variando entre $-22,40 \%$ e $-20,27 \%$. De $40 \mathrm{ka} \mathrm{a} \sim 24 \mathrm{ka}$, seus valores aumentaram, seguindo-se uma diminuição entre 24 ka e $\sim 8$ ka (quando se observa o menor valor). Por fim, os valores de $\delta^{13} \mathrm{C}$ tornaram a aumentar até 2,5 ka (Figura 10c).

A razão $\mathrm{C} / \mathrm{N}$ obteve desvio padrão de 1,12, variando entre 3,67 e 10,16. Em geral, os valores da razão $\mathrm{C} / \mathrm{N}$ variaram em torno da média $(6,36)$ de 40 até $\sim 11 \mathrm{ka}$, diminuindo, em seguida, de 11 a 8 ka. Seguiu-se, então, um aumento de 8 a 2,5 ka (Figura 10d). 


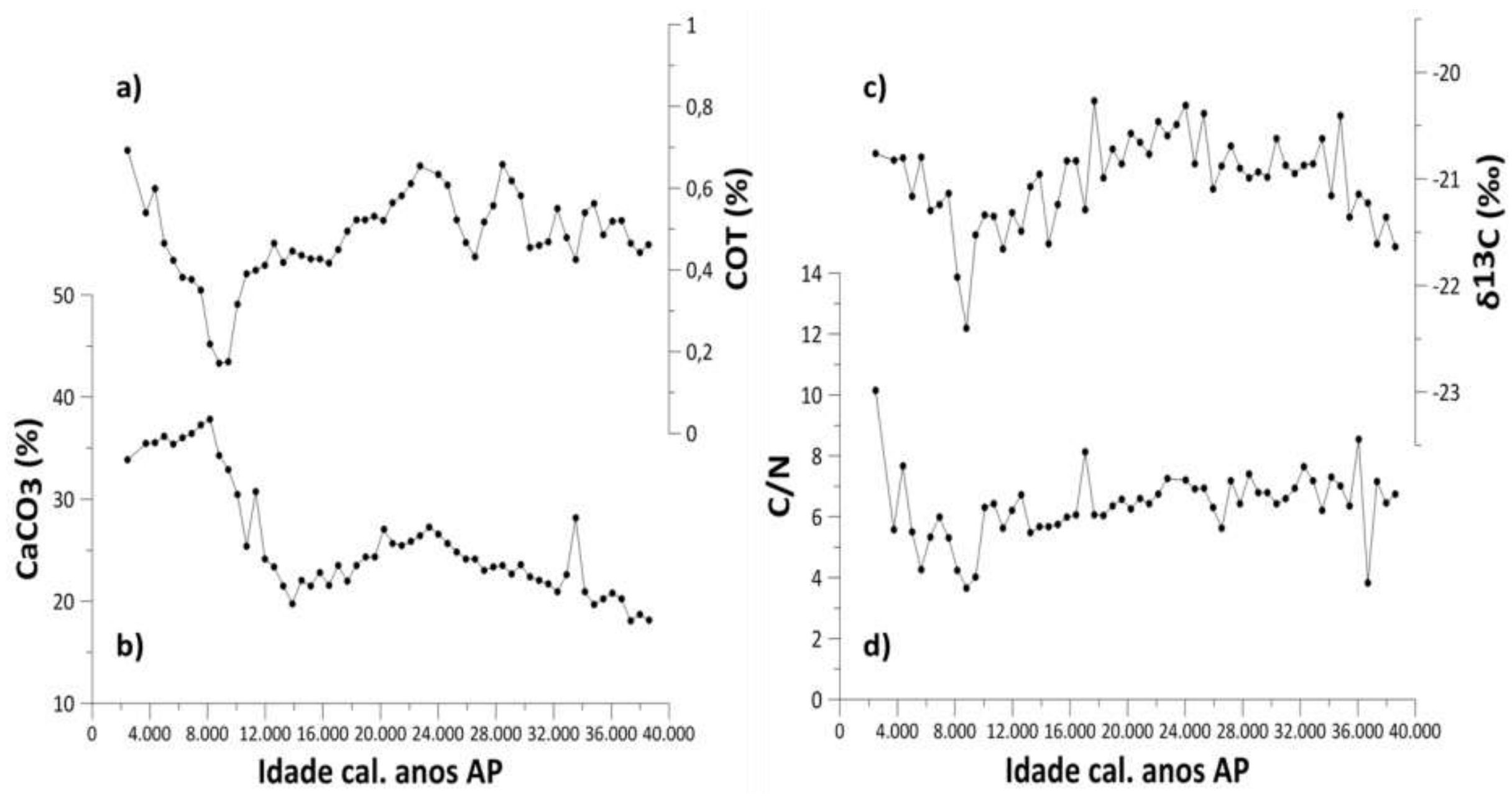

Figura 10 - Distribuição das variáveis (a) $\mathrm{COT}(\%)$, (b) $\mathrm{CaCO}_{3}(\%)$, (c) $\delta^{13} \mathrm{C}(\%)$ e (d) $\mathrm{C} / \mathrm{N}$ ao longo do testemunho NAP63-1 em função da Idade cal. (anos AP). 


\section{Discussão}

Nossos resultados sugerem que, nos últimos $40 \mathrm{ka}$, as águas intermediárias presentes na região do talude SE brasileiro apresentaram condições óxicas, uma vez que as razões elementares $\mathrm{V} / \mathrm{Cr}$, Ni/Co e V/Sc exibiram valores abaixo de 2, 5 e 9,1 , respectivamente, o que define o ambiente como óxico, segundo a classificação sugerida por Jones e Manning (1994), e Kimura e Watanabe (2001).

No entanto, é possível observar variação nos proxies de condições redox ao longo dos últimos $40 \mathrm{ka}$, o que indica que houve variações na quantidade de oxigênio dissolvido dessas águas em determinados períodos. A seguir, iremos discutir essas variações, buscando entender melhor os mecanismos sob perspectiva global (i.e., AMOC) e regional (i.e., aporte de sedimentos terrígenos e produtividade oceânica), bem como sua relação com eventos climáticos globais de escala orbital e milenar.

\subsection{Variabilidade em escala orbital}

Mudanças em escala orbital são regidas primeiramente pela insolação, isto é, a quantidade de calor que a Terra recebe do Sol em uma determinada região. A intensidade dessa insolação é governada por variações nos parâmetros orbitais do planeta, como aquelas causadas pelo ciclo de precessão. Assim, essa forçante controla principalmente a variação do nível do mar através do aumento ou da diminuição do volume de neve e gelo (Siddall et al., 2008). Ela também exerce influência sobre a temperatura da superfície do mar, a qual, por sua vez, gere o regime de ventos da circulação atmosférica, como, por exemplo, os Sistemas de Monções da América do Sul (Cruz et al., 2005, 2006, 2009). Esses autores observaram que, em períodos de máxima insolação de verão no Hemisfério Sul, há intensificação do Sistema de Monção da América do Sul (SMAS), o qual desloca a Zona de Convergência Intertropical (ZCIT) para o sul, aumentando o padrão de precipitação do SE do Brasil.

De maneira geral, nossos resultados não apresentam uma clara variação das condições redox das águas intermediárias do Atlântico SW durante o MIS 3 (40 a 29 ka) (Figura 11). As razões V/Cr e V/Al, no entanto, sugerem tendência de aumento das condições óxicas das águas intermediárias do Atlântico nesse intervalo de 
tempo (Figura 11b e c). As condições redox na área de estudo podem estar relacionadas: (i) mudanças nas condições de oxigenação na região de formação da AIA e/ou (ii) variações no consumo de oxigênio na interface água-sedimento, principalmente associadas à degradação de matéria orgânica sedimentar, que chega tanto com o aporte terrígeno quanto pelo fluxo de carbono da produção primária das águas superficiais. 

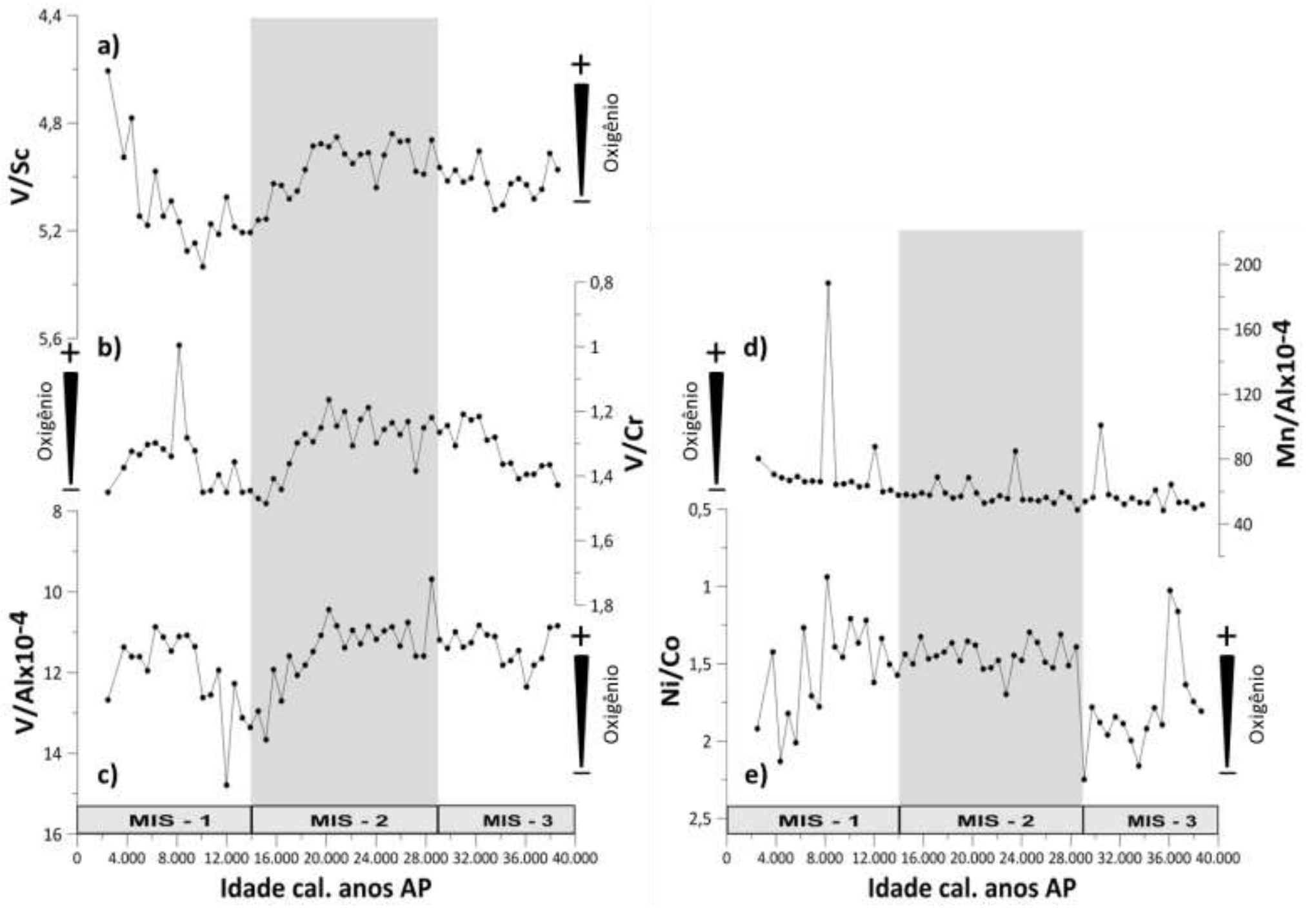

Figura 11 - Distribuição das razões elementares (a) V/Sc, (b) V/Cr, (c) V/Al x10-4, (d) $\mathrm{Mn} / \mathrm{Al} \times 10^{-4}$ e (e) Ni/Co ao longo do testemunho NAP63 em função da Idade cal. (anos AP). Em destaque, os limites dos estágios isotópicos marinhos (MIS 1, 2 e 3) (Lisiecki e Raymo, 2005). Os eixos das coordenadas (Y) dos gráficos a, b, c e d estão invertidos para facilitar a interpretação. 
Ao longo do MIS 3, o aporte de sedimentos terrígenos (p.e., razão $\ln (\mathrm{Ti} / \mathrm{Ca})$ ) demonstraram uma tendência de diminuição (Figura 12b). Nesse período, as curvas globais do nível médio do mar indicam que ele estava de $\sim 90$ a $100 \mathrm{~m}$ abaixo do valor atual (Figura 12d). Isso promoveria um encurtamento da plataforma da margem continental e deslocaria o aporte fluvial para offshore. Dessa forma, a diminuição no aporte de sedimentos terrígenos ao longo do MIS 3, parece não acompanhar a diminuição do nível médio do mar. Estudos recentes (Mahiques et al., 2011; Silva et al., 2014; Salvaterra et al., 2017) realizados na costa SE brasileira, sugerem que, durante o MIS 3, o nível do mar apresentava-se mais alto do que o relatado em curvas globais de variação do nível do mar. Desse modo, esses estudos reforçam a baixa influência da variação do nível do mar em nossos dados durante esse período.

Ainda, apesar de o aporte fluvial para a margem continental SE do Brasil ser restrito, o talude recebe sedimentos terrígenos não só do continente adjacente, mas também de áreas continentais remotas, transportados pela $\mathrm{CCl}$ (Mahiques et al., 2017). Ou seja, como a CCl representa um fluxo para norte ao longo da margem SE brasileira os sedimentos terrígenos encontrados na área de estudo, possivelmente, sofrem influência de áreas mais ao sul, potencialmente do Estuário do Rio de La Plata.

Por outro lado, ao analisarmos os proxies de produtividade observamos discreto aumento durante o MIS 3 (p.e. COT Figura 12a). Mahiques et al. (2007), em um estudo sobre avaliação de mudanças sedimentares dos últimos 35 ka na região do talude superior (374 $\mathrm{m}$ ), próximo à área coberta pela nossa pesquisa, também observaram em seus valores de COT baixa variabilidade da produtividade durante 0 MIS 3. Esses autores propõem que, durante esse intervalo, o nível do mar alto (em relação ao UMG) deslocaria as águas quentes da CB para perto da costa SE brasileira, impedindo um aumento da produtividade na região do talude, além de evitar a deposição de lama e, consequentemente, de matéria orgânica (MO) devido ao efeito de "enceradeira" pela CB no fundo do mar, como descrito por Mahiques et al. (2004). A complexa hidrodinâmica descrita nesses trabalhos pode ter influenciado na baixa variabilidade dos nossos dados de produtividade, uma vez que um cenário assim inibiria o suprimento de nutrientes das áreas mais rasas para a área abrangida pelo nosso estudo. 


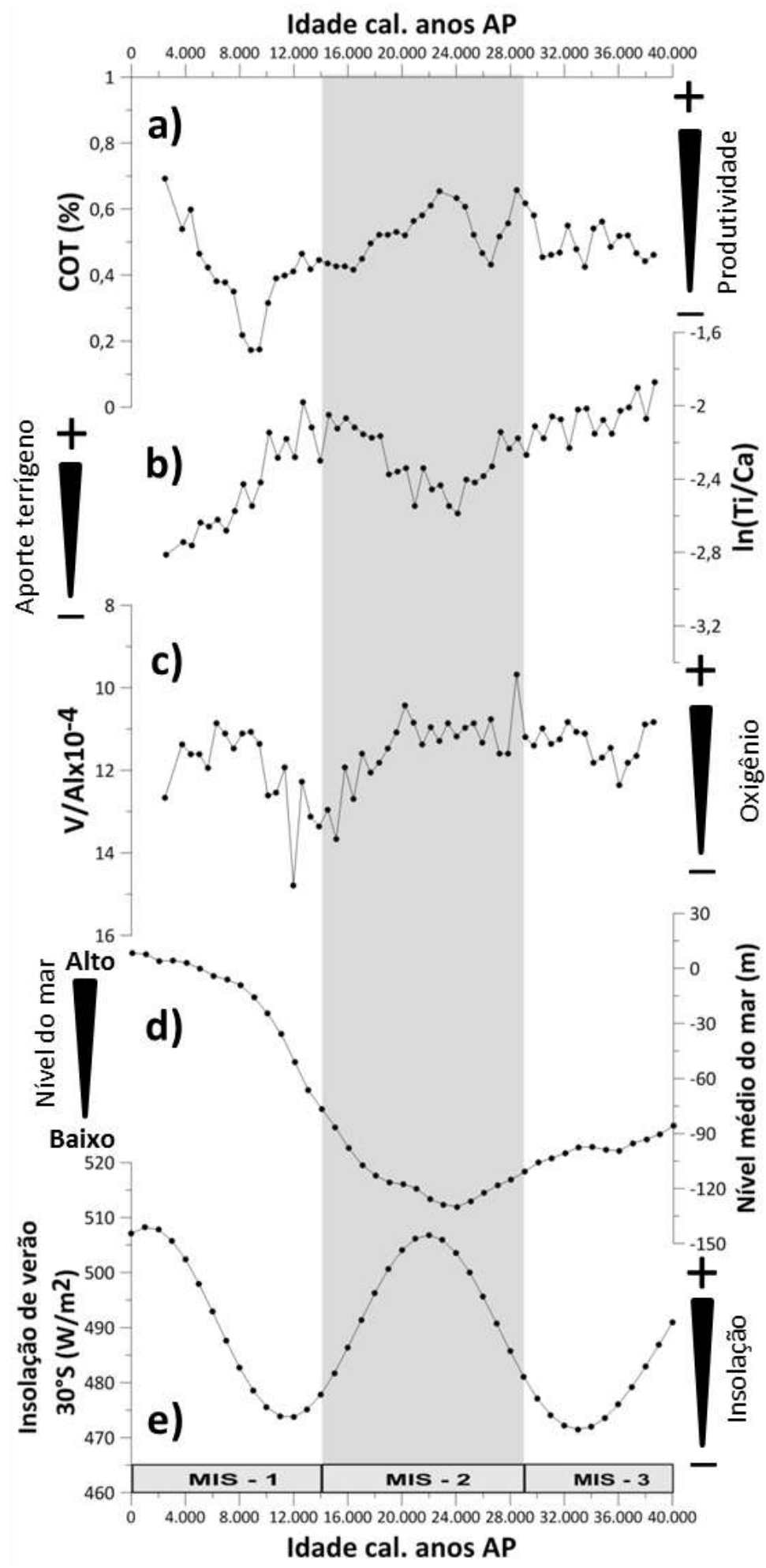

Figura 12 - Distribuição de (a) COT (\%); (b) In(Ti/Ca); (c) razão V/Al x10-4 (eixo Y invertido); (d) nível médio do mar (m) (Spratt e Lisiecki, 2016) e (e) insolação de verão a $30^{\circ} \mathrm{S}\left(\mathrm{W} / \mathrm{m}^{2}\right)$ (Berger e Loutre, 1991) ao longo dos últimos $40 \mathrm{ka}$. Em destaque, os limites dos estágios isotópicos marinhos (MIS 1, 2 e 3) (Lisiecki e Raymo, 2005). 
Os nossos resultados de $\mathrm{CaCO}_{3}$ demonstraram aumento durante o MIS 3 (Figura 13b). No entanto, observamos que este proxy apresenta alta correlação com os proxies de aporte de sedimentos terrígenos $\left(r^{2}=-0,80, p=10^{-14}, n=57\right)$, de forma que essa variável pode ter sofrido efeito de diluição pelos proxies de aporte terrígeno, porém para afirmarmos teríamos que comparar esses resultados com os dados granulométricos (não contemplado neste trabalho). Assim neste trabalho não vamos atribuir a variabilidade da produtividade a esse proxy, interpretação que será considerada para os demais períodos.

Ainda, com auxílio dos proxies $\delta^{13} \mathrm{C}$ e razão $\mathrm{C} / \mathrm{N}$ em sedimento, caracterizamos a $\mathrm{MO}$ como de origem marinha para todo o período estudado (MIS 1, 2 e 3). Uma vez que o $\delta^{13} \mathrm{C}$ variou entre -22 e $-20 \%$ e a razão $\mathrm{C} / \mathrm{N}$ entre 3,40 e 10, intervalos que, segundo Mahiques et al. (1999), endossam essa caracterização para região da margem SE brasileira com valores médios de $-19 \%$ e 6 para $\delta^{13} \mathrm{C}$ e $\mathrm{C} / \mathrm{N}$, respectivamente (Figura 13c e d).

Assim, o aumento das condições óxicas das águas intermediárias do Atlântico SW observada nas razões $\mathrm{V} / \mathrm{Cr}$ e V/Al durante o MIS 3 pode estar relacionado a uma diminuição de aporte de terrígenos e à baixa variabilidade da produtividade, uma vez que haveria uma diminuição do consumo desse oxigênio na interface água-sedimento. É sabido que houve mudanças nas condições de oxigenação na região de formação dessas águas (Anderson et al., 2009; Hendry et al., 2012), porém esses trabalhos observaram as mudanças em escala milenar e não orbital. Dessa maneira, não podemos inferir um aumento da oxigenação dessas águas por tais mecanismos ao longo do MIS 3. 

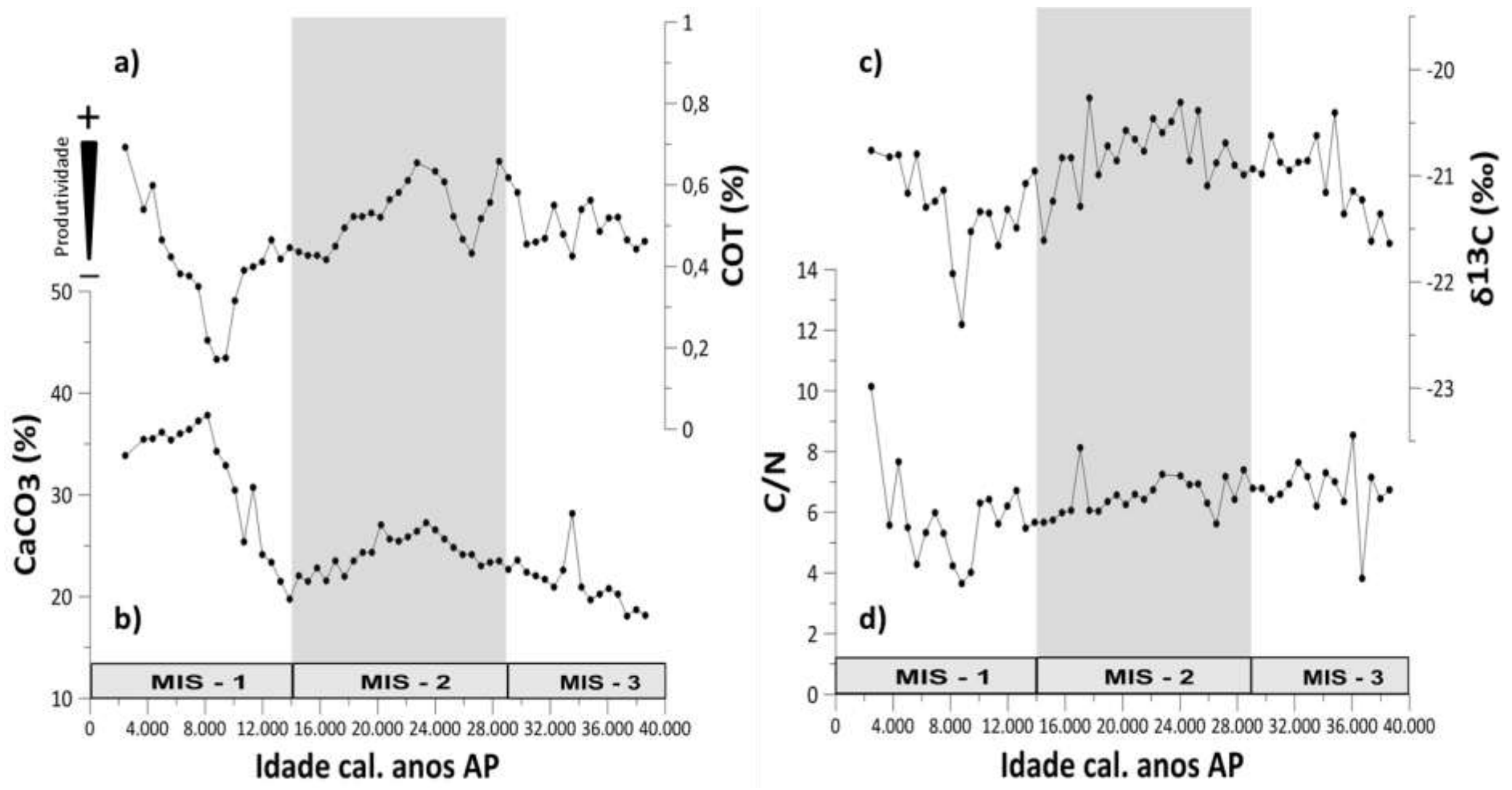

Figura 13 - Distribuição das variáveis (a) COT (\%), (b) $\mathrm{CaCO}_{3}(\%)$, (c) $\delta^{13} \mathrm{C}(\%)$ e (d) $\mathrm{C} / \mathrm{N}$ ao longo do testemunho NAP63 em função da Idade cal. (anos AP). Em destaque, os limites dos estágios isotópicos marinhos (MIS 1, 2 e 3) (Lisiecki e Raymo, 2005). 
Durante o MIS 2, os resultados apontam para mudanças nas condições redox em um cenário de nível médio do mar baixo (Spratt e Lisiecki, 2016) e um aumento na insolação de verão em $30^{\circ} \mathrm{S}$ (Berger e Loutre, 1991). Há a tendência de aumento da concentração de oxigênio até aproximadamente 20 ka seguida de uma diminuição dessa concentração, tendendo a um ambiente mais redutor até o final do MIS 2 (Figura 11).

É interessante notar que durante o MIS 2 são observados baixos valores dos proxies de aporte de sedimentos terrígenos para o talude da margem continental SE brasileira (Figura 12b), mesmo dentro de um cenário de nível médio do mar mais baixo e com altos valores de insolação de verão em $30^{\circ} \mathrm{S}$. No entanto, durante 0 UMG, Mahiques et al. (2007) e Nagai et al. (2010) reportaram aumento no aporte de sedimentos terrígenos para o talude superior (até $400 \mathrm{~m}$ ) sob o domínio da CB. Segundo os autores, esse aumento pode ser explicado pelo encurtamento da plataforma da margem continental devido ao baixo nível do mar e ao deslocamento da CB para ao largo da costa SE brasileira (offshore). No entanto, como mencionado anteriormente, nosso registro encontra-se sob domínio da $\mathrm{CCl}$, que seria o agente responsável pelo transporte de sedimentos oriundos de áreas mais a sul para o talude médio da margem SE brasileira (Mahiques et al., 2017).

Os valores de COT demonstraram um aumento até 23 ka, seguido de diminuição até o final do MIS 2 (Figura 12a). Entretanto, observamos os maiores valores desse proxy durante o MIS 2, caracterizando um período de alta produtividade. Esse aumento corrobora outros trabalhos realizados na margem SE brasileira durante este período (Mahiques et al., 2007; Toledo et al., 2008; Nagai et al., 2010), o que será melhor discutido na próxima seção deste capítulo.

Desse modo, observamos dois cenários distintos relacionados às condições redox das águas intermediárias do Atlântico SW durante o MIS 2. (i) aumento das condições óxicas; diminuição de aporte de sedimentos terrígenos; e aumento da produtividade; (ii) diminuição das condições óxicas; aumento de aporte de sedimentos terrígenos; e diminuição da produtividade (Figura 12c, b e a).

No primeiro cenário, inferimos que, possivelmente, as condições redox sejam governadas por mudanças em escala global, como o aumento da ventilação na região da Antártica favorecendo a formação da AIA, — como sugerido por Wainer et 
al. (2012) - durante o UMG, uma vez que tanto os baixos valores de aporte de sedimentos terrígenos quanto o aumento da produtividade parecem não influenciar na variação das condições redox durante esse primeiro cenário. Entretanto, durante o segundo cenário, podemos inferir que a diminuição da concentração de oxigênio dessas águas pode estar relacionada ao aumento de aporte de sedimentos terrígenos e ao consumo desse oxigênio pela alta produtividade do cenário anterior.

Durante o MIS 1, a maior parte dos nossos proxies de condições redox demonstraram aumento da concentração de oxigênio das águas intermediárias do Atlântico SW do início do MIS 1 até aproximadamente 8 ka, o que foi seguido por uma diminuição da concentração de oxigênio até 2.5 ka, como pode ser visto nas razões $\mathrm{V} / \mathrm{Cr}$, V/Al e Ni/Co (Figuras 11b, c e e, respectivamente). A razão Mn/Al apresentou aumento durante o MIS 1 e um sinal singular durante 8 ka que será discutido no próximo item desta discussão (Figura 11d).

Os nossos proxies de aporte de sedimentos terrígenos atingiram altos valores no início do MIS 1, tendendo a diminuição ao longo desse período (Figura 12b) o que coincide com o aumento do nível médio do mar, o qual demonstrou ascensão do início do MIS 1 de $70 \mathrm{~m}$ até $\sim 4 \mathrm{~m}$ em 2.5 ka acima do nível zero observado em torno de 5 ka (Spratt e Lisiecki, 2016) (Figura 12d). No entanto, os valores do COT decresceram do início do MIS 1 até $8 \mathrm{ka}$, seguindo-se uma alta até $2.5 \mathrm{ka}$, o que pode corresponder a dois períodos, diminuição e aumento da produtividade respectivamente (Figura $12 \mathrm{a}$ ).

Dessa forma, durante o MIS 1 observamos dois períodos distintos das condições redox das águas intermediárias do Atlântico SW - antes e depois de 8 ka. Antes de 8 ka, o aumento da concentração de oxigênio das águas intermediárias pode estar relacionado tanto à diminuição do aporte de sedimentos terrígenos quanto à diminuição da produtividade que estaria associada a redução do consumo de oxigênio no processo de degradação da $\mathrm{MO}$, e, consequentemente, provocando aumento da sua disponibilidade nessas águas.

No entanto, no segundo período depois de $8 \mathrm{ka}$, observamos aumento da produtividade, o que pode estar relacionado ao deslocamento para sul da ZCIT (devido à ampliação da insolação de verão a $30^{\circ} \mathrm{S}$ ), o que teria resultado na intensificação da CB, a qual, por sua vez, aumentaria a disponibilidade de nutrientes 
para a região do talude devido ao aumento da ressurgência formada pelos vórtices da CB (Toledo et al., 2008). 


\subsection{Variabilidade em escala milenar}

Com base em nossos dados, é também possível observar a existência de mudanças em escala milenar, em sobreposição às variações em escala orbital, nas condições redox, no aporte de sedimentos terrígenos e na produtividade da margem SE brasileira nos últimos $40 \mathrm{ka}$. Neste trabalho, demos ênfase aos eventos milenares frios do HN (i.e., Heinrich Stadials, UMG, YD e 8.2). Esses eventos dão sinais de mudanças abruptas do clima, registradas tanto nos registros de gelo em altas latitudes quanto nos registros sedimentares marinhos em baixas e médias latitudes (Peterson et al., 2000; Andersen et al., 2004; Böhm et al., 2015). Apesar de os últimos $40 \mathrm{ka}$ também terem sido pontuados por eventos quentes de curta duração (p.e., Dansgaard-Oeschger Interstadials (D-O) (Andersen et al., 2004; Böhm et al., 2015), essas ocorrências não foram analisadas neste trabalho, dada a limitação de resolução temporal do nosso registro.

Nos últimos 40 ka, são conhecidos quatro eventos Heinrich $(\mathrm{H} 1, \mathrm{H} 2, \mathrm{H} 3$ e H4) (Hemming, 2004). Durante esses eventos, a maior parte dados sugerem que há mudança nas condições redox das águas intermediárias do Atlântico SW (Figura 14). De maneira geral, todos os proxies redox utilizados neste estudo sugerem condições relativamente mais óxicas das águas intermediárias do Atlântico SW, ou seja, um aumento da concentração de oxigênio dissolvido durante esses eventos (Figura 14). 

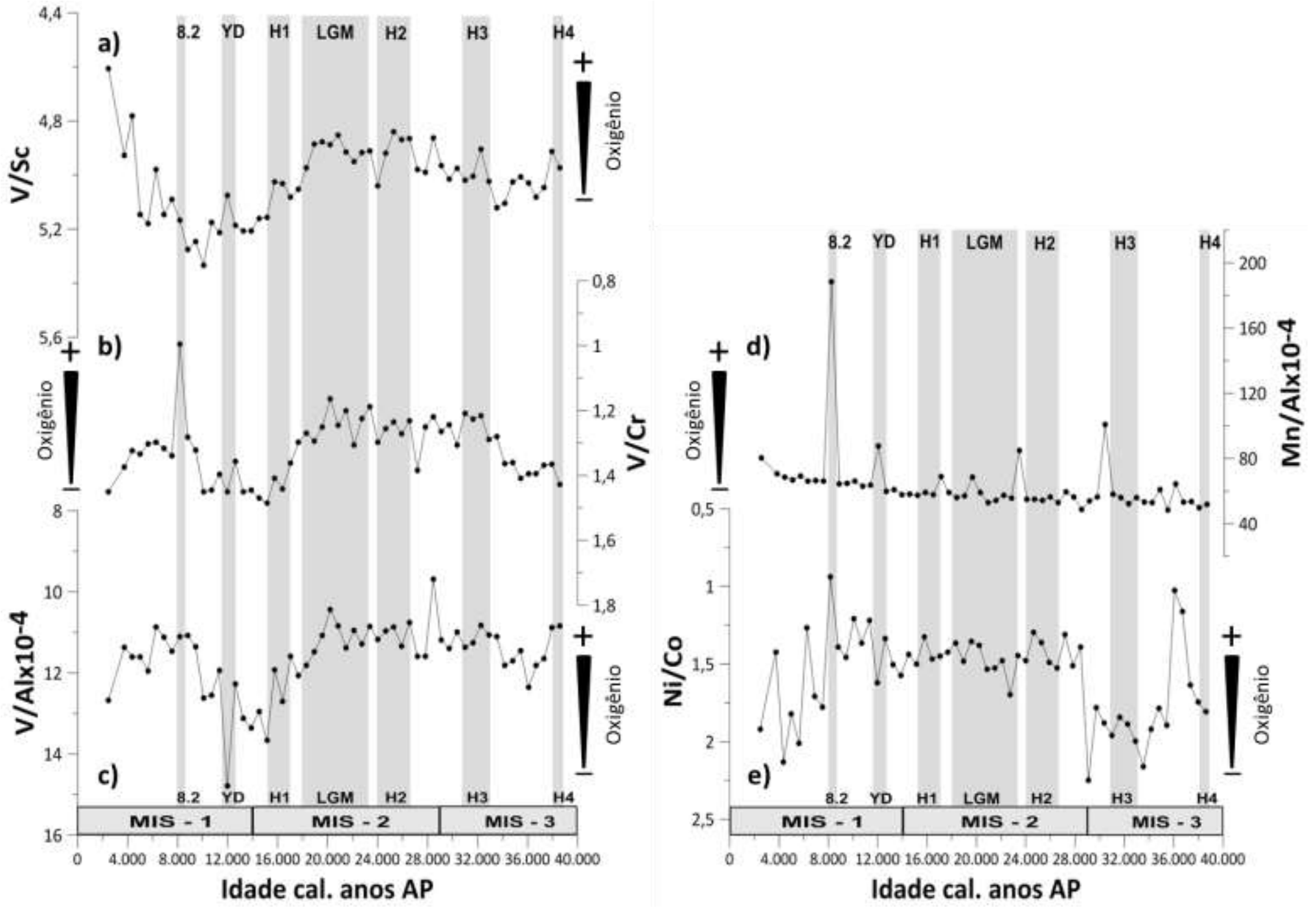

Figura 14 - Distribuição das razões elementares (a) V/Sc, (b) V/Cr, (c) V/Al x10-4, (d) $\mathrm{Mn} / \mathrm{Al} \times 10^{-4}$ e (e) Ni/Co ao longo do testemunho NAP63 em função da Idade cal. (anos AP) com os respectivos eventos climáticos abruptos (H4, H3, H2, LGM, H1, YD e 8.2) dos últimos 40 ka e os limites dos estágios isotópicos marinhos (MIS 1, 2 e 3) (Lisiecki e Raymo, 2005). Os eixos das coordenadas (Y) dos gráficos a, b, c e e estão invertidos para facilitar a interpretação. 
Assim, a variação das condições redox das águas intermediárias do Atlântico SW nesses eventos Heinrich $(\mathrm{H})$ pode estar associada à variabilidade milenar da AMOC. Dessa maneira, entendermos a dinâmica da AMOC nos permite avaliar como a sua variabilidade pode afetar as condições redox das águas intermediárias que banham nossa costa. Como é sabido, a área abrangida pelo nosso estudo está sob o domínio da Água Intermediária Antártica (AIA), transportada para norte pela Corrente de Contorno Oeste Intermediária ( $\mathrm{CCl}$ ) ao longo da margem continental SE brasileira, representando um importante componente do membro superior da AMOC, a qual está associada ao transporte de calor e sal para o Atlântico Norte (Silveira et al., 2004; Wainer et al., 2012; Huang et al., 2014, Howe et al., 2016).

De acordo com Lynch-Stieglitz (2017), desde o último ciclo glacial, o Atlântico apresentou três estados distintos de circulação (Figura 15), a saber: (a) o estado de circulação quente, como no Holoceno e nos eventos D-O, caracterizado por uma AMOC forte, com a formação das áquas da componente norte ${ }^{6}$ (ACN) mais profunda e menor influência das águas da componente sul ${ }^{7}$ (ACS) no Atlântico Norte; (b) o estado de circulação fria, como o que sucedeu durante o UMG, caracterizado por uma AMOC fraca, com a formação das águas da componente norte em águas rasas e maior influência das águas da componente sul no Atlântico Norte; e (c) o estado sem circulação, sem a formação das águas da componente norte, sendo caracterizado pelo grande aporte de água doce na região do Atlântico Norte, como o que ocorreu durante os eventos Heinrich.

\footnotetext{
${ }^{6}$ Águas da componente norte (ACN): Northern Source Water (NSW) são caracterizadas pela Água Profunda do Atlântico Norte (APAN) e representa a circulação do Atlântico Norte.

${ }^{7}$ Águas da componente sul (ACS): Southern Source Water (SSW) são caracterizadas pela Água de Fundo Antártica (AFA) e representa a circulação do Atlântico Sul.
} 


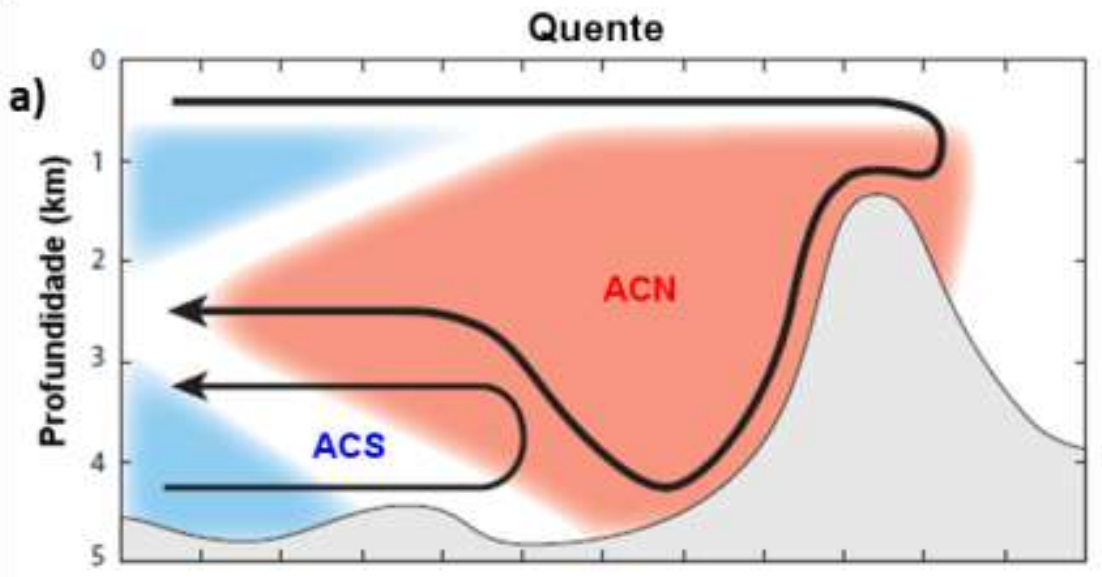

Frio
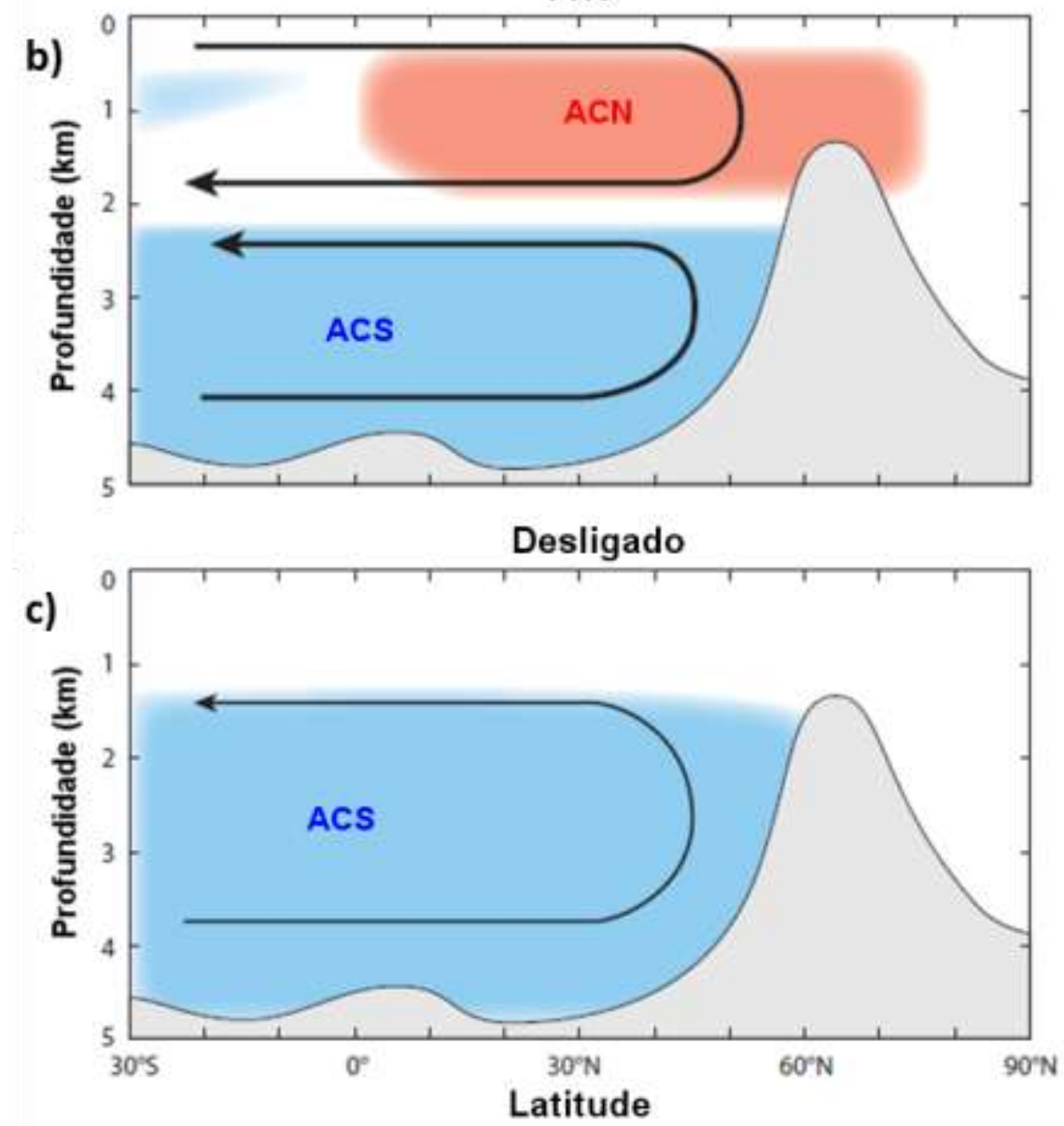

Figura 15 - Representação esquemática dos três modelos propostos da circulação do Atlântico (AMOC). (a) O estado de circulação quente com a AMOC forte e profunda; (b) O estado de circulação fria típico do Último Máximo Glacial, com a AMOC fraca e rasa; (c) E um estado sem circulação (Desligado) típica dos eventos Heinrich. ACN - águas da componente norte e ACS - águas da componente sul (Lynch-Stieglitz, 2017). 
Ainda, durante eventos frios no Atlântico Norte ocorre a reorganização da circulação atmosférica global, com o deslocamento para sul dos westerlies no Hemisfério Sul, o que intensificaria a ressurgência da ACP na região da Antártica, elevando os índices de $\mathrm{CO}_{2}$ atmosférico e favorecendo a formação da AIA (Anderson et al., 2009; Hendry et al., 2012; Howe et al., 2016). Esse aumento da ventilação na região da Antártica pode ser um dos mecanismos responsáveis pelos sinais de aumento de oxigênio das águas intermediárias do Atlântico SW durante os eventos frios observados em nossos resultados.

Os outros mecanismos que têm potencial para alterar as condições redox das águas intermediárias da margem continental SE brasileira em escala milenar são: o aporte de sedimentos terrígenos e a produtividade. No entanto, com base nos nossos resultados não é possível observar padrão claro de variação dos proxies de aporte de sedimentos terrígenos e produtividade durante os eventos Heinrich (Figura 16 e 17). Entretanto, quando analisamos separadamente cada evento Heinrich, observamos que esses proxies apresentam diferentes respostas para cada evento.

$\mathrm{O} \mathrm{H} 1$ foi o evento Heinrich mais estudado recentemente, o qual marca o início do último período deglacial. Esse evento ocorreu num período em que os índices de insolação de verão a $30^{\circ} \mathrm{S}$ estavam em declínio $\left(<490 \mathrm{~W} / \mathrm{m}^{2}\right.$, Berger e Loutre, 1991) e o nível médio do mar em ascensão, porém ainda baixo ( 100 m abaixo do atual) (Figura 12d e e).

Apesar do aumento dos valores dos proxies de condições redox — ou seja, tendendo para ambiente redutor desde meados do UMG até o final do $\mathrm{H} 1$ observamos em todas as razões redox um aumento na concentração de oxigênio das águas intermediárias durante $\mathrm{o} \mathrm{H} 1$, corroborando a hipótese de aumento da oxidação dessas águas em sua área de formação durante esse evento (Anderson et al., 2009; Hendry et al., 2012; Howe et al., 2016; Jaccard et al., 2016) (Figura 14).

Em caráter regional observamos altos valores nos proxies de aporte sedimentos terrígenos durante o $\mathrm{H} 1$ (Figura 16), os quais podem ser uma resposta ao baixo nível do mar e ao aumento de precipitação na região devido ao deslocamento para sul do ZCIT causada pela intensificação dos SMAS (Stríkis et al., 2015). Nesse mesmo período, os valores de COT demonstraram ser menores do que o registrado durante o UMG e outros eventos Heinrich (Figura 17a), mesmo que 
alguns autores apontem para um aumento do teor de nutrientes das águas intermediárias durante o H1 (Clark et al., 2012; Hendry et al., 2012).

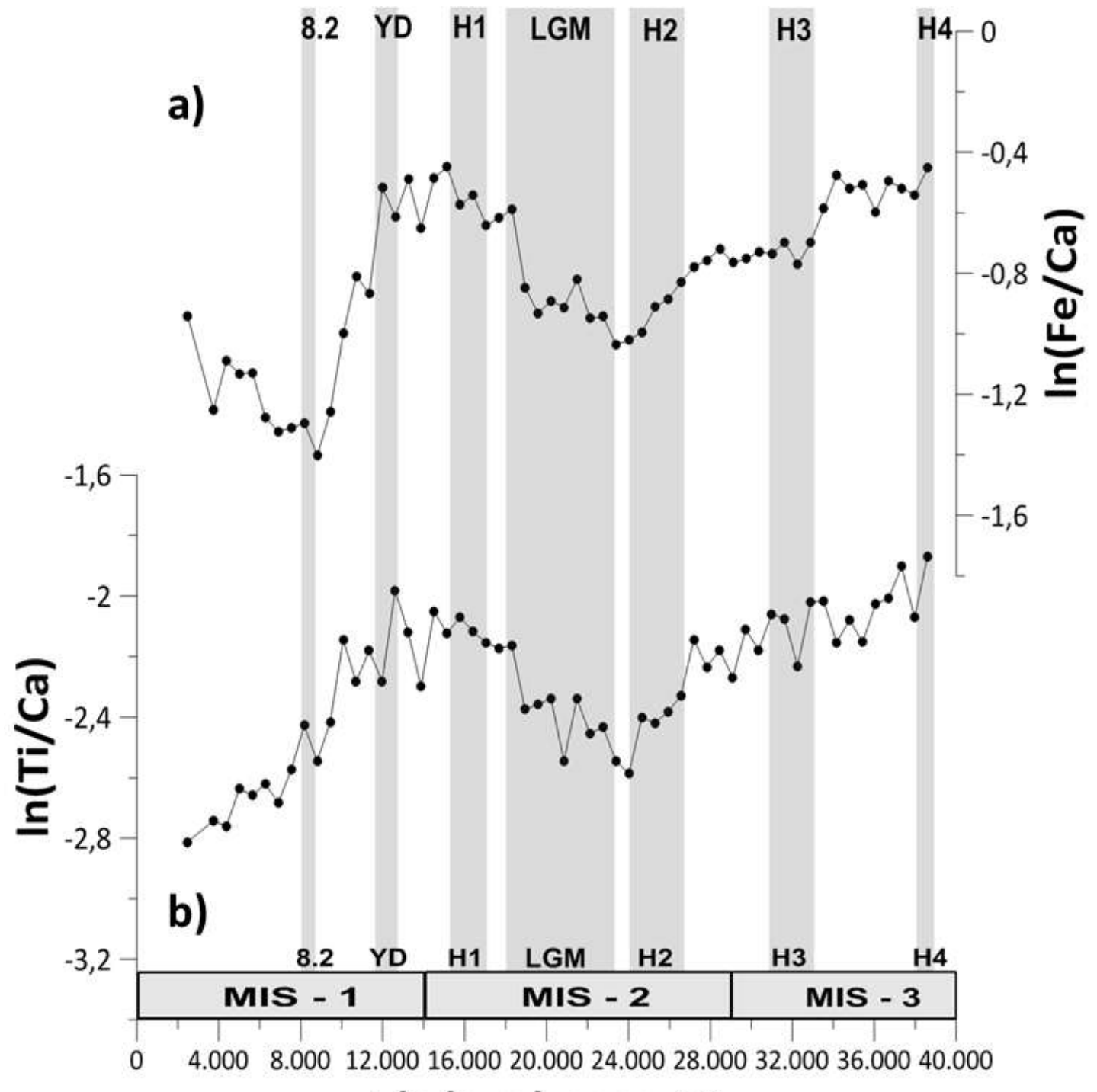

Idade cal. anos AP

Figura 16 - Distribuição das razões (a) $\ln (\mathrm{Fe} / \mathrm{Ca})$ e (b) $\ln (\mathrm{Ti} / \mathrm{Ca})$ ao longo do testemunho NAP63 em função da Idade cal. (anos AP) com os respectivos eventos climáticos abruptos dos últimos 40 ka e os limites dos estágios isotópicos marinhos (MIS 1, 2 e 3) (Lisiecki e Raymo, 2005). 

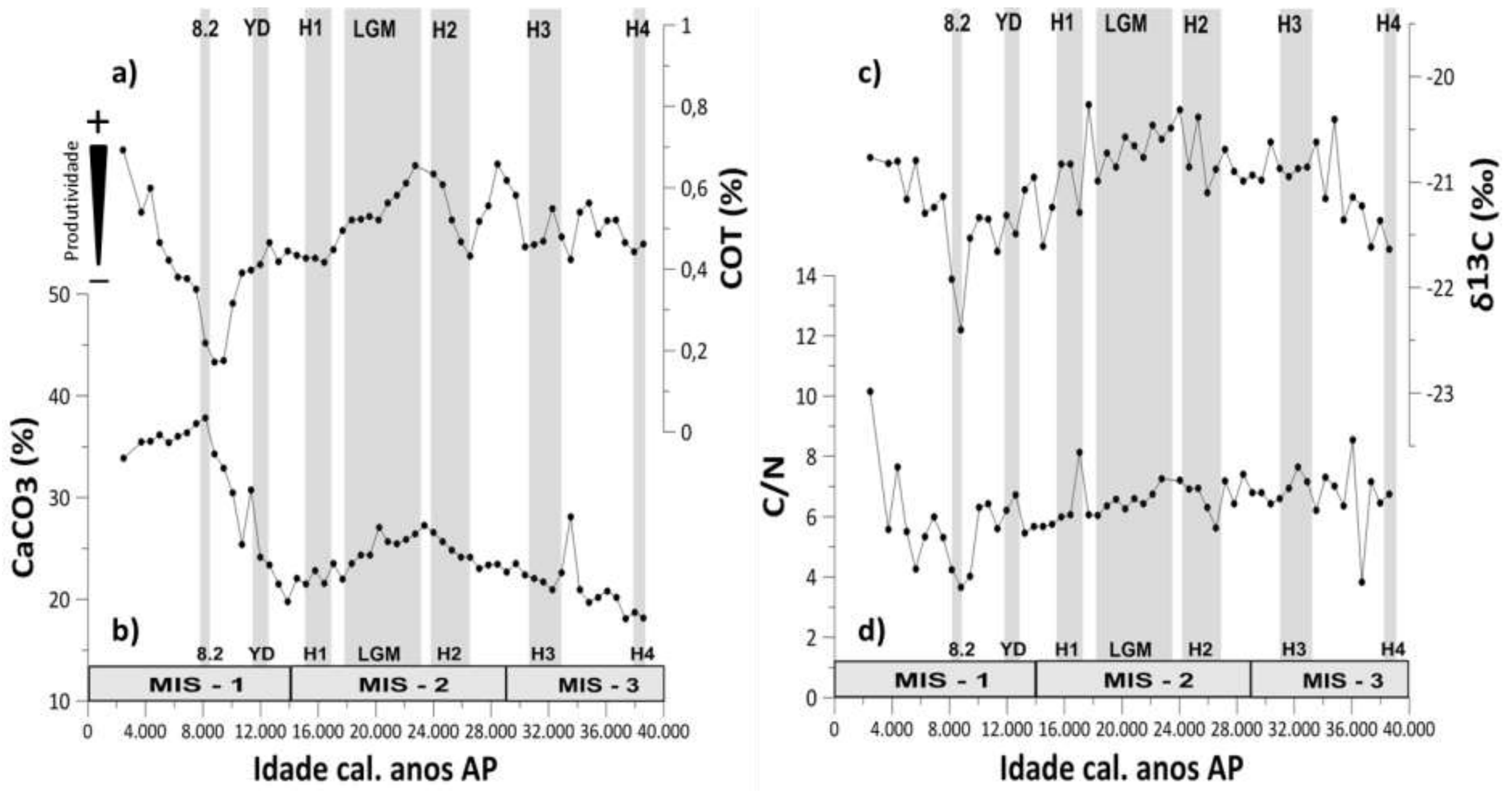

Figura 17 - Distribuição das variáveis (a) COT (\%), (b) $\mathrm{CaCO}_{3}(\%)$, (c) $\delta^{13} \mathrm{C}(\%)$ e (d) $\mathrm{C} / \mathrm{N}$ ao longo do testemunho NAP63 em função da Idade cal. (anos AP) com os respectivos eventos climáticos abruptos dos últimos 40 ka e os limites dos estágios isotópicos marinhos (MIS 1, 2 e 3) (Lisiecki e Raymo, 2005). 
Assim durante o $\mathrm{H} 1$ não foi observada relação entre os mecanismos de caráter regional e as condições redox das águas intermediárias do Atlântico SW. Desse modo, inferimos que as variações das condições redox durante $\circ \mathrm{H} 1$ são respostas predominantemente oriundas da região de formação dessas águas (Figura 3).

Contudo, antes do H1, o Último Máximo Glacial (UMG) marca o término do último período glacial, período que apresenta grandes mudanças no sistema climático da Terra, devido, principalmente, às grandes extensões de gelo e neve nas altas latitudes (Clark et al., 2009), e, por consequência, o menor nível médio do mar ( 130 m) dos últimos 40 ka (Spratt e Lisiecki, 2016).

No UMG (23 a $20 \mathrm{ka}$ ) os proxies de condições redox apresentaram tendência de aumento das condições óxicas das águas intermediárias do Atlântico SW, o que pode ser visto nas razões V/Sc, V/Cr e V/Al (Figura 14a, b e c, respectivamente). Esse aumento corrobora as conclusões de Wainer et al. (2012), os quais atribuíram aumento da formação da AIA durante o UMG à intensificação dos westerlies. Contudo, a partir desse período ( $20 \mathrm{ka}$ ) observamos tendência de diminuição da concentração de oxigênio dessas águas, o que pode ter sido ocasionado por influências regionais.

Os proxies de aporte de sedimentos terrígenos obtiveram aumento durante 0 UMG (Figura 16). Entretanto, apesar do baixo nível do mar observamos baixos valores desses proxies em nosso registro durante esse período, evidenciando a baixa influencia de aporte de sedimentos terrígenos do continente adjacente para área de estudo durante o UMG com sugerido em Mahiques et al. (2017).

Em geral o proxy de produtividade apresentou resultados maiores durante 0 UMG, como pode ser visto nos valores de COT (Figura 17a). Esse aumento corrobora outros trabalhos realizados na margem continental SE brasileira para o mesmo período (Mahiques et al., 2007; Toledo et al., 2008; Nagai et al., 2010). Os autores mencionados atribuem os altos valores desse proxy ao maior aporte de nutrientes vindos do continente adjacente devido ao baixo nível médio do mar e ao deslocamento da Corrente do Brasil para ao largo da costa brasileira (offshore). Isso também contribuiria para maior disponibilidade de nutrientes (p. e., fenômeno de 
ressurgência) na região do talude causada pelos meandros e vórtices formados pela CB.

Desse modo, a variação das condições redox das águas intermediárias do Atlântico SW durante o UMG pode estar relacionada tanto às mudanças em escala global (AMOC e circulação atmosférica), que podem influenciar na dinâmica da área de formação dessas águas, quanto às variações de escala regional, como o aporte de material terrígeno e produtividade local. Tais variações podem ter sido influenciadas pelo aumento da insolação de verão no Hemisfério Sul e por mudanças no regime de ventos, ocasionando o deslocamento da ZCIT para sul, o que, por sua vez, intensificou o SMAS, aumentando o regime de chuvas na região (Pivel et al., 2010).

O evento climático que marca o término da última deglaciação ( 18 a 11.7 ka, (ICS, 2017)), Younger Dryas (YD), cuja a causa é semelhante à proposta aos eventos Heinrich, tal como a redução da intensidade da AMOC derivada das descargas de água de degelo provindas do glaciar Laurentidea para o Atlântico Norte (Carlson et al., 2007). Durante esse evento, observam-se baixos valores de insolação de verão na latitude de $30^{\circ} \mathrm{S}$, o que pode ter enfraquecido o SMAS, diminuindo a precipitação na região de estudo (Pivel et al., 2010). Nesse período, o nível médio do mar ainda se encontrava em ascensão ( 60 abaixo do atual) (Figura 12 e e d).

Em geral, durante o YD, os proxies de condições redox sugerem um período de diminuição da concentração de oxigênio das águas intermediárias do Atlântico SW, como pode ser visto nas razões V/Cr, V/Al e Ni/Co (Figura 14b, c e e, respectivamente). Esse sinal fica mais evidente na razão V/Al. No entanto, as razões V/Sc e Mn/Al apontaram aumento na concentração de oxigênio durante esse evento, gerando, assim, contradição entre os dados (Figura 14a e d).

Porém estudos recentes apontam para um aumento da oxigenação das águas intermediárias do Atlântico SW durante o YD (Anderson et al., 2009; Hendry et al., 2012; Howe et al., 2016; Jaccard et al., 2016).

Nesse período os proxies de aporte de sedimentos terrígenos obtiveram altos valores, como observado durante o H1 (Figura 16). Em geral, o proxy de produtividade também aumentou durante esse evento climático, como pode ser visto 
nos valores de COT (Figura 17a). Este aumento corrobora o trabalho de Toledo et al. (2008), o qual analisou a produtividade da margem SE brasileira dos últimos 30 ka. Clark et al. (2012) e Hendry et al. (2012) observaram ainda que, nesse período, as águas intermediárias mostraram-se mais ricas em nutrientes.

Logo, apesar do aumento de oxigenação das águas intermediárias na sua área de formação relatada por alguns autores (Anderson et al., 2009; Hendry et al., 2012; Howe et al., 2016; Jaccard et al., 2016), os nossos dados indicam diminuição desse indicador na região do Atlântico SW. Tal fato pode ser explicado por um aumento do consumo desse oxigênio causado pelo aumento da produtividade relatado anteriormente.

Por fim, o evento 8.2 aparece como o último evento de mudança abrupta do clima em nosso estudo. Semelhante ao YD e aos eventos Heinrich, o 8.2 apresenta como causa o degelo de grande parte do glaciar Laurentidea na região do Atlântico Norte, resultando no enfraquecimento da AMOC (Barber et al., 1999; Ljung et al., 2008). Durante esse evento, os índices de insolação de verão a $30^{\circ} S$ encontravamse baixos, porém em ascensão, ao mesmo tempo em que o nível médio do mar encontrava-se alto ( 10 m abaixo do atual) (Figura 12e e d).

Segundo Kobashi et al. (2007), esse evento durou aproximadamente 150 anos, iniciando-se em $8175 \pm 30$ anos AP. Os autores chegaram a essa precisão ao analisar proxies de isótopos de metano e nitrogênio em bolhas de ar aprisionadas em testemunho de gelo da Groenlândia. Apesar desse curto período tempo e da baixa resolução dos nossos dados, observamos sinais singulares dos proxies redox, os quais nesse ínterim demonstraram aumento das condições óxicas das águas intermediárias do Atlântico SW (Figura 14).

Os proxies de aporte de sedimentos terrígenos após o evento YD tiveram decréscimo em direção ao evento 8.2. No entanto, durante o 8.2, eles apresentaram aumento (Figura 16). Posteriormente, é interessante notar que os proxies de aporte de terrígenos exibem comportamentos distintos, uma vez que o $\ln (\mathrm{Ti} / \mathrm{Ca})$ segue em decréscimo até $\sim 2.5 \mathrm{ka}$, enquanto o $\ln (\mathrm{Fe} / \mathrm{Ca})$ indica acréscimo até 2.5 ka (Figura $16 \mathrm{a}$ e b). Isso pode ser explicado pelo fato de que o Fe pode se comportar como nutriente, enquanto o Ti apresenta comportamento mais conservativo e sofre menos influência dos processos biológicos. 
Além disso, observamos grande variação do sinal do proxy de produtividade (COT), o qual apresentou diminuição durante o evento $8.2 \mathrm{e}$, em seguida, aumento até $2.5 \mathrm{ka}$, como pode ser visto na Figura 17a. Essa diminuição da produtividade corrobora o trabalho de Mahiques et al. 2007, porém esses autores observaram uma diminuição desses proxies até $\sim 5 \mathrm{ka} \mathrm{e}$, na sequência, aumento até o Presente.

Dessa maneira, o evento 8.2 apresenta-se como o episódio de mudança climática complexa, visto que, durante esse evento, contemplamos aumento das concentrações de oxigênio das águas intermediárias do Atlântico SW e baixos valores de produtividade. Assim, podemos supor que, durante esse período, houve aumento da oxigenação destas das águas durante sua formação e, devido a esse aumento, ocorreu crescimento da degradação da $\mathrm{MO}$, já que houve diminuição dos valores de СОT. Outra hipótese para esse aumento de oxigênio é a diminuição da produtividade, de modo que haveria menor consumo desse elemento, aumentando a sua disponibilidade durante o período. 


\section{Conclusões}

Nossos resultados mostram que, nos últimos $40 \mathrm{ka}$, as águas intermediárias da região do talude SE brasileiro apresentaram condições óxicas. No entanto, é possível observar variações na quantidade de oxigênio dissolvido nessas águas durante determinados eventos climáticos tanto de escala orbital quanto em escala milenar.

Em escala orbital, observamos que a insolação de verão e a variação do nível do mar, as quais são governadas pelo ciclo de precessão, foram os principais mecanismos que influenciaram as variações das condições redox dessas águas.

Em escala milenar, observamos que a variabilidade da AMOC apresenta-se como o principal mecanismo responsável pelas mudanças das condições redox dessas águas nos últimos 40 mil anos. 


\section{Referências}

AITCHISON, J.; J. EGOZCUE, J. Compositional Data Analysis: Where Are We and Where Should We Be Heading? Mathematical Geology, v. 37, n. 7, p. 829850, 2005. Disponível em: <http://link.springer.com/10.1007/s11004-005-7383-7>. .

ALGEO, T. J.; ROWE, H. Paleoceanographic applications of trace-metal concentration data. Chemical Geology, v. 324-325, p. 6-18, 2012. Elsevier B.V. Disponível em: <http://dx.doi.org/10.1016/j.chemgeo.2011.09.002>. .

ALLEY, R. B.; MAYEWSKI, P. A.; SOWERS, T.; et al. Holocene climatic instability: A prominent, widespread event 8200 yr ago. Geology, v. 25, n. 6, p. 483486, 1997.

ANDERSEN, K. K.; AZUMA, N.; BARNOLA, J. M.; et al. High-resolution record of Northern Hemisphere climate extending into the last interglacial period. Nature, v. 431, n. 7005, p. 147-151, 2004.

ANDERSON, R. F.; ALI, S.; BRADTMILLER, L. I.; et al. Wind-Driven Upwelling in the Southern Ocean and the Deglacial Rise in Atmospheric CO2. Science, v. 323, n. 5920, p. 1443-1448, 2009. Disponível em: <http://www.sciencemag.org/cgi/doi/10.1126/science.1167441>. .

ARZ, H. W.; PÄTZOLD, J.; WEFER, G. Correlated Millennial-Scale Changes in Surface Hydrography and Terrigenous Sediment Yield Inferred from Last-Glacial Marine Deposits off Northeastern Brazil. , v. 166, p. 157-166, 1998.

BARBER, D. C.; DYKE, A.; HILLAIRE-MARCEL, C.; et al. Forcing of the cold event of 8,200 years ago by catastrophic drainage of Laurentide lakes. Nature, v. 400, n. July, p. 344-348, 1999.

BARD, E.; ROSTEK, F.; TURON, J.; GENDREAU, S. Hydrological Impact of Heinrich Events in the Subtropical Northeast Atlantic. Science, v. 289, n. 5483, p. 1321-1324, $2000 . \quad$ Disponível em: <http://www.sciencemag.org/cgi/doi/10.1126/science.289.5483.1321>. .

BARKER, S.; DIZ, P.; VAUTRAVERS, M. J.; et al. Interhemispheric Atlantic seesaw response during the last deglaciation. Nature, v. 457, n. 7233, p. 10971102, 2009. Nature Publishing Group. Disponível em: <http://www.nature.com/doifinder/10.1038/nature07770>. . 
BERGER, A. L. Astronomical theory of Paleoclimates and the last glacialinterglacial cycle. Quaternary Science Reviews, v. 11, n. 5, p. 571-581, 1992.

BERGER, A.; LOUTRE, M. F. Insolation values for the climate of the last 10 million years. Quaternary Science Reviews, v. 10, n. 4, p. 297-317, 1991.

BIANCHI, G. G.; CANUEL, E. A. Chemical biomarkers in aquatic ecosystems. New Jersey: Princeton University Press, 2011.

BILÓ, T. C.; ALMEIDA, C.; CECCOPIERI, W.; BELMIRO, B.; CASTRO, M. DE. Methods for estimating the velocities of the Brazil Current in the pre-salt reservoir area off southeast Brazil ( $23 \circ S-26 \circ S$ ). , p. 1431-1446, 2014.

BOEBEL, O.; DAVIS, R. E.; OLLITRAULT, M.; et al. The intermediate depth circulation of the western South Atlantic. Geophysical Research Letters, v. 26, n. 21, p. 3329-3332, 1999.

BÖHM, E.; LIPPOLD, J.; GUTJAHR, M.; et al. Strong and deep Atlantic meridional overturning circulation during the last glacial cycle. Nature, v. 517, n. 7532, p. 73-76, $2015 . \quad$ Disponível em: <http://www.nature.com/doifinder/10.1038/nature14059>. .

BROECKER, W. S.; DENTON, G. H.; EDWARDS, R. L.; et al. Putting the Younger Dryas cold event into context. Quaternary Science Reviews, v. 29, n. 910, p. 1078-1081, 2010. Elsevier Ltd. Disponível em: <http://dx.doi.org/10.1016/j.quascirev.2010.02.019>. .

BRUMMER, G. J. A.; VAN EIJDEN, A. J. M. "Blue-ocean" paleoproductivity estimates from pelagic carbonate mass accumulation rates. Marine Micropaleontology, v. 19, n. 1-2, p. 99-117, 1992. Elsevier. Disponível em: <http://www.sciencedirect.com/science/article/pii/037783989290023D>. Acesso em: 7/10/2017.

BURCKEL, P.; WAELBROECK, C.; GHERARDI, J. M.; et al. Atlantic Ocean circulation changes preceded millennial tropical South America rainfall events during the last glacial. , p. 411-418, 2015.

BURONE, L.; ORTEGA, L.; FRANCO-FRAGUAS, P.; et al. A multiproxy study between the Río de la Plata and the adjacent South-western Atlantic inner shelf to assess the sediment footprint of river vs. marineinfluence. Continental Shelf 
Research, v. 55, p. 141-154, 2013.

BUSO, J. A. A. Dinâmica ambiental holocênica (vegetação, clima e nível relativo marinho) baseada em estudos interdisciplinares de alta resolução, no litoral norte do estado do Espírito Santo, 2010. Universidade de São Paulo.

CACHO, I.; GRIMALT, J. O.; CANALS, M.; et al. Variability of the western Mediterranean Sea surface temperature during the last 25,000 years and its connection with the Northern Hemisphere climatic changes. Paleoceanography, v. 16, n. 1, p. 40-52, 2001.

CALVERT, S. E.; PEDERSEN, T. F. Elemental Proxies for Palaeoclimatic and Palaeoceanographic Variability in Marine Sediments : Interpretation and Application. , v. 1, n. 7, p. 567-644, 2007.

CAMPOS, M. C.; CHIESSI, C. M.; VOIGT, I.; et al. $\delta 13 \mathrm{C}$ decreases in the upper western South Atlantic during Heinrich Stadials 3 and 2. Climate of the Past, v. 13, p. 345-358, 2017.

CARLSON, A. E. PALEOClimAte | The Younger Dryas Climate Event. $2^{\circ}$ ed. Elsevier B.V., 2013.

CARLSON, A. E.; CLARK, P. U.; HALEY, B. A.; et al. Geochemical proxies of North American freshwater routing during the Younger Dryas cold event. Proceedings of the National Academy of Sciences, v. 104, n. 16, p. 6556-6561, 2007. Disponível em: <http://www.pnas.org/cgi/doi/10.1073/pnas.0611313104>. .

CHANG, H. K.; ASSINE, M. L.; CORREA, F. S.; et al. Sistemas petroliferos e modelos de acumulacao de hidrocarbonetos na Bacia de Santos. Revista Brasileira de Geociências, v. 38, n. 2, p. 29-46, 2008. Disponível em: <http://ojs.c3sl.ufpr.br/ojs2/index.php/rbg/article/view/13017/8801>. .

CHENG, H.; FLEITMANN, D.; EDWARDS, R. L.; et al. Timing and structure of the 8.2. kyr B.P. event inferred from $\delta 180$ records of stalagmites from China, Oman, and Brazil. Geology, v. 37, n. 11, p. 1007-1010, 2009.

CHIESSI, C. M.; MULITZA, S.; GROENEVELD, J.; et al. Variability of the Brazil Current during the late Holocene. Palaeogeography, Palaeoclimatology, Palaeoecology, v. 415, p. 28-36, 2014. Elsevier B.V. Disponível em: <http://dx.doi.org/10.1016/j.palaeo.2013.12.005>. . 
CHIESSI, C. M.; MULITZA, S.; MOLLENHAUER, G.; et al. Thermal evolution of the western South Atlantic and the adjacent continent during Termination 1. , p. 915-929, 2015.

CLARK, P. U.; DYKE, A. S.; SHAKUN, J. D.; et al. The Last Glacial Maximum. Science, v. 325, n. 2009, p. 710-715, 2009.

CLARK, P. U.; SHAKUN, J. D.; BAKER, P. A.; et al. Global climate evolution during the last deglaciation. Proceedings of the National Academy of Sciences of the United States of America, v. 109, n. 19, p. 1134-1142, 2012. Disponível em: <http://www.pnas.org/content/109/19/E1134.short>. .

COSTA, K. B.; CABARCOS, E.; SANTAROSA, A. C. A.; BATTAGLIN, B. B. F.; TOLEDO, F. A. L. A multiproxy approach to the climate and marine productivity variations along MIS 5 in SE Brazil: A comparison between major components of calcareous nannofossil assemblages and geochemical records. Palaeogeography, Palaeoclimatology, Palaeoecology, v. 449, p. 275-288, 2016. Elsevier B.V. Disponível em: <http://dx.doi.org/10.1016/j.palaeo.2016.02.032>. .

CRUZ, F. W.; BURNS, S. J.; KARMANN, I.; et al. Insolation-driven changes in atmospheric circulation over the past 116,000 years in subtropical Brazil. Nature, v. 434, p. 63-66, 2005. Disponível em: <http://doi.wiley.com/10.1029/2000JB000050>. .

CRUZ, F. W.; BURNS, S. J.; KARMANN, I.; SHARP, W. D.; VUILLE, M. Reconstruction of regional atmospheric circulation features during the late Pleistocene in subtropical Brazil from oxygen isotope composition of speleothems. Earth and Planetary Science Letters, v. 248, n. 1-2, p. 494-506, 2006.

CRUZ, F. W.; VUILLE, M.; BURNS, S. J.; et al. Orbitally driven east-west antiphasing of South American precipitation. Nature Geoscience, v. 2, n. 3, p. $210-$ 214, 2009. Nature Publishing Group. Disponível em: <http://www.nature.com/doifinder/10.1038/ngeo444>. .

DOUG, S. M.; CUSACK, S.; COLMAN, A. W.; et al. Improved Surface Temperature Prediction for the Coming Decade from a Global Climate Model. , v. 796, n. August, p. 796-800, 2007.

EGEOTRACE. eGEOTRACES Electronic Atlas. Disponível em: <http://www.egeotraces.org/sections/GA02_OXYGEN_D_CONC.html>. Acesso em: 
18/10/2017.

ESSINGTON, M. E. Soil and water chemistry: an integrative approach. CRC press, 2015.

FIGUEIREDO, A. G.; TESSLER, M. G. Topografia do Talude. Programa de Avaliação do Potencial Sustentável de Recursos Vivos na Zona Econômica Exclusiva - REVIZEE. Relatório . Subcomitê Regional Sul. Área de Oceanografia Geológica. p.26-36, 1999.

FISCHER, G.; WEFER, G. Use of Proxies in Paleoceanography. Bremen, 1999.

FRY, B. Stable isotope ecology. Berlim: Springer, 2006.

GARREAUD, R. D.; VUILLE, M.; COMPAGNUCCI, R.; MARENGO, J. Present-day South American climate. Palaeogeography, Palaeoclimatology, Palaeoecology, v. 281, n. 3-4, p. 180-195, 2009. Elsevier B.V. Disponível em: <http://dx.doi.org/10.1016/j.palaeo.2007.10.032>. .

GARZOLI, S. L.; MATANO, R. The South Atlantic and the Atlantic Meridional Overturning Circulation. Deep Sea Research Part II: Topical Studies in Oceanography, v. 58, n. 17-18, p. 1837-1847, 2011. Elsevier. Disponível em: <http://dx.doi.org/10.1016/j.dsr2.2010.10.063>. .

GOVIN, A.; HOLZWARTH, U.; HESLOP, D.; et al. Distribution of major elements in Atlantic surface sediments $\left(36^{\circ} \mathrm{N}-49^{\circ} \mathrm{S}\right)$ : Imprint of terrigenous input and continental weathering. Geochemistry, Geophysics, Geosystems, v. 13, n. 1, p. n/a-n/a, 2012. Disponível em: <http://doi.wiley.com/10.1029/2011GC003785>. .

GREEN, B.; MARSHALL, J. Coupling of trade winds with ocean circulation damps itcz shifts. Journal of Climate, v. 30, n. 12, p. 4395-4411, 2017.

HARRISON, S. P.; SANCHEZ GOÑI, M. F. Global patterns of vegetation response to millennial-scale variability and rapid climate change during the last glacial period. Quaternary Science Reviews, v. 29, n. 21-22, p. 2957-2980, 2010. Elsevier Ltd. Disponível em: <http://dx.doi.org/10.1016/j.quascirev.2010.07.016>. .

HEMMING, S. R. Heinrich events: Massive late Pleistocene ditritus layers of the North Atlanitc and their global cliamate imprint. Reviews of Geophysics, v. 42, n. 2003, p. 1-43, 2004. 
HENDRY, K. R.; ROBINSON, L. F.; MEREDITH, M. P.; et al. Abrupt changes in high-latitude nutrient supply to the Atlantic during the last glacial cycle. Geology, v. 40, n. 2, p. 123-126, 2012.

HOWE, J. N. W.; PIOTROWSKI, A. M.; OPPO, D. W.; et al. Antarctic intermediate water circulation in the South Atlantic over the past 25,000 years. Paleoceanography, v. 31, n. 10, p. 1302-1314, 2016. Disponível em: <http://doi.wiley.com/10.1002/2016PA002975>. .

HUANG, K.; OPPO, D. W.; CURRY, W. B. Decreased influence of Antarctic intermediate water in the tropical Atlantic during North Atlantic cold events. Earth and Planetary Science Letters, v. 389, p. 200-208, 2014. Elsevier B.V. Disponível em: <http://dx.doi.org/10.1016/j.epsl.2013.12.037>. .

ICS. International Comission on Stratigraphy. Disponível em: <http://www.stratigraphy.org/lCSchart/ChronostratChart2017-02.pdf>. Acesso em: 9/10/2017.

JACCARD, S. L.; GALBRAITH, E. D.; MARTÍNEZ-GARCIÁ, A.; ANDERSON, R. F. Covariation of deep Southern Ocean oxygenation and atmospheric CO2through the last ice age. Nature, v. 530, n. 7589, p. 207-210, 2016. Nature Publishing Group. Disponível em: <http://dx.doi.org/10.1038/nature16514>. .

JAESCHKE, A.; RÜHLEMANN, C.; ARZ, H.; HEIL, G.; LOHMANN, G. Coupling of millennial-scale changes in sea surface temperature and precipitation off northeastern Brazil with high-latitude climate shifts during the last glacial period. , v. 22, p. 1-10, 2007.

JONES, B.; MANNING, D. A. C. A comparison and correlation of different geochemical indices used for the interpretation of depositional environments in ancient mudstones. Chemical Geology, v. 111, n. 1-4, p. 111-129, 1994. Disponível em: <http://dx.doi.org/10.1016/0009-2541(94)90085-X>. .

JONKERS, L.; ZAHN, R.; THOMAS, A.; et al. Deep circulation changes in the central South Atlantic during the past 145 kyrs reflected in a combined $231 \mathrm{~Pa} / 230$ Th , Neodymium isotope and benthic $\delta 13 \mathrm{C}$ record. , v. 419, p. 14-21, 2015.

JOUZEL, J.; MASSON-DELMOTTE, V.; CATTANI, O.; et al. Orbital and Millennial Antarctic Climate Variability over the Past 800,000 Years. Science, v. 317, 
n. 5839, p. 793-796, $2007 . \quad$ Disponível em: <http://www.sciencemag.org/cgi/doi/10.1126/science.1141038>. .

KIMURA, H.; WATANABE, Y. Oceanic anoxia at the Precambrian-Cambrian boundary. Geology, v. 29, n. 11, p. 995-998, 2001.

KOBASHI, T.; SEVERINGHAUS, J. P.; BROOK, E. J.; BARNOLA, J. M.; GRACHEV, A. M. Precise timing and characterization of abrupt climate change 8200 years ago from air trapped in polar ice. Quaternary Science Reviews, v. 26, n. 910, p. 1212-1222, 2007.

LISIECKI, L. E.; RAYMO, M. E. A Pliocene-Pleistocene stack of 57 globally distributed benthic $\delta 180$ records. Paleoceanography, v. 20, n. 1, p. 1-17, 2005.

LJUNG, K.; BJÖRCK, S.; RENSSEN, H.; HAMMARLUND, D. of the Past South Atlantic island record reveals a South Atlantic response to the. Climate of the Past, v. 4, p. 35-45, 2008.

LUND, D. C.; TESSIN, A. C.; HOFFMAN, J. L.; SCHMITTNER, A. Southwest Atlantic water mass evolution during the last deglaciation. , , n. Figure 1, p. 477-494, 2015.

LYNCH-STIEGLITZ, J. The Atlantic Meridional Overturning Circulation and Abrupt Climate Change. Annual Review of Marine Science, v. 9, n. 1, p. 83-104, 2017. Disponível em: <http://www.annualreviews.org/doi/10.1146/annurev-marine010816-060415>. .

MAHIQUES, M. M. DE; HANEBUTH, T. J. J.; NAGAI, R. H.; et al. Inorganic and organic geochemical fingerprinting of sediment sources and ocean circulation on a complex continental margin (São Paulo Bight, Brazil). , p. 209-222, 2017.

MAHIQUES, M. M.; FUKUMOTO, M. M.; SILVEIRA, I. C. A.; et al. Sedimentary changes on the Southeastern Brazilian upper slope during the last 35,000 years. Anais da Academia Brasileira de Ciencias, v. 79, n. 1, p. 171-181, 2007.

MAHIQUES, M. M.; MISHIMA, Y.; RODRIGUES, M. Characteristics of the sedimentary organic matter on the inner and middle continental shelf between Guanabara Bay and Sao Francisco do Sul, southeastern Brazilian margin. Continental Shelf Research, v. 19, n. 6, p. 775-798, 1999. 
MAHIQUES, M. M.; DA SILVEIRA, I. C. A.; DE MELLO E SOUSA, S. H.; RODRIGUES, M. Post-LGM sedimentation on the outer shelf-upper slope of the northernmost part of the S??o Paulo Bight, southeastern Brazil. Marine Geology, v. 181, n. 4, p. 387-400, 2002.

MAHIQUES, M. M.; SOUSA, S. H. M.; BURONE, L.; et al. Radiocarbon geochronology of the sediments of the São Paulo Bight (southern Brazilian upper margin). Anais da Academia Brasileira de Ciencias, v. 83, n. 3, p. 817-834, 2011.

MAHIQUES, M. M.; TASSINARI, C. C. G.; MARCOLINI, S.; et al. Nd and Pb isotope signatures on the Southeastern South American upper margin: Implications for sediment transport and source rocks. Marine Geology, v. 250, n. 1-2, p. 51-63, 2008.

MAHIQUES, M. M.; TESSLER, M. G.; MARIA CIOTTI, A.; et al. Hydrodynamically driven patterns of recent sedimentation in the shelf and upper slope off Southeast Brazil. Continental Shelf Research, v. 24, n. 15, p. 1685-1697, 2004.

MAKOU, M. C.; OPPO, D. W.; CURRY, W. B. South Atlantic intermediate water mass geometry for the last glacial maximum from foraminiferal $\mathrm{Cd} / \mathrm{Ca}$. , v. 25, n. July, p. 1-7, 2010.

MARTINEZ-RUIZ, F.; KASTNER, M.; GALLEGO-TORRES, D.; et al. Paleoclimate and paleoceanography over the past 20,000yr in the Mediterranean Sea Basins as indicated by sediment elemental proxies. Quaternary Science Reviews, v. 107, p. 25-46, 2015.

MASLIN, M.; SHACKLETON, N.; PFLAUMANN, U. Surface water temperature, salinity, and density changes in the northeast Atlantic during the last 45, 000 years: Heinrich events, deep water formation, and climatic rebounds. Paleoceanography, v. 10, n. 3, p. 527-544, 1995.

MEYERS, P. A. Organic geochemical proxies of paleoceanographic, paleolimnologic, and paleoclimatic processes. Org. Geochem., v. 27, p. 213-250, 1997.

MIDDAG, R.; VAN HULTEN, M. M. P.; VAN AKEN, H. M.; et al. Dissolved aluminium in the ocean conveyor of the West Atlantic Ocean: Effects of the biological 
cycle, scavenging, sediment resuspension and hydrography. Marine Chemistry, v. 177, p. 69-86, 2015. Elsevier B.V. Disponível em: <http://dx.doi.org/10.1016/j.marchem.2015.02.015>. .

MONNIN, E.; INDERMÜHLE, A.; DÄLLENBACH, A.; et al. Atmospheric CO2 Concentrations over the Last Glacial Termination. Science, v. 291, n. 5501, p. 112114 , 2001.

Disponível

em: <http://www.sciencemag.org/cgi/doi/10.1126/science.291.5501.112>. .

MORENO, A.; CACHO, I.; CANALS, M. Millennial-scale variability in the productivity signal from the Alboran Sea record, Western Mediterranean Sea., v. 211, p. 205-219, 2004.

MORENO, P. I.; KAPLAN, M. R.; FRANÇOIS, J. P.; et al. Renewed glacial activity during the Antarctic cold reversal and persistence of cold conditions until 11.5 ka in southwestern Patagonia. Geology, v. 37, n. 4, p. 375-378, 2009.

NAGAI, R.; BÍCEGO, M. C.; MAHIQUES, M. M. DE. PALEOPRODUCTIVITY CHANGES DURING THE LATE QUATERNARY IN THE SOUTHEASTERN. , v. 58, p. 31-41, 2010.

NAGAI, R. H.; SOUSA, S. H. M.; BURONE, L.; MAHIQUES, M. M. Paleoproductivity changes during the Holocene in the inner shelf of Cabo Frio, southeastern Brazilian continental margin: Benthic foraminifera and sedimentological proxies. Quaternary International, v. 206, n. 1-2, p. 62-71, 2009.

ODO, M. Y. K. O MÉTODO DO RADIOCARBONO: PRINCÍPIOS, TÉCNICAS, APLICAÇÕES E CARACTERÍSTICAS DE UM CONTADOR PROPORCIONAL DE 80 mL, 2000. Universidade de São Paulo.

PATTAN, J. N.; PEARCE, N. J. G. Bottom water oxygenation history in southeastern Arabian Sea during the past $140 \mathrm{ka}$ : Results from redox-sensitive elements. Palaeogeography, Palaeoclimatology, Palaeoecology, v. 280, n. 3-4, p. 2009. $396-405, \quad$ Elsevier B.V. Disponível em: <http://dx.doi.org/10.1016/j.palaeo.2009.06.027>. .

PAYTAN, A. Ocean Paleoproductivity. In: V. Gornitz (Org.); Encyclopedia of Paleoclimatology and Ancient Environments. Encycloped ed., 2006.

PERRETTI, A. R.; AMIBRIZZI, T.; JACOBI, P. R.; DUTRA, L. M. M. Evolução 
climática e oceanográfica no Brasil e no oceano adjacente durante o Pleistoceno Superior e o Holoceno: Uma atualização. Annablume ed. São Paulo, 2015.

PETERSON, L. C.; HAUG, G. H.; HUGHEN, K. A.; RÖHL, U. Rapid Changes in the Hydrologic Cycle of the Tropical Atlantic During the Last Glacial. Science, v. 290, n. 5498, p. 1947-1951, 2000. Disponível em: <http://www.sciencemag.org/content/290/5498/1947.abstract\%5Cnhttp://www.scienc emag.org/cgi/doi/10.1126/science.290.5498.1947>. .

PIERZYNSKI, G. M.; VANCE, G. F.; SIMS, J. T. Soils and environmental quality. CRC press, 2005.

PIVEL, M. A. G.; SAntarosa, A. C. A.; TOledo, F. A. L.; COStA, K. B. The Holocene onset in the southwestern South Atlantic. Palaeogeography, Palaeoclimatology, Palaeoecology, v. 374, p. 164-172, 2013. Elsevier B.V. Disponível em: <http://dx.doi.org/10.1016/j.palaeo.2013.01.014>. .

PIVEL, M. G.; TOLEDO, F. A. L.; COSTA, K. B. Foraminiferal record of changes in summer monsoon precipitation at the southeastern Brazilian continental margin since the Last Glacial Maximum. Revista Brasileira de Paleontologia, v. 13, n. 2, p. 79-88, 2010.

POWELL, W. G.; JOHNSTON, P. A.; COLLOM, C. J. Geochemical evidence for oxygenated bottom waters during deposition of fossiliferous strata of the Burgess Shale Formation. , v. 201, 2003.

PRADO, L. F.; WAINER, I.; CHIESSI, C. M.; LEDRU, M. P.; TURCQ, B. A mid-Holocene climate reconstruction for eastern South America. , p. 2117-2133, 2013.

RASMUSSEN, S. O.; ANDERSEN, K. K.; SVENSSON, A. M.; et al. A new Greenland ice core chronology for the last glacial termination. Journal of Geophysical Research, v. 111, n. D6, p. D06102, 2006. Disponível em: <http://doi.wiley.com/10.1029/2005JD006079>. Acesso em: 4/11/2017.

REIMER, P.; BARD, E.; BAYLISS, A.; et al. IntCal13 and Marine13 Radiocarbon Age Calibration Curves 0-50,000 Years cal BP. Radiocarbon, v. 55, n. 4,

p. 1869-1887, 2013. Disponível em: 
<http://researchcommons.waikato.ac.nz/handle/10289/8955\%5Cnhttps://journals.uair .arizona.edu/index.php/radiocarbon/article/view/16947>. .

ROHLING, E. J.; PÄLIKE, H. Centennial-scale climate cooling with a sudden cold event around 8,200 years ago. Nature, v. 434, n. April, p. 975-979, 2005.

RUDDIMAN, W. F. Earth's Climate: Past and Future. 2008.

RÜHLEMANN, C.; MÜLLER, P. J.; SCHNEIDER, R. R. Organic carbon and carbonate as paleoproductivity proxies: examples from high and low productivity areas of the Tropical Atlantic. Use of proxies in Paleoceanography: Examples from the South Atlantic. p.315-344, 1999. Berlim.

SALVATERRA, A. DA S.; SANTOS, R. F. DOS; SALAROLI, A. B.; FIGUEIRA, R. C. L.; MAHIQUES, M. M. DE. Evidence of an Marine Isotope Stage 3 transgression at the Baixada Santista, south-eastern Brazilian coast. Brazilian Journal of Geology, v. 47, n. 4, p. 693-702, 2017. Disponível em: $<$ http://www.scielo.br/scielo.php?script=sci_arttext\&pid=S231748892017000400693\&lng=en\&tlng=en>. .

SCHEEL-YBERT, R. CONSIDERAÇÕES SOBRE O MÉTODO DE DATAÇÃO PELO CARBONO-14 E ALGUNS COMENTÁRIOS SOBRE A DATAÇÃO DE SAMBAQUIS. Revista do Museu de Arqueologia e Etnologia, São Paulo., v. 9, p. 297-301, 1999.

SCHMID, C.; SIEDLER, G.; ZENK, W. Dynamics of Intermediate Water Circulation in the Subtropical South Atlantic. Journal of Physical Oceanography, v. 30, n. 12, p. 3191-3211, 2000. Disponível em: <http://dx.doi.org/10.1175/15200485(2000)030\%3C3191:DOIWCI\%3E2.0.CO;2>. .

SCHMITTNER, A.; LUND, D. C. Early deglacial Atlantic overturning decline and its role in atmospheric CO 2 rise inferred from carbon isotopes ( $\delta 13 \mathrm{C}$ )., p. 135-152, 2015.

SHAKUN, J. D.; CARLSON, A. E. A global perspective on Last Glacial Maximum to Holocene climate change. Quaternary Science Reviews, v. 29, n. 1516, p. 1801-1816, 2010. Elsevier Ltd. Disponível em: <http://dx.doi.org/10.1016/j.quascirev.2010.03.016>. .

SIDDALL, M.; ROHLING, E. J.; THOMPSON, W. G.; WAELBROECK, C. 
Marine Isotope Stage 3 sea level fluctuations: data synthesis and new outlook. Reviews of Geophysics, v. 46, n. RG4003, p. 1-29, 2008. Disponível em: <http://www.agu.org/pubs/crossref/2008/2007RG000226.shtml>. .

SILLIMAN, J. E.; MEYERS, P. A.; BOURBONNIERE, R. A. Record of postglacial organic matter delivery and burial in sediments of Lake Ontario. Organic Geochemistry, v. 24, n. 4, p. 463-472, 1996.

SILVA, A. L. C. DA; SILVA, M. A. M. DA; GAMBÔA, L. A. P.; RODRIGUES, A. R. Sedimentary architecture and depositional evolution of the Quaternary coastal plain of Maricá, Rio de Janeiro, Brazil. Brazilian Journal of Geology, v. 44, n. 2, p. 191-206, $2014 . \quad$ Disponível em: $<$ http://ppegeo.igc.usp.br/scielo.php?script=sci_arttext\&pid=S2317$48892014000200002 \& \operatorname{lng}=p t \& n r m=i s o \&$ tIng=pt $>$. .

SILVEIRA, I. C. A.; CALADO, L.; CASTRO, B. M.; et al. On the baroclinic structure of the Brazil Current-Intermediate Western Boundary Current system at $22^{\circ}-3^{\circ}$ S. Geophysical Research Letters, v. 31, n. 14, p. 1-5, 2004.

SILVEIRA, I. C. A.; CASTRO, B. M.; SOUTELINO, R. G. A dinâmica vital das correntes marinhas. Oceanos. Scientific American Brasil, 2009.

SILVEIRA, I. C. A. DA; SCHMIDT, A. C. K.; CAMPOS, E. J. D.; GODOI, S. S. DE; IKEDA, Y. A corrente do Brasil ao largo da costa leste brasileira. Brazilian Journal of Oceanography, v. 48, n. 2, p. 171-183, 2000.

SILVEIRA, I. C. A.; NETO, H. F.; COSTA, T. P.; et al. Caracterição da Oceanografia Física do Talude Continental e Região Oceânica da Bacia de Campos. Ambiente Bentônico, Vol 3, p. 259-306, 2015. Disponível em: <http://linkinghub.elsevier.com/retrieve/pii/B9788535272635500096>. .

SOUTELINO, R. G.; GANGOPADHYAY, A.; DA SILVEIRA, I. C. A. The roles of vertical shear and topography on the eddy formation near the site of origin of the Brazil Current. Continental Shelf Research, v. 70, p. 46-60, 2013. Elsevier. Disponível em: <http://dx.doi.org/10.1016/j.csr.2013.10.001>. .

SPARKS, D. L. Environmental soil chemistry. Academic press, 2003.

SPRATT, R. M.; LISIECKI, L. E. A Late Pleistocene sea level stack. Climate of the Past, v. 12, n. 4, p. 1079-1092, 2016. 
STOCKER, T. F.; JOHNSEN, S. J. A minimum thermodynamic model for the bipolar seesaw. Paleoceanography, v. 18, n. 4, p. 1-9, 2003.

STRAMMA, L.; ENGLAND, M. On the water masses and mean circulation of the South Atlantic Ocean. Journal of Geophysical Research, v. 104, n. C9, p. 20863, 1999.

STRÍKIS, N. M.; CHIESSI, C. M.; CRUZ, F. W.; et al. Timing and structure of Mega-SACZ events during Heinrich Stadial 1. Geophysical Research Letters, v. 42, n. 13, p. 5477-5484, 2015.

TOLEDO, F. A. L.; COSTA, K. B.; PIVEL, M. A. G.; CAMPOS, E. J. D. Tracing past circulation changes in the western South Atlantic based on planktonic foraminifera. Revista Brasileira de Paleontologia, v. 11, n. 3, p. 169-178, 2008.

TOMCZAK, M.; GODFREY, J. S. Regional Oceanography: an Introduction. $2^{\circ}$ ed. Daya Publishing House, Delhi, 2003.

TRIBOVILLARD, N.; ALGEO, T. J.; LYONS, T.; RIBOULLEAU, A. Trace metals as paleoredox and paleoproductivity proxies: An update. CHEMICAL GEOLOGY, v. 232, n. 1-2, p. 12-32, 2006.

USEPA. Method 3052. ReVision, , n. December, p. 1-20, 1996.

USEPA. METHOD 6010C. ReVision, v. 1, n. November, p. 1-30, 2007.

VALDÉS, J. Evaluación de metales redox-sensitivos como proxies de paleoxigenación en un ambiente marino hipóxico del norte de Chile. Revista Chilena de Historia Natural, v. 77, n. 1, p. 121-138, 2004.

VERA, C.; HIGGINS, W.; AMADOR, J.; et al. Toward a unified view of the American monsoon systems. Journal of Climate, v. 19, n. 20, p. 4977-5000, 2006.

VILLALBA, R.; GROSJEAN, M.; KIEFER, T. Long-term multi-proxy climate reconstructions and dynamics in South America (LOTRED-SA): State of the art and perspectives. Palaeogeography, Palaeoclimatology, Palaeoecology, v. 281, n. 34, p. 175-179, 2009. Elsevier B.V. Disponível em: <http://dx.doi.org/10.1016/j.palaeo.2009.08.007>. .

VOLAT, J.-L.; PASTOURET, L.; VERGNAUD-GRAZZINI, C. Dissolution and carbonate fluctuations in Pleistocene deep-sea cores: A review. Marine Geology, v. 
34, n. 1-2, p. 1-28, 1980. Elsevier. Disponível em: <http://www.sciencedirect.com/science/article/pii/0025322780901383>. Acesso em: $7 / 10 / 2017$.

WAINER, I.; GOES, M.; MURPHY, L. N.; BRADY, E. Changes in the intermediate water mass formation rates in the global ocean for the Last Glacial Maximum, mid-Holocene and pre-industrial climates. Paleoceanography, v. 27, n. 3, p. PA3101--, 2012. Disponível em: <http://dx.doi.org/10.1029/2012PA002290>. .

WANG, X.; AULER, A. S.; EDWARDS, R. L.; et al. Interhemispheric antiphasing of rainfall during the last glacial period. Quaternary Science Reviews, v. 25, n. 23-24, p. 3391-3403, 2006.

WELDEAB, S.; SCHNEIDER, R. R.; KÖLLING, M. Deglacial sea surface temperature and salinity increase in the western tropical Atlantic in synchrony with high latitude climate instabilities. Earth and Planetary Science Letters, v. 241, n. 34, p. 699-706, 2006.

WRIGHT, J. D. Global Climate Change in Marine Stable Isotope Records. Quaternary Geochronology: Methods and Applications, p. 427-433, 2013.

ZACHOS, J.; PAGANI, M.; SLOAN, L.; THOMAS, E.; BILLUPS, K. Trends , Rhythms , and Aberrations in Global Climate 65 Ma to Present. Science, v. 292, n. 5517, p. 686-693, 2001.

ZEMBRUSCKI, S. G. Geomorfologia da margem continental sul brasileira e das bacias oceânicas adjacentes. Reconhecimento global da margem continental brasileira geomorfologia da margem continental brasileira e das áreas oceânicas adjacentes (Relatório final). v. 7, p.129-177, 1979. Rio de Janeiro: Petrobrás.

ZHANG, Y.; CHIESSI, C. M.; MULITZA, S.; et al. Origin of increased terrigenous supply to the NE South American continental margin during Heinrich Stadial 1 and the Younger Dryas. Earth and Planetary Science Letters, v. 432, p. 493-500, 2015. Elsevier B.V. Disponível em: <http://dx.doi.org/10.1016/j.epsl.2015.09.054>. .

ZHOU, J.; WU, Y.; ZHANG, J.; KANG, Q.; LIU, Z. Carbon and nitrogen composition and stable isotope as potential indicators of source and fate of organic 
matter in the salt marsh of the Changjiang Estuary, China. Chemosphere, v. 65, n. 2. p. 310-317, 2006. Pergamon. Disponível em: <http://www.sciencedirect.com/science/article/pii/S0045653506002177>. Acesso em: 7/10/2017. 


\section{Anexo}

Tabela 1 - Resultados

\begin{tabular}{|c|c|c|c|c|c|c|c|c|c|c|c|c|c|}
\hline Prof. (cm) & Idade cal. anos AP & $\mathrm{Ca}$ & Sc & $\mathrm{Ti}$ & v & $\mathrm{Cr}$ & Mn & $\mathrm{Fe}$ & Co & $\mathbf{N i}$ & Al & $\mathrm{Ti} / \mathrm{Ca}$ & $\mathrm{Fe} / \mathrm{Ca}$ \\
\hline 2 & 2463 & 77183 & 13,40 & 4634 & 61,73 & 42,58 & 392 & 30137 & 11,30 & 21,70 & 48737 & 0,060 & 0,390 \\
\hline 4 & 3731 & 70950 & 9,89 & 4569 & 48,72 & 35,47 & 303 & 20300 & 9,85 & 14,01 & 42854 & 0,064 & 0,286 \\
\hline 6 & 4365 & 74816 & 11,09 & 4731 & 53,04 & 40,09 & 313 & 25171 & 9,16 & 19,53 & 45714 & 0,063 & 0,336 \\
\hline 8 & 4999 & 67796 & 9,72 & 4854 & 50,02 & 37,50 & 289 & 21853 & 6,10 & 11,12 & 43090 & 0,072 & 0,322 \\
\hline 10 & 5633 & 72176 & 10,23 & 5061 & 53,01 & 40,70 & 307 & 23342 & 6,14 & 12,34 & 44379 & 0,070 & 0,323 \\
\hline 12 & 6267 & 68013 & 9,12 & 4943 & 45,39 & 34,96 & 277 & 18958 & 8,62 & 10,90 & 41797 & 0,073 & 0,279 \\
\hline 14 & 6900 & 77015 & 9,53 & 5269 & 49,03 & 37,27 & 293 & 20533 & 6,20 & 10,58 & 44131 & 0,068 & 0,267 \\
\hline 16 & 7534 & 64476 & 8,92 & 4914 & 45,41 & 33,91 & 262 & 17388 & 5,33 & 9,46 & 39603 & 0,076 & 0,270 \\
\hline 18 & 8168 & 57538 & 8,00 & 5078 & 41,34 & 41,52 & 701 & 15760 & 7,69 & 7,20 & 37208 & 0,088 & 0,274 \\
\hline 20 & 8802 & 61599 & 7,62 & 4835 & 40,20 & 31,38 & 234 & 15175 & 4,83 & 6,71 & 36306 & 0,078 & 0,246 \\
\hline 22 & 9436 & 57548 & 8,37 & 5133 & 43,89 & 33,22 & 251 & 16376 & 5,19 & 7,57 & 38637 & 0,089 & 0,285 \\
\hline 24 & 10070 & 50381 & 9,66 & 5896 & 51,52 & 35,52 & 271 & 18581 & 6,62 & 8,00 & 40846 & 0,117 & 0,369 \\
\hline 26 & 10704 & 52673 & 11,30 & 5373 & 58,45 & 40,46 & 293 & 23438 & 6,88 & 9,40 & 46590 & 0,102 & 0,445 \\
\hline 28 & 11338 & 44692 & 8,99 & 5048 & 46,88 & 33,59 & 250 & 18773 & 6,16 & 7,52 & 39284 & 0,113 & 0,420 \\
\hline 30 & 11972 & 54467 & 15,63 & 5561 & 79,33 & 54,71 & 470 & 32486 & 9,37 & 15,19 & 53644 & 0,102 & 0,596 \\
\hline 32 & 12606 & 37807 & 9,77 & 5215 & 50,67 & 37,38 & 247 & 20504 & 6,40 & 8,55 & 41293 & 0,138 & 0,542 \\
\hline 34 & 13240 & 43949 & 12,51 & 5278 & 65,12 & 44,88 & 302 & 26934 & 8,35 & 12,55 & 49626 & 0,120 & 0,613 \\
\hline 36 & 13874 & 53578 & 13,21 & 5376 & 68,79 & 47,61 & 298 & 27981 & 7,80 & 12,25 & 51512 & 0,100 & 0,522 \\
\hline 38 & 14507 & 43011 & 12,39 & 5533 & 63,93 & 43,50 & 287 & 26508 & 7,57 & 10,87 & 49357 & 0,129 & 0,616 \\
\hline 40 & 15141 & 47807 & 14,34 & 5721 & 73,92 & 49,76 & 311 & 30524 & 8,36 & 12,54 & 54110 & 0,120 & 0,638 \\
\hline 42 & 15775 & 45608 & 11,60 & 5759 & 58,30 & 41,40 & 289 & 25685 & 6,96 & 9,22 & 48890 & 0,126 & 0,563 \\
\hline 44 & 16409 & 49452 & 13,29 & 5951 & 66,86 & 46,40 & 304 & 28790 & 7,61 & 11,16 & 52654 & 0,120 & 0,582 \\
\hline 46 & 17043 & 47311 & 11,23 & 5485 & 57,05 & 41,87 & 338 & 24897 & 6,89 & 10,00 & 49195 & 0,116 & 0,526 \\
\hline 48 & 17677 & 45947 & 11,27 & 5229 & 56,94 & 43,88 & 279 & 24808 & 6,98 & 9,94 & 47210 & 0,114 & 0,540 \\
\hline 50 & 18311 & 46318 & 11,05 & 5320 & 54,94 & 43,26 & 261 & 25701 & 6,84 & 9,34 & 46489 & 0,115 & 0,555 \\
\hline
\end{tabular}




\begin{tabular}{|c|c|c|c|c|c|c|c|c|c|c|c|c|c|}
\hline Prof. (cm) & Idade cal. anos AP & $\mathrm{Ca}$ & Sc & $\mathrm{Ti}$ & v & $\mathrm{Cr}$ & Mn & $\mathrm{Fe}$ & Co & $\mathrm{Ni}$ & Al & $\mathrm{Ti} / \mathrm{Ca}$ & $\mathrm{Fe} / \mathrm{Ca}$ \\
\hline 52 & 18945 & 51574 & 10,45 & 4801 & 51,04 & 39,46 & 254 & 22093 & 6,02 & 8,92 & 44476 & 0,093 & 0,428 \\
\hline 54 & 19579 & 48679 & 9,28 & 4606 & 45,27 & 36,19 & 280 & 19165 & 6,21 & 8,42 & 40878 & 0,095 & 0,394 \\
\hline 56 & 20213 & 51688 & 9,33 & 4985 & 45,60 & 39,20 & 259 & 21209 & 5,80 & 7,99 & 43711 & 0,096 & 0,410 \\
\hline 58 & 20847 & 61692 & 10,68 & 4840 & 51,82 & 41,60 & 252 & 24758 & 6,35 & 9,72 & 47783 & 0,078 & 0,401 \\
\hline 60 & 21481 & 55320 & 10,69 & 5332 & 52,52 & 43,74 & 251 & 24400 & 6,41 & 9,78 & 46155 & 0,096 & 0,441 \\
\hline 62 & 22115 & 55611 & 9,50 & 4775 & 47,01 & 36,01 & 246 & 21523 & 5,72 & 8,44 & 42915 & 0,086 & 0,387 \\
\hline 64 & 22748 & 52627 & 9,29 & 4621 & 45,70 & 37,30 & 226 & 20507 & 5,54 & 9,40 & 40478 & 0,088 & 0,390 \\
\hline 66 & 23382 & 63738 & 9,83 & 5002 & 48,25 & 40,62 & 378 & 22605 & 6,18 & 8,93 & 44432 & 0,078 & 0,355 \\
\hline 68 & 24016 & 65611 & 9,83 & 4939 & 49,55 & 38,16 & 243 & 23649 & 5,84 & 8,64 & 44331 & 0,075 & 0,360 \\
\hline 70 & 24650 & 55759 & 9,35 & 5053 & 45,98 & 36,62 & 231 & 20633 & 6,10 & 7,91 & 41928 & 0,091 & 0,370 \\
\hline 72 & 25284 & 58408 & 10,11 & 5198 & 48,94 & 39,60 & 244 & 23467 & 6,17 & 8,39 & 45039 & 0,089 & 0,402 \\
\hline 74 & 25918 & 55389 & 10,33 & 5106 & 50,30 & 39,58 & 249 & 22831 & 6,01 & 8,96 & 44370 & 0,092 & 0,412 \\
\hline 76 & 26552 & 52371 & 9,97 & 5099 & 48,48 & 39,36 & 238 & 22847 & 5,95 & 9,06 & 45084 & 0,097 & 0,436 \\
\hline 78 & 27186 & 44415 & 9,52 & 5205 & 47,41 & 34,24 & 243 & 20407 & 5,90 & 7,75 & 40911 & 0,117 & 0,459 \\
\hline 80 & 27820 & 49237 & 10,38 & 5270 & 51,79 & 41,42 & 252 & 23099 & 6,21 & 9,38 & 44669 & 0,107 & 0,469 \\
\hline 82 & 28454 & 58867 & 11,03 & 6664 & 53,62 & 44,00 & 270 & 28680 & 9,29 & 12,91 & 55381 & 0,113 & 0,487 \\
\hline 84 & 29088 & 50990 & 10,35 & 5270 & 51,39 & 40,65 & 247 & 23737 & 6,31 & 14,18 & 45915 & 0,103 & 0,466 \\
\hline 86 & 29722 & 47409 & 10,08 & 5746 & 50,53 & 40,64 & 249 & 22337 & 6,60 & 11,76 & 44337 & 0,121 & 0,471 \\
\hline 88 & 30355 & 46692 & 10,00 & 5289 & 49,75 & 38,11 & 457 & 22509 & 6,40 & 12,04 & 45280 & 0,113 & 0,482 \\
\hline 90 & 30989 & 44995 & 9,59 & 5738 & 48,15 & 39,84 & 247 & 21558 & 6,03 & 11,81 & 42378 & 0,128 & 0,479 \\
\hline 92 & 31623 & 42878 & 9,60 & 5379 & 48,02 & 39,16 & 239 & 21363 & 6,06 & 11,17 & 42688 & 0,125 & 0,498 \\
\hline 94 & 32257 & 49969 & 10,26 & 5363 & 50,34 & 41,42 & 242 & 23132 & 6,56 & 12,38 & 46499 & 0,107 & 0,463 \\
\hline 96 & 32891 & 41134 & 9,27 & 5454 & 46,55 & 36,12 & 235 & 20460 & 5,81 & 11,61 & 42059 & 0,133 & 0,497 \\
\hline 98 & 33525 & 42095 & 9,86 & 5604 & 50,49 & 39,43 & 242 & 23419 & 6,58 & 14,21 & 45459 & 0,133 & 0,556 \\
\hline 100 & 34159 & 45242 & 11,38 & 5252 & 58,10 & 42,61 & 260 & 28093 & 7,36 & 14,13 & 49170 & 0,116 & 0,621 \\
\hline 102 & 34793 & 42739 & 11,15 & 5346 & 56,04 & 41,21 & 291 & 25378 & 6,88 & 12,26 & 47917 & 0,125 & 0,594 \\
\hline 104 & 35427 & 47442 & 12,00 & 5512 & 60,09 & 42,64 & 254 & 28587 & 7,55 & 14,30 & 52451 & 0,116 & 0,603 \\
\hline 106 & 36061 & 39958 & 10,51 & 5262 & 52,88 & 37,91 & 275 & 21999 & 10,37 & 10,64 & 42781 & 0,132 & 0,551 \\
\hline
\end{tabular}




\begin{tabular}{|c|c|c|c|c|c|c|c|c|c|c|c|c|c|}
\hline Prof. (cm) & Idade cal. anos AP & $\mathrm{Ca}$ & Sc & $\mathrm{Ti}$ & v & $\mathrm{Cr}$ & Mn & $\mathrm{Fe}$ & Co & $\mathrm{Ni}$ & Al & $\mathrm{Ti} / \mathrm{Ca}$ & $\mathrm{Fe} / \mathrm{Ca}$ \\
\hline 108 & 36695 & 40445 & 10,80 & 5433 & 54,89 & 39,34 & 248 & 24654 & 10,52 & 12,21 & 46459 & 0,134 & 0,610 \\
\hline 110 & 37329 & 34239 & 9,71 & 5109 & 48,97 & 35,80 & 225 & 20396 & 6,19 & 10,12 & 42041 & 0,149 & 0,596 \\
\hline 112 & 37963 & 41374 & 10,47 & 5215 & 51,45 & 37,68 & 236 & 24102 & 6,53 & 11,39 & 47268 & 0,126 & 0,583 \\
\hline \multirow[t]{5}{*}{114} & 38596 & 35818 & 9,92 & 5521 & 49,36 & 34,56 & 236 & 22795 & 6,06 & 10,94 & 45548 & 0,154 & 0,636 \\
\hline & Máximo & 77183 & 15,63 & 6664 & 79,33 & 54,71 & 701 & 32486 & 11,30 & 21,70 & 55381 & 0,15 & 0,64 \\
\hline & Mínimo & 34239 & 7,62 & 4569 & 40,20 & 31,38 & 225 & 15175 & 4,83 & 6,71 & 36306 & 0,06 & 0,25 \\
\hline & Média & 52395 & 10,47 & 5241 & 52,54 & 39,77 & 283 & 23105 & 6,93 & 10,83 & 45157 & 0,10 & 0,46 \\
\hline & Desvio Padrão & 10417 & 1,48 & 379 & 7,55 & 4,20 & 75 & 3630 & 1,40 & 2,80 & 4138 & 0,02 & 0,11 \\
\hline
\end{tabular}

Cont. Tabela 1 - Resultados

\begin{tabular}{|c|c|c|c|c|c|c|c|c|c|c|c|c|c|}
\hline Prof. (cm) & Idade cal. anos AP & $\ln (\mathrm{Ti} / \mathrm{Ca})$ & $\ln (\mathrm{Fe} / \mathrm{Ca})$ & V/AI $\times 10^{-4}$ & $\mathrm{~V} / \mathrm{Cr}$ & $\mathrm{V} / \mathrm{Sc}$ & $\mathrm{Ni} / \mathrm{Co}$ & $\mathrm{Mn} / \mathrm{Al} \times 10^{-4}$ & $\mathrm{CaCO}_{3}(\%)$ & СОT (\%) & NT (\%) & $\mathrm{C} / \mathrm{N}$ & $\delta^{13} \mathrm{C}(\%)$ \\
\hline 2 & 2463 & $-2,81$ & $-0,94$ & 12,67 & 1,45 & 4,61 & 1,92 & 80,44 & 33,85 & 0,69 & 0,07 & 10,16 & $-20,76$ \\
\hline 4 & 3731 & $-2,74$ & $-1,25$ & 11,37 & 1,37 & 4,93 & 1,42 & 70,64 & 35,45 & 0,54 & 0,10 & 5,59 & $-20,83$ \\
\hline 6 & 4365 & $-2,76$ & $-1,09$ & 11,60 & 1,32 & 4,78 & 2,13 & 68,52 & 35,52 & 0,60 & 0,08 & 7,66 & $-20,80$ \\
\hline 8 & 4999 & $-2,64$ & $-1,13$ & 11,61 & 1,33 & 5,15 & 1,82 & 66,97 & 36,18 & 0,46 & 0,08 & 5,52 & $-21,16$ \\
\hline 10 & 5633 & $-2,66$ & $-1,13$ & 11,95 & 1,30 & 5,18 & 2,01 & 69,24 & 35,38 & 0,42 & 0,10 & 4,28 & $-20,80$ \\
\hline 12 & 6267 & $-2,62$ & $-1,28$ & 10,86 & 1,30 & 4,98 & 1,27 & 66,24 & 36,03 & 0,38 & 0,07 & 5,34 & $-21,30$ \\
\hline 14 & 6900 & $-2,68$ & $-1,32$ & 11,11 & 1,32 & 5,15 & 1,71 & 66,45 & 36,40 & 0,38 & 0,06 & 5,99 & $-21,24$ \\
\hline 16 & 7534 & $-2,57$ & $-1,31$ & 11,47 & 1,34 & 5,09 & 1,78 & 66,22 & 37,26 & 0,35 & 0,07 & 5,31 & $-21,13$ \\
\hline 18 & 8168 & $-2,43$ & $-1,29$ & 11,11 & 1,00 & 5,17 & 0,94 & 188,49 & 37,85 & 0,22 & 0,05 & 4,25 & $-21,92$ \\
\hline 20 & 8802 & $-2,54$ & $-1,40$ & 11,07 & 1,28 & 5,28 & 1,39 & 64,43 & 34,27 & 0,17 & 0,05 & 3,67 & $-22,40$ \\
\hline 22 & 9436 & $-2,42$ & $-1,26$ & 11,36 & 1,32 & 5,25 & 1,46 & 64,85 & 32,93 & 0,18 & 0,04 & 4,02 & $-21,53$ \\
\hline 24 & 10070 & $-2,15$ & $-1,00$ & 12,61 & 1,45 & 5,33 & 1,21 & 66,23 & 30,45 & 0,32 & 0,05 & 6,31 & $-21,34$ \\
\hline 26 & 10704 & $-2,28$ & $-0,81$ & 12,55 & 1,44 & 5,17 & 1,37 & 62,89 & 25,39 & 0,39 & 0,06 & 6,42 & $-21,35$ \\
\hline
\end{tabular}




\begin{tabular}{|c|c|c|c|c|c|c|c|c|c|c|c|c|c|}
\hline Prof. (cm) & Idade cal. anos AP & $\ln (\mathrm{Ti} / \mathrm{Ca})$ & $\ln (\mathrm{Fe} / \mathrm{Ca})$ & $\mathrm{V} / \mathrm{Al} \times 10^{-4}$ & $\mathrm{~V} / \mathrm{Cr}$ & $\mathrm{V} / \mathrm{Sc}$ & $\mathrm{Ni} / \mathrm{Co}$ & $\mathrm{Mn} / \mathrm{Al} \times 10^{-4}$ & $\mathrm{CaCO}_{3}(\%)$ & сOT (\%) & NT (\%) & $\mathrm{C} / \mathrm{N}$ & $\delta^{13} \mathrm{C}(\%)$ \\
\hline 28 & 11338 & $-2,18$ & $-0,87$ & 11,93 & 1,40 & 5,21 & 1,22 & 63,68 & 30,76 & 0,40 & 0,07 & 5,62 & $-21,66$ \\
\hline 30 & 11972 & $-2,28$ & $-0,52$ & 14,79 & 1,45 & 5,07 & 1,62 & 87,57 & 24,13 & 0,41 & 0,07 & 6,22 & $-21,32$ \\
\hline 32 & 12606 & $-1,98$ & $-0,61$ & 12,27 & 1,36 & 5,19 & 1,34 & 59,73 & 23,41 & 0,46 & 0,07 & 6,73 & $-21,49$ \\
\hline 34 & 13240 & $-2,12$ & $-0,49$ & 13,12 & 1,45 & 5,21 & 1,50 & 60,91 & 21,51 & 0,42 & 0,08 & 5,47 & $-21,08$ \\
\hline 36 & 13874 & $-2,30$ & $-0,65$ & 13,35 & 1,44 & 5,21 & 1,57 & 57,91 & 19,79 & 0,45 & 0,08 & 5,67 & $-20,96$ \\
\hline 38 & 14507 & $-2,05$ & $-0,48$ & 12,95 & 1,47 & 5,16 & 1,44 & 58,23 & 22,03 & 0,43 & 0,08 & 5,67 & $-21,61$ \\
\hline 40 & 15141 & $-2,12$ & $-0,45$ & 13,66 & 1,49 & 5,16 & 1,50 & 57,41 & 21,49 & 0,43 & 0,07 & 5,76 & $-21,24$ \\
\hline 42 & 15775 & $-2,07$ & $-0,57$ & 11,92 & 1,41 & 5,02 & 1,32 & 59,12 & 22,82 & 0,43 & 0,07 & 5,98 & $-20,83$ \\
\hline 44 & 16409 & $-2,12$ & $-0,54$ & 12,70 & 1,44 & 5,03 & 1,47 & 57,74 & 21,57 & 0,42 & 0,07 & 6,06 & $-20,83$ \\
\hline 46 & 17043 & $-2,15$ & $-0,64$ & 11,60 & 1,36 & 5,08 & 1,45 & 68,73 & 23,51 & 0,45 & 0,06 & 8,14 & $-21,29$ \\
\hline 48 & 17677 & $-2,17$ & $-0,62$ & 12,06 & 1,30 & 5,05 & 1,42 & 59,01 & 21,98 & 0,50 & 0,08 & 6,06 & $-20,27$ \\
\hline 50 & 18311 & $-2,16$ & $-0,59$ & 11,82 & 1,27 & 4,97 & 1,37 & 56,06 & 23,49 & 0,52 & 0,09 & 6,05 & $-20,99$ \\
\hline 52 & 18945 & $-2,37$ & $-0,85$ & 11,48 & 1,29 & 4,89 & 1,48 & 57,20 & 24,38 & 0,52 & 0,08 & 6,35 & $-20,72$ \\
\hline 54 & 19579 & $-2,36$ & $-0,93$ & 11,07 & 1,25 & 4,88 & 1,36 & 68,43 & 24,33 & 0,53 & 0,08 & 6,58 & $-20,86$ \\
\hline 56 & 20213 & $-2,34$ & $-0,89$ & 10,43 & 1,16 & 4,89 & 1,38 & 59,25 & 27,04 & 0,52 & 0,08 & 6,26 & $-20,57$ \\
\hline 58 & 20847 & $-2,55$ & $-0,91$ & 10,84 & 1,25 & 4,85 & 1,53 & 52,73 & 25,69 & 0,56 & 0,09 & 6,60 & $-20,66$ \\
\hline 60 & 21481 & $-2,34$ & $-0,82$ & 11,38 & 1,20 & 4,91 & 1,52 & 54,30 & 25,44 & 0,58 & 0,09 & 6,42 & $-20,77$ \\
\hline 62 & 22115 & $-2,45$ & $-0,95$ & 10,95 & 1,31 & 4,95 & 1,48 & 57,35 & 25,89 & 0,61 & 0,09 & 6,75 & $-20,46$ \\
\hline 64 & 22748 & $-2,43$ & $-0,94$ & 11,29 & 1,23 & 4,92 & 1,70 & 55,78 & 26,41 & 0,65 & 0,09 & 7,25 & $-20,59$ \\
\hline 66 & 23382 & $-2,54$ & $-1,04$ & 10,86 & 1,19 & 4,91 & 1,44 & 84,98 & 27,28 & & 0,09 & & $-20,49$ \\
\hline 68 & 24016 & $-2,59$ & $-1,02$ & 11,18 & 1,30 & 5,04 & 1,48 & 54,86 & 26,56 & 0,63 & 0,09 & 7,20 & $-20,31$ \\
\hline 70 & 24650 & $-2,40$ & $-0,99$ & 10,97 & 1,26 & 4,92 & 1,30 & 55,02 & 25,70 & 0,61 & 0,09 & 6,92 & $-20,86$ \\
\hline 72 & 25284 & $-2,42$ & $-0,91$ & 10,87 & 1,24 & 4,84 & 1,36 & 54,24 & 24,85 & 0,52 & 0,08 & 6,95 & $-20,39$ \\
\hline 74 & 25918 & $-2,38$ & $-0,89$ & 11,34 & 1,27 & 4,87 & 1,49 & 56,20 & 24,15 & 0,47 & 0,07 & 6,30 & $-21,10$ \\
\hline 76 & 26552 & $-2,33$ & $-0,83$ & 10,75 & 1,23 & 4,86 & 1,52 & 52,83 & 24,15 & 0,43 & 0,08 & 5,62 & $-20,88$ \\
\hline 78 & 27186 & $-2,14$ & $-0,78$ & 11,59 & 1,38 & 4,98 & 1,31 & 59,34 & 23,01 & 0,52 & 0,07 & 7,18 & $-20,69$ \\
\hline 80 & 27820 & $-2,23$ & $-0,76$ & 11,59 & 1,25 & 4,99 & 1,51 & 56,42 & 23,38 & 0,56 & 0,09 & 6,44 & $-20,90$ \\
\hline 82 & 28454 & $-2,18$ & $-0,72$ & 9,68 & 1,22 & 4,86 & 1,39 & 48,82 & 23,48 & 0,66 & 0,09 & 7,40 & $-20,99$ \\
\hline
\end{tabular}




\begin{tabular}{|c|c|c|c|c|c|c|c|c|c|c|c|c|c|}
\hline Prof. (cm) & Idade cal. anos AP & $\ln (\mathrm{Ti} / \mathrm{Ca})$ & $\ln (\mathrm{Fe} / \mathrm{Ca})$ & V/Al x $10^{-4}$ & $\mathrm{~V} / \mathrm{Cr}$ & $\mathrm{V} / \mathrm{Sc}$ & $\mathrm{Ni} / \mathrm{Co}$ & $\mathrm{Mn} / \mathrm{Al} \times 10^{-4}$ & $\mathrm{CaCO}_{3}(\%)$ & СОт (\%) & NT (\%) & $\mathrm{C} / \mathrm{N}$ & $\delta^{13} \mathrm{C}(\%)$ \\
\hline 84 & 29088 & $-2,27$ & $-0,76$ & 11,19 & 1,26 & 4,96 & 2,25 & 53,88 & 22,69 & 0,62 & 0,09 & 6,79 & $-20,93$ \\
\hline 86 & 29722 & $-2,11$ & $-0,75$ & 11,40 & 1,24 & 5,02 & 1,78 & 56,19 & 23,55 & 0,58 & 0,09 & 6,79 & $-20,98$ \\
\hline 88 & 30355 & $-2,18$ & $-0,73$ & 10,99 & 1,31 & 4,97 & 1,88 & 100,98 & 22,37 & 0,46 & 0,07 & 6,44 & $-20,62$ \\
\hline 90 & 30989 & $-2,06$ & $-0,74$ & 11,36 & 1,21 & 5,02 & 1,96 & 58,27 & 22,03 & 0,46 & 0,07 & 6,59 & $-20,87$ \\
\hline 92 & 31623 & $-2,08$ & $-0,70$ & 11,25 & 1,23 & 5,00 & 1,84 & 56,10 & 21,69 & 0,47 & 0,07 & 6,93 & $-20,95$ \\
\hline 94 & 32257 & $-2,23$ & $-0,77$ & 10,83 & 1,22 & 4,90 & 1,89 & 52,12 & 20,94 & 0,55 & 0,07 & 7,64 & $-20,87$ \\
\hline 96 & 32891 & $-2,02$ & $-0,70$ & 11,07 & 1,29 & 5,02 & 2,00 & 55,94 & 22,60 & 0,48 & 0,07 & 7,17 & $-20,86$ \\
\hline 98 & 33525 & $-2,02$ & $-0,59$ & 11,11 & 1,28 & 5,12 & 2,16 & 53,34 & 28,13 & 0,42 & 0,07 & 6,22 & $-20,62$ \\
\hline 100 & 34159 & $-2,15$ & $-0,48$ & 11,82 & 1,36 & 5,10 & 1,92 & 52,80 & 20,91 & 0,54 & 0,07 & 7,30 & $-21,16$ \\
\hline 102 & 34793 & $-2,08$ & $-0,52$ & 11,70 & 1,36 & 5,03 & 1,78 & 60,76 & 19,70 & 0,56 & 0,08 & 7,01 & $-20,41$ \\
\hline 104 & 35427 & $-2,15$ & $-0,51$ & 11,46 & 1,41 & 5,01 & 1,90 & 48,34 & 20,21 & 0,49 & 0,08 & 6,36 & $-21,36$ \\
\hline 106 & 36061 & $-2,03$ & $-0,60$ & 12,36 & 1,39 & 5,03 & 1,03 & 64,29 & 20,83 & 0,52 & 0,06 & 8,55 & $-21,14$ \\
\hline 108 & 36695 & $-2,01$ & $-0,50$ & 11,81 & 1,40 & 5,08 & 1,16 & 53,37 & 20,21 & 0,52 & 0,14 & 3,82 & $-21,22$ \\
\hline 110 & 37329 & $-1,90$ & $-0,52$ & 11,65 & 1,37 & 5,05 & 1,63 & 53,45 & 18,10 & 0,47 & 0,07 & 7,16 & $-21,61$ \\
\hline 112 & 37963 & $-2,07$ & $-0,54$ & 10,88 & 1,37 & 4,91 & 1,74 & 49,89 & 18,73 & 0,44 & 0,07 & 6,45 & $-21,36$ \\
\hline \multirow[t]{5}{*}{114} & 38596 & $-1,87$ & $-0,45$ & 10,84 & 1,43 & 4,97 & 1,81 & 51,87 & 18,18 & 0,46 & 0,07 & 6,75 & $-21,63$ \\
\hline & Máximo & $-1,87$ & $-0,45$ & 14,79 & 1,49 & 5,33 & 2,25 & 188,49 & 37,85 & 0,69 & 0,14 & 10,16 & $-20,27$ \\
\hline & Mínimo & $-2,81$ & $-1,40$ & 9,68 & 1,00 & 4,61 & 0,94 & 48,34 & 18,10 & 0,17 & 0,04 & 3,67 & $-22,40$ \\
\hline & Média & $-2,29$ & $-0,81$ & 11,61 & 1,32 & 5,02 & 1,57 & 63,11 & 25,72 & 0,48 & 0,08 & 6,36 & $-21,02$ \\
\hline & Desvio Padrão & 0,23 & 0,26 & 0,86 & 0,09 & 0,14 & 0,28 & 19,47 & 5,52 & 0,11 & 0,01 & 1,12 & 0,41 \\
\hline
\end{tabular}

